Florida International University

FIU Digital Commons

FIU Electronic Theses and Dissertations

University Graduate School

$7-6-2012$

\title{
An Economic Analysis of Carbon Sequestration and Storage Service by Mangrove Forests in Everglades National Park, Florida
}

Meenakshi Jerath

Florida International University, mjera001@fiu.edu

DOI: $10.25148 /$ etd.FI12080626

Follow this and additional works at: https:// digitalcommons.fiu.edu/etd

\section{Recommended Citation}

Jerath, Meenakshi, "An Economic Analysis of Carbon Sequestration and Storage Service by Mangrove Forests in Everglades National Park, Florida" (2012). FIU Electronic Theses and Dissertations. 702.

https://digitalcommons.fiu.edu/etd/702

This work is brought to you for free and open access by the University Graduate School at FIU Digital Commons. It has been accepted for inclusion in FIU Electronic Theses and Dissertations by an authorized administrator of FIU Digital Commons. For more information, please contact dcc@fiu.edu. 


\section{FLORIDA INTERNATIONAL UNIVERSITY \\ Miami, Florida}

\section{AN ECONOMIC ANALYSIS OF CARBON SEQUESTRATION AND STORAGE SERVICE BY MANGROVE FORESTS IN EVERGLADES NATIONAL PARK, FLORIDA}

A thesis submitted in partial fulfillment of

the requirements for the degree of

MASTER OF SCIENCE

in

ENVIRONMENTAL STUDIES

by

Meenakshi Jerath 
To: Dean Kenneth G. Furton

College of Arts and Sciences

This thesis, written by Meenakshi Jerath, and entitled An Economic Analysis of Carbon Sequestration and Storage Service by the Mangrove Forests in Everglades National Park, Florida, having been approved in respect to style and intellectual content, is referred to you for judgment.

We have read this thesis and recommend that it be approved.

$\begin{array}{r}\hline \text { Michael Sukop } \\ \hline \text { Jennifer Rehage } \\ \hline \text { Pallab Mozumder } \\ \hline \text { Mahadev G. Bhat, Major Professor }\end{array}$

Date of Defense: July 6, 2012

The thesis of Meenakshi Jerath is approved.

$\begin{array}{r}\begin{array}{r}\text { Dean Kenneth G. Furton } \\ \text { College of Arts and Sciences }\end{array} \\ \hline \begin{array}{r}\text { Dean Lakshmi N. Reddi } \\ \text { University Graduate School }\end{array}\end{array}$

Florida International University, 2012 


\section{DEDICATION}

I dedicate this thesis to my dear late father, Kailash Chabba, whose wisdom, values and influences continue to inspire and guide me long since he has been gone, and to my mother, Pushpa, whose unconditional love is a constant in my life. I dedicate this thesis to my husband, Sanjay, for his unwavering love, support and encouragement. Without his loving patience I could not have accomplished this work. I dedicate this thesis to both our families. I also dedicate this thesis to my dearest uncle Akash and his family, my dear siblings, Rajiv and Mamta, Jyotsna and Raju: their enduring belief in me has fueled my enthusiasm every step of the way. Lastly, I dedicate this thesis to Varun, Vania and Kabir, whose generation, I hope, will carve a future that tangibly values the world's ecosystems that provide innumerable services to humanity. 


\section{ACKNOWLEDGMENTS}

I wish to thank my major advisor, Dr. Mahadev G. Bhat for his constant guidance, support and encouragement during the span of my graduate program, for his unwavering belief in my abilities and for the many invaluable lessons I learned from him. I am sincerely grateful for the opportunities that I have had because of him. I also wish to thank the members of my committee, Dr. Sukop, Dr. Mozumder and Dr. Rehage who gave unstinting support and encouragement at every step of the process. I would like to thank the Department of Earth and Environment and Dr. Krish Jayachandran for awarding me the necessary funding to pursue my Master's degree. I thank the National Science Foundation (Grant \# EAR-1039223) for funding my international travel to share my research with the International Society for Ecological Economics.

I wish to express my sincere thanks to Dr. Victor H. Rivera-Monroy for providing me with the core data for this study and for the memorable and educative journey into the mangroves of the Everglades. I am deeply grateful for his valuable advice and guidance, the time he generously shared, and the friendship he unhesitatingly offered. I also wish to express my thanks to Dr. Edward Castañeda-Moya for sharing the data for root biomass and soil carbon, and Dr. Marc Simard for providing me with the data on aboveground biomass for ENP mangroves. I would like to offer my sincere thanks to Daniel Gann and Himadri Biswas for their invaluable help with the GIS data. I am thankful to Dr. Len Scinto for being a wonderful teacher and moral support. I would like to thank Seema Sah, Brett Pierce, Stephany Alvarez-Ventura, Melissa Ussa and Sreenath Shanker for their support and invaluable companionship though the last two years. 
ABSTRACT OF THE THESIS

AN ECONOMIC ANALYSIS OF CARBON SEQUESTRATION AND STORAGE SERVICE BY MANGROVE FORESTS OF EVERGLADES NATIONAL PARK, FLORIDA

\author{
by \\ Meenakshi Jerath \\ Florida International University, 2012 \\ Miami, Florida \\ Professor Mahadev G. Bhat, Major Professor
}

The purpose of this study was to provide a methodological framework for the first estimates of the total carbon storage and its economic valuation in the mangrove forests of Everglades National Park (ENP), Florida. The total carbon storage in the ENP mangroves is estimated to be $7,144 \mathrm{Mg} \mathrm{C} / \mathrm{ha}$, much higher than tropical, boreal and temperate forests. The final selection of carbon prices for the valuation was based on the social, economic and political milieu of the study site, the biological attributes influencing the quantity and quality of carbon storage, and the status of the ENP mangroves as a protected area. The carbon storage in ENP mangroves is estimated at $\$ 50,000 /$ ha and $\$ 614,000 /$ ha based on the U.S. market price and social cost of carbon, respectively. The study also estimates the change in the economic value of the carbon stock in ENP mangroves in response to different scenarios of sea level rise. 


\section{TABLE OF CONTENTS}

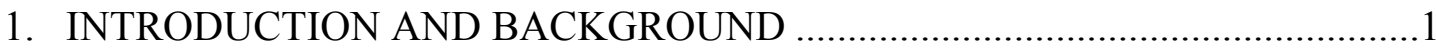

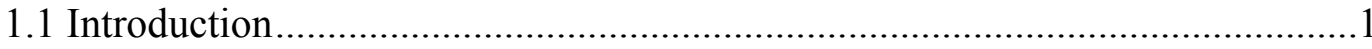

1.2 Mangrove Wetland Forests of the Everglades ..................................................

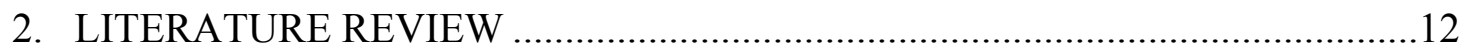

2.1 Carbon Sequestration in Mangroves ...........................................................12

2.1.1 Mangroves and Ecosystem Services ...............................................12

2.1.2 Carbon Sinks in Mangroves and Terrestrial forests .........................14

2.1.3 Mangrove Production and Biomass .................................................16

2.1.4 Mangroves are Non-linear, Dynamic Ecosystems ............................19

2.1.5 Uncertainties in Estimates of Carbon Storage in Mangroves ...........20

2.1.6 Press and Pulse Stressors of Mangrove Forests ...............................22

2.1.7 Patterns of Biomass Production in Mangrove Forests of Everglades

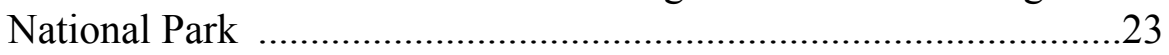

2.1.7.1 Aboveground Biomass ......................................................26

2.1.7.2 Belowground Biomass .......................................................28

2.2 Economic Valuation of Carbon Sequestration.................................................30

2.2.1 The Damage Cost Approach ...........................................................31

2.2.2 The Cost of Damage Avoidance Approach ......................................35

2.2.3 The Market Price Method ..............................................................38

2.2.3.1 Regulatory Carbon Markets ……………………...............38

2.2.3.2 Voluntary Carbon Markets .................................................40

2.2.3.3 Reducing Emissions from Deforestation and Forest

Degradation-Plus (REDD+)...........................................41

2.2.4 Stated Valuation Approach................................................................43

2.2.5 Shadow Price of Carbon ..................................................................4

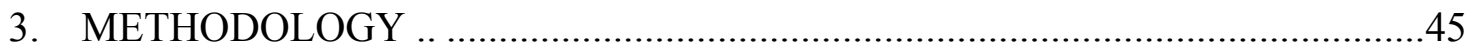

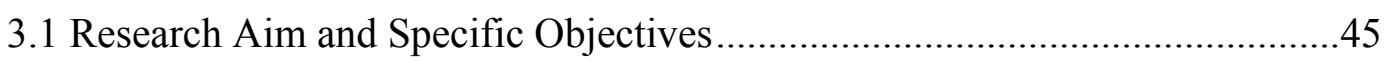

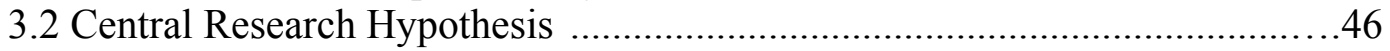

3.3 Research Questions .............................................................................4

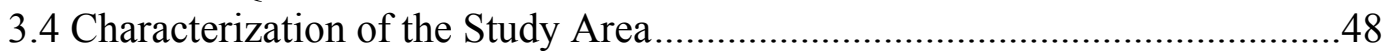

3.4.1 Fresh Water Flow and Water Management ....................................49

3.4.2 Sea Level Rise............................................................................

3.4.3 Hurricanes and Tropical Storms ……………………………….....53

3.5 Estimation of the Total Carbon present in the Mangrove Forests of Everglades

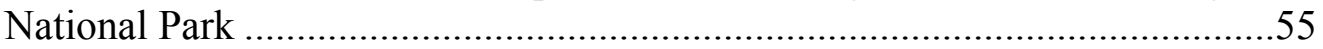

3.5.1 Aboveground Carbon in the Mangrove Forests of Everglades

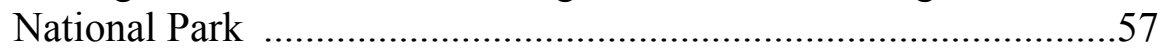

3.5.1.1 Data Sources ..................................................................57

3.1.5.2 Landscape Level Estimation of Aboveground Carbon $\left(\mathrm{C}_{\mathrm{AG}}\right)$ 
3.5.2 Belowground Carbon in the Roots of Mangrove Forests of

Everglades National Park..............................................................61

3.5.2.1 Data Sources ................................................................61

3.5.2.2 Landscape Level Estimation of Carbon in Fine Roots $\left(\mathrm{C}_{\mathrm{BGR}}\right)$

3.5.3 Carbon in Sediments of Mangrove Forests of Everglades National

Park

3.5.3.1 Data Sources ..............................................................64

3.5.3.2 Landscape Level Estimation of Carbon in Soil $\left(\mathrm{C}_{\mathrm{BGS}}\right)$.....66

3.5.4 Estimation of Total Carbon (TC) ..................................................66

3.6 Selection and Development of Carbon Prices based on Valuation

Methodologies Appropriate for Coastal Ecosystems like Mangroves..............66

3.7 Economic Valuation of the Carbon Stored in the Mangrove Forests of

Everglades National Park................................................................................71

3.8 Estimation of Economic Value Changes in the Carbon Stock of ENP

Mangroves in Response to Sea Level Rise.... .72

3.8.1 Estimation of Total Carbon Sequestered in the Next 100 years as a result of Mangrove Transgression into Upland Fresh Water Habitats under

3 Sea Level Rise Scenarios ...............................................................76

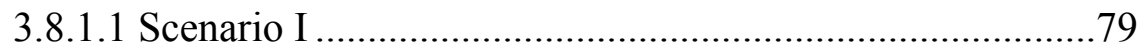

3.8.1.2 Scenarios II and III.................................................... 80

3.8.2 Estimation of Change in Economic Value of Carbon Stored in ENP

Mangroves.

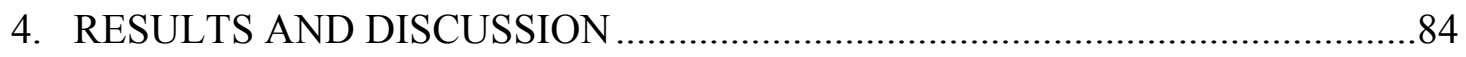

4.1 Carbon Storage in the Mangrove Forests of Everglades National Park, Florida

4.1.1 Carbon Storage in the FCE-LTER Sites .......................................84

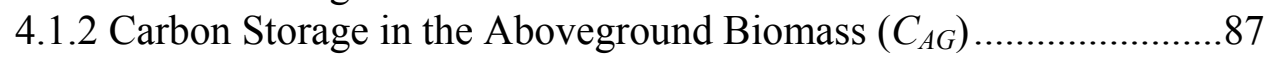

4.1.3 Carbon Storage in the Belowground Biomass (roots) $\left(C_{B G R}\right) \ldots \ldots \ldots . . .89$

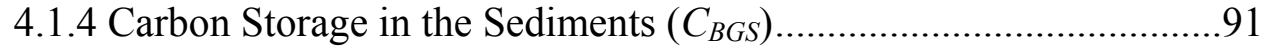

4.1.5 Belowground Carbon Storage (soil and roots) $\left(C_{B G R-S}\right) \ldots \ldots \ldots \ldots \ldots \ldots . . .93$

4.1.6 Total Carbon Storage (TC) in the Mangrove Forest Ecosystem in

Everglades National Park, Florida ..............................................95

4.1.7 Comparison of Carbon Stock in ENP Mangroves with Terrestrial

Ecosystems and Mangroves in the Indo-Pacific.....................................................99

4.2 Comparative Analysis of Carbon Prices across Valuation Methodologies .. 100

4.2.1 Social Costs of Carbon

101

4.2.2 Marginal Abatement Costs ....................................................103

4.2.3 Market Prices .............................................................................104

4.2.4 Discussion on Comparative Analysis of Carbon Prices based on different Valuation Methodologies 105 
4.2.5 Economic, Political and Social Criteria for Valuation of Mangroves

4.3 Economic Valuation of the Carbon Stored in the Mangrove Forests of

Everglades National Park, Florida 115

4.4 Estimation of Total Carbon Sequestered in the Zone of Mangrove

Transgression as a result of Sea Level Rise in the next 100 years

4.5 Estimation of Economic Value Changes in the Carbon Stock of ENP

Mangroves in Response to Sea Level Rise

5. SUMMARY OF RESULTS AND CONCLUSIONS

References. 


\section{LIST OF TABLES}

TABLE

PAGE

2.1 Mangroves and Ecosystem Services .13

3.1 Raster Information for the Map of Mangrove Standing Biomass Distribution in Everglades National Park

3.2 Information on Aboveground and Belowground Biomass of FCE LTER Sites in the Everglades Mangrove Ecotone .................................................................................62

3.3 Aboveground:Belowground Carbon Ratios...............................................................64

3.4 Soil Carbon Values in FCE LTER Mangrove Sites ..................................................65

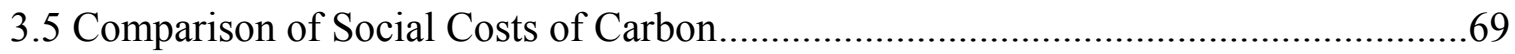

3.6 Comparison of Marginal Abatement Costs..............................................................70

3.7 Comparison of Market Prices of Carbon ..............................................................

3.8 Landward Migration of ENP Mangroves under selected Sea Level Rise Scenarios...76

3.9 Projected Scenarios for Sea Level Rise and Areal Extent of Mangrove Transgression

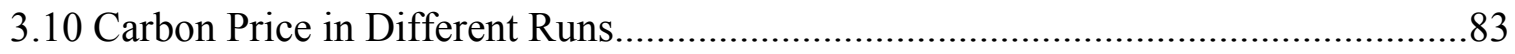

4.1 Carbon Storage in the Six FCE LTER Sites in ENP Mangrove Forests ......................85

4.2 Carbon Storage in the Mangrove Forests of the Everglades National Park, Florida ..97

4.3 Comparison of Carbon Storage across Different Ecosystems......................100

4.4 Criteria for Valuation of ENP Mangroves ...............................................................112

4.5 Monetary valuation for Carbon Storage in ENP

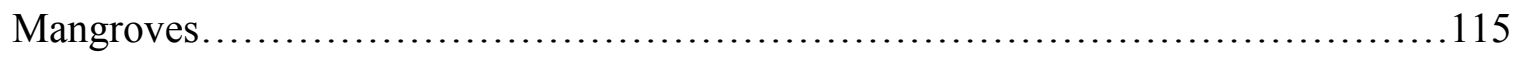

4.6 Economic Valuation of Total Carbon Storage in the Mangrove Forests of the Everglades National Park, Florida 
4.7 Change in the Carbon Stock in the ENP Mangroves and its Economic Value under

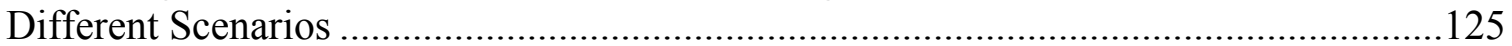

4.8 Change in Economic Value of the total Carbon Stock in ENP Mangroves under Different Scenarios........................................................... 130 


\section{LIST OF FIGURES}

FIGURE

PAGE

1.1 Mangrove Forests in Everglades National Park, Florida ........................................

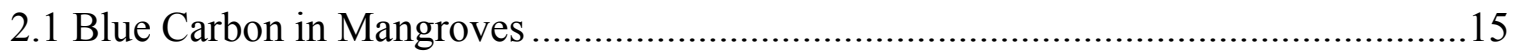

2.2 Location of the Florida Coastal Everglades (FCE) LTER Study Sites in Everglades

National Park, South Florida.............................................................................25

3.1 Map of Mangrove Standing Biomass Distribution in Everglades National Park, Florida....

3.2 Map of Mangrove Forest of Everglades National Park, Florida, showing the projected

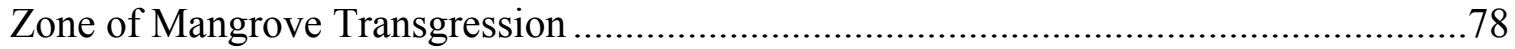

4.1 Total Carbon Storage in the Six FCE-LTER Study Sites in ENP Mangrove Forests

4.2 Map of Mangrove Aboveground Carbon Distribution in the Everglades National Park, Florida.

4.3 Map of Belowground Carbon Distribution in Roots of Mangrove Forests of the Everglades National Park, Florida

4.4 Map of Carbon Distribution in the Soil of Mangrove Forests in Everglades National Park, Florida

4.5 Map of Total Belowground Carbon Distribution in the Mangrove Forests in Everglades National Park, Florida

4.6 Map of Total Carbon Distribution in the Mangrove Forests in Everglades National Park, Florida

4.7 Carbon Storage in the Different Forest Components of ENP Mangroves.

4.8 Quantity of Carbon Storage in Different Forest Components as a Percentage of Total Carbon Storage (990.72 million $\mathrm{Mg} \mathrm{C}$ ) in ENP mangroves

4.9 Comparison of Social Costs of Carbon

4.10 Comparison of Marginal Abatement Costs 104

4.11 Comparison of Market Prices 105 
4.12 Comparison of Total Economic Value of Carbon Storage across Valuation Methodologies in the Mangrove Forests of the Everglades National Park, Florida.....119 


\section{LIST OF ABBREVIATIONS AND ACRONYMS}

C

$\mathrm{C}_{\mathrm{AG}}$

CASES

$\mathrm{C}_{\mathrm{BGR}}$

$\mathrm{C}_{\mathrm{BGS}}$

CCX

CDM

CER

CERP

$\mathrm{CO}_{2}$

COP

$\mathrm{DBH}$

DICE

ECX

ENP

ERU

EU ETS

FAO

FCE LTER

FUND
Carbon

Carbon Stored in the Aboveground Biomass

The Cost Assessment for Sustainable Energy Systems

Carbon Stored Belowground in Fine Roots

Carbon Stored in the Peat Soil

Chicago Climate Exchange

Clean Development Mechanism

Certified Emission Reduction

Comprehensive Everglades Restoration Project

Carbon dioxide

Conference of Parties

Diameter-at-Breast Height

The Dynamic Integrated Climate Economy model

European Climate Exchange

Everglades National Park

Emission Reduction Unit

European Union's Emission Trading System

Food and Agricultural Organization

Florida Coastal Everglades Long Term Ecological Research

The Climate Framework for Uncertainty Negotiation and Distribution Model 


\begin{tabular}{ll} 
GHG & Greenhouse Gas \\
GIS & Geographic Information System \\
ha & hectare \\
IAM & Integrated Assessment Model \\
IMAGE & The Integrated Model to Assess the Greenhouse Effect \\
IPCC & Intergovernmental Panel on Climate Change \\
JI & Joint Implementation \\
LiDAR & Light Detection and Ranging \\
LULUCF & Land Use, Land Use Change and Forestry \\
MAC & Marginal Abatement Cost \\
MANGRO & Spatially Explicit Stand Simulation Model \\
MERGE & Model for Estimating the Regional and Global Effects of GHG policies \\
Mg & Megagram; 1 Mg = 1 ton \\
N & Petagram; 1 petagram = 1,000,000,000 megagram \\
PPV & Nitrogen \\
OC & Net Present Value \\
OECD & Organic Carbon \\
OTC Market & Organization for Economic Co-operation and Development \\
\hline & Pead
\end{tabular}




$\begin{array}{ll}\text { PRTP } & \text { Pure Rate of Time Preference } \\ \text { REDD } & \text { Reducing Emissions from Deforestation and Forest Degradation } \\ \text { RGGI } & \text { Regional Greenhouse Gas Initiative } \\ \text { RICE } & \text { Regional Integrated Model of Climate and the Economy } \\ \text { S.e.m } & \text { Standard Error Mean } \\ \text { SCC } & \text { Social Cost of Carbon } \\ \text { SELVA } & \text { Spatially Explicit Landscape Vegetation Analysis Model } \\ \text { SPC } & \text { Shadow Price of Carbon } \\ \text { SRS } & \text { Shark River Slough } \\ \text { SRTM } & \text { Shuttle Radar Topography Mission } \\ \text { WTP } & \text { Willingness to Pay } \\ \text { TC } & \text { Total Carbon Stored in the ENP Mangrove Forest Ecosystem } \\ \text { TEV } & \text { Total Economic Valuation } \\ \text { TS } & \text { Taylor Slough }\end{array}$




\section{Chapter 1}

\subsection{Introduction}

Mangroves are phylogenetically unrelated groups of plant species that thrive along tropical and subtropical coastlines, with similar morphological and physiological adaptations that allow them to tolerate saline environments in the intertidal zone. Mangrove wetlands are well known for a vast array of ecosystem services that provide direct and indirect benefits to human beings, e.g., coastal protection, erosion control, water purification, and maintenance of fisheries (Alongi, 2008, 2011; Barbier et al., 2011). In particular, mangroves have the potential to act as highly efficient "biological scrubbers" (Stavins \& Richards, 2005) that can sequester atmospheric carbon and store it in their biomass and in sediments. Carbon (C) sequestration by mangroves reduces global warming by removing the harmful greenhouse gas carbon dioxide $\left(\mathrm{CO}_{2}\right)$ from the atmosphere. The location of mangroves at the interface of land, coasts and watersheds produces cumulative benefits of $\mathrm{C}$ storage, which can be more significant than other ecosystems (Barbier et al., 2011). The mean C storage in tropical mangrove forests (1023 $\mathrm{Mg} \mathrm{Cha}^{-1} \pm 88$ s.e.m.) far exceeds the mean C stock in tropical upland, temperate, and boreal forests (200 - $400 \mathrm{Mg} \mathrm{C} \mathrm{ha}^{-1}$ ) (Donato et al., 2011). Chmura et al. (2003) estimated the permanent global $\mathrm{C}$ sequestration by mangroves as $2.1 \mathrm{MgC} \mathrm{ha}^{-1} \mathrm{yr}^{-1}$.

Carbon sequestration and storage by mangroves provides global benefits as it mitigates the effects of climate change, thereby lending economic value to this significant ecosystem service. However, the continued undervaluation of benefits from $\mathrm{C}$ sequestration perpetuates the international free riding of this public good, and exacerbates 
the rapid worldwide loss of mangroves through extensive degradation and over exploitation (Aburto-Oropeza et al., 2008). According to the Intergovernmental Panel on Climate Change (IPCC), deforestation and land-use change account for $8-20 \%$ of the total global anthropogenic $\mathrm{CO}_{2}$ emissions (IPCC, 2007). A third of the global area of mangroves has been lost over the last 50 years (Alongi, 2002) as a result of land use change and degradation. Despite occupying only $0.7 \%$ of tropical forest area, deforestation of mangroves is responsible for $10 \%(0.02-0.12 \mathrm{Pg} \mathrm{C}$ per year) of global emissions from deforestation (Donato et al., 2011). The complementary strategy of conserving natural sinks that sequester and store a significant amount of $\mathrm{C}$ along with the conventional approach of reduction of anthropogenic emissions has gained wider acceptance towards meeting climate change mitigation goals (Canadell \& Raupach, 2008). However, the failure to successfully link sequestration services of natural $\mathrm{C}$ sinks to utilitarian benefits leads to inefficient decision making regarding mangrove ecosystems.

The valuation of ecosystem services like carbon sequestration helps to underscore their tangible economic benefits to society. The persistent moral argument against economic valuation gives credence to intrinsic values alone (Reid, 2006). But there is little doubt that the process of making choices with regard to ecosystems is in itself an exercise in valuation (Barbier et al., 2011). Monetary valuation is inevitable in the light of the significant economic consequences that arise from the use of ecosystem services (Kulshreshtha et al., 2000). Provisioning ecosystem services like food and fuel provide tangible benefits that are easily valued as they are regularly bought and sold in the market. For example, the value of a structural attribute like timber products derived from 
a mangrove forest is easy to calculate. Cultural ecosystem services related to tourism and recreation, too, have been extensively studied. On the other hand, the value of regulating ecosystem services like sediment accretion or $\mathrm{C}$ sequestration is less obvious, and the process of their economic valuation is replete with complications. In addition, the valuation of protected areas in which mangroves are often located is mostly restricted to the value of commercially extracted resources and benefits from tourism, excluding the benefits from regulating ecosystem services. Consequently, national or regional plans for resource management remain incomplete without the inclusion of the value of regulating services like C sequestration. Sustainable management of such protected areas must incorporate all aspects of the benefits (intrinsic, cultural and economic) that flow from mangrove ecosystems.

The economic value of any resource-environment system lies in the contribution of its ecosystem services and functions to human well-being. Consequently, the economic value of the change in ecosystem service flow can be derived by measurement of the effect on changes in human welfare (Freeman, 2003). Economists employ a suite of valuation methodologies to assess the welfare contribution of ecosystem services (Barbier et al., 2011). Carbon sequestration and storage by mangroves is a public good with nonrival and non-excludable characteristics. Public goods are not governed by property rights and therefore do not fit into the framework of a conventional market system. The price of carbon reflected in the present carbon markets, therefore, is not a reflection of the true value of carbon sequestration and storage services of natural ecosystems. As no single valuation method can encompass the value of $\mathrm{C}$ sequestration and storage to society and 
human welfare, an analysis of appropriate methodologies becomes necessary to estimate a price range for $\mathrm{C}$ that would be scientifically justified and socially acceptable. Information regarding the value of carbon sequestration service is an invaluable tool for effective and sustainable management of natural carbon sinks.

There is now a common consensus on the need for a more integrative approach to environment science that views the environment as a social-ecological system and recognizes the linkages between the biophysical and social domains of study (Collins et al., 2010). Human impacts and environmental stressors on ecosystems can be chronic or sustained "press" events like sea level rise, or can be sudden or discrete "pulse" events like hurricanes. Both presses and pulses alter ecosystem functions which in turn affect the quantity and quality of ecosystem services. This change influences human behaviors and attitudes towards the environment and initiates feedbacks that affect the original dynamics and processes (Collins et al., 2010). In the case of mangroves, pulses like storms and hurricanes, and presses like land use change, sea level rise, and altered hydrology are stressors (Alongi, 2002) that can change the $\mathrm{C}$ burial capacity of mangrove wetlands (Rivera-Monroy et al., 2011; McLeod et al., 2011). The recent economic recession, a stressor of human origin, affects strategies that enable society to manage $\mathrm{C}$ sinks in mangrove forests. Deterioration in benefits provided by carbon sequestration service by mangroves can alter human behavior and attitudes which may be manifested as changes in public perceptions about climate change, the perceived value of $\mathrm{C}$ storage, development of climate change mitigation policy, and establishment of carbon markets. The growing realization among people of the value of carbon sequestration and storage 
by mangroves has the potential to initiate feedbacks that affect the original dynamics and processes.

The design of a sustainable management plan for carbon sinks in mangrove forests around the world will require quantifiable metrics of how changes in the presses and pulses will affect the stored $\mathrm{C}$ in amount and economic value. Regionally relevant and reliable economic valuations of carbon sequestration services by mangroves that make a cogent case for its utilitarian benefits to society are urgently needed. However, a robust economic valuation of this ecosystem service must be supported by reliable, scientific methods that estimate the total C (aboveground, belowground and soil carbon) stored in the mangrove ecosystem (Donato et al. 2011; Alongi, 2011). Few studies have documented the total quantity of $\mathrm{C}$ present in mangrove ecosystems and its economic value relevant to the socio-economic conditions prevalent in that particular area. Primary production, the production of organic compounds within plants via the process of photosynthesis, is indicative of the amount of $\mathrm{C}$ stored in plants. With respect to $\mathrm{C}$ sequestration the two significant pools of carbon in the mangrove forests are: (a) the net growth of forest biomass which serves as a shorter term C sink (decennial), and (b) the carbon stored in mangrove soils which is a long-term C sink (millennial) (Bouillon et al., 2009). This study will quantify the total carbon present in the mangrove forests of Everglades National Park (ENP), Florida, and provide an economic valuation of such storage. The study will also examine the economic implications of the potential changes in carbon storage in the mangrove forests of ENP as a result of sea level rise. 


\subsection{Mangrove Wetland Forests of the Everglades}

The mangrove wetland forests in the Everglades National Park (ENP) in Florida, USA offer a unique case study because of their distinct geographical location, ecological attributes, hydrogeomorphological features, and the nature of the presses and pulses that operate upon them. The largest mangrove community found in the North American continent (Lodge, 2005), they are also characterized by a unique set of socio-economic and political conditions that influence their management.

The mangrove forests of the sub-tropical Florida Coastal Everglades (FCE) lie on a carbonate platform (Chen \& Twilley, 1999a), between freshwater marshes of the Everglades and marine waters of the Gulf of Mexico and Florida Bay (Figure 1.1). The Everglades' fresh water-estuarine landscape is an oligotrophic phosphorus (P) limited ecosystem (Noe et al., 2001). The limiting nutrient $\mathrm{P}$ is supplied by the marine waters of the Gulf of Mexico rather than the freshwaters of the upper watershed, making the mangroves of the Everglades function as an upside down estuary (Childers et al., 2006). 


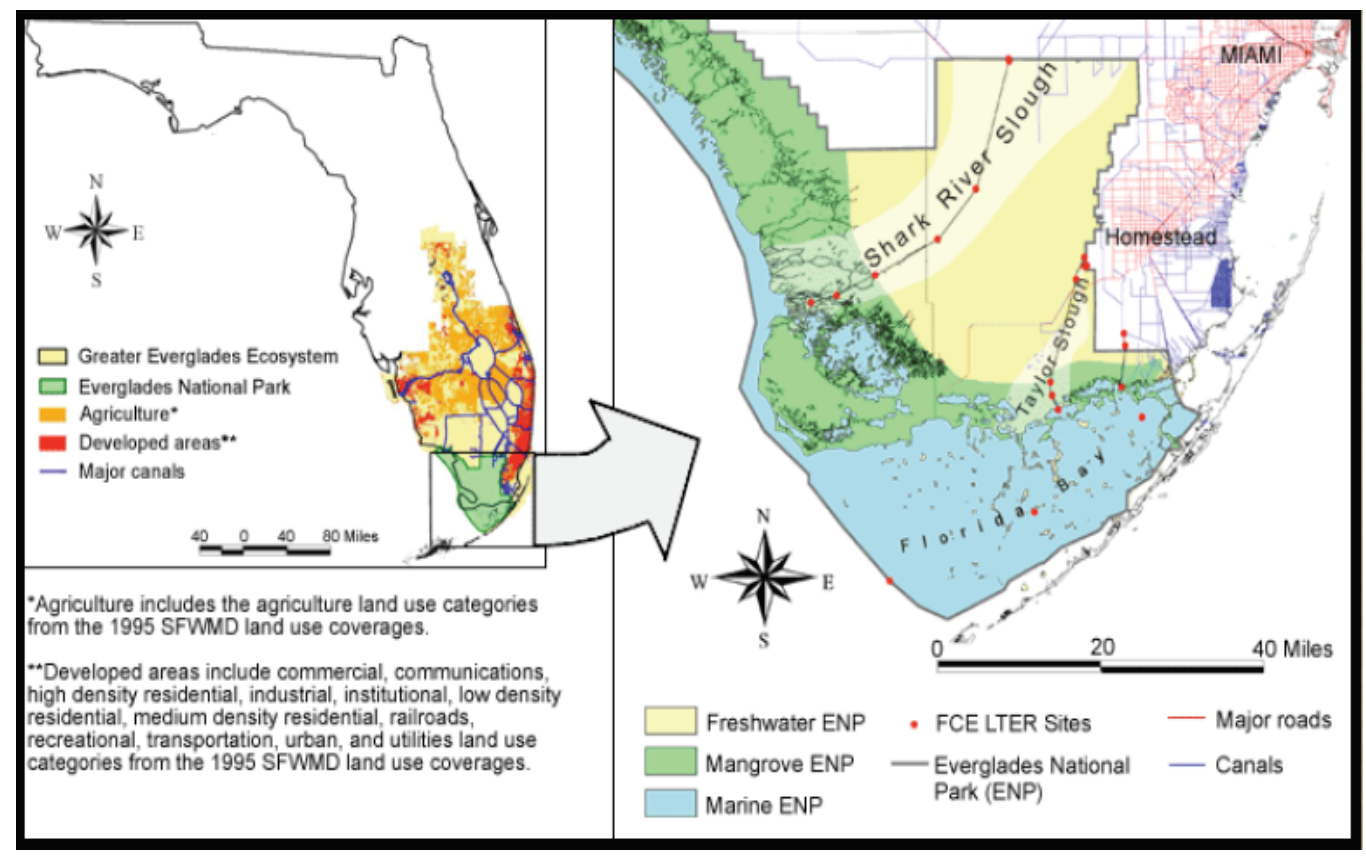

Figure 1.1: Mangrove Forests in Everglades National Park, Florida (Map courtesy: FCE LTER)

Unlike most mangrove forests located in the Americas, the mangroves of ENP have faced low direct human impacts (e.g., deforestation) for several decades in the recent past. However, they are subject to various anthropogenic and natural stressors in the form of freshwater flow from the north and sea level rise along the southern shorelines respectively, affecting mangrove structure and productivity (Davis et al., 2005). Extensive hydrological changes in the past 100 years have vastly altered drainage patterns and reduced fresh water flows into Everglades estuaries by more than $50 \%$ (Smith \& Whelan, 2006), affecting salinity gradients (Davis et al., 2005). The annual sea level rise of $2.0 \mathrm{~mm}$ along with fresh water reduction has led to a $1.5-3.3 \mathrm{~km}$ of inland migration of mangroves during the past 50 years in the southeastern region of the 
Everglades (Ross et al., 2000). ENP mangroves are subject to frequent pulsing events like hurricanes that can render widespread destruction but also serve as a positive influence in maintaining soil elevation relative to changing sea levels. Castañeda-Moya et al. (2010) report that the allochthonous mineral inputs brought in by Hurricane Wilma in 2005 were a significant source of sediments to the vertical accretion rates of soil and served as nutrient $(\mathrm{P})$ resources to the southwestern region of the Everglades forest.

The presence of environmental gradients that act at local scales like hydroperiod, resources such as nutrients levels, and regulators such as salinity and their interactions define the structure and productivity of mangrove wetlands (Twilley \& Rivera-Monroy, 2009) in the Everglades. The combined presence of the strong environmental gradients and a high recurrence of tropical storms and hurricanes results in a distinct gradient of mangrove productivity and biomass in the Everglades (Chen \& Twilley, 1999b; Childers et al., 2006; Rivera-Monroy et al., 2011). The different presses (e.g., sea level rise, water management, coastal development) and pulses (e.g., hurricanes) that operate at varying spatial and temporal scales on the mangroves of ENP influence the carbon storage capacity of these productive forested wetlands. The Everglades are currently under a massive restoration program under the Comprehensive Everglades Restoration Project (CERP) which is expected to increase the quantity, quality, and timing of fresh water reaching the Florida coast (Rivera-Monroy et al., 2011). Sea level rise and alterations in the fresh water inflow from upland sources are the major hydrological disturbances that the ENP mangroves face (Engel, 2010). In addition, the recent economic downturn has led to significant decreases in the funding available to continue the restoration activities 
as planned. The documentation of the quantity and economic value of the stored carbon of ENP mangroves can be used to establish a baseline for future comparisons. An estimation of incremental changes in the economic value of the carbon stored in the mangrove forest as a result of the potential changes in sea level rise, in particular, will provide a useful tool for management of the mangrove $\mathrm{C}$ sink in the Everglades.

According to an economic valuation of the impact of restoration by Mather Economics (2010), CERP will result in significant economic benefits that arise from ecosystem services provided by the Everglades. The study estimated that CERP will result in an increase in economic welfare of approximately $\$ 46.5$ billion in net present value (NPV) terms with an upper value of $\$ 123.9$ billion. The economic benefits arising from six categories of ecosystem services like groundwater purification ( $\$ 13.15$ billion), real estate ( $\$ 16.10$ billion), park visitation ( $\$ 1.3$ billion), open space ( $\$ 830.7$ million), recreational fishing ( $\$ 2.03$ billion), commercial fishing ( $\$ 524.1$ million), and wildlife habitat and hunting ( $\$ 12.5$ billion) were estimated in NPV terms. The economic benefits arising from the restoration on carbon sequestration services of the Everglades ecosystem were not investigated (McCormick et al., 2010). The uncertainty regarding the science of carbon sequestration and the lack of well-developed carbon markets prevents most studies from estimating the economic value of carbon sequestration.

The main premise of this study is that mangrove forests in the Everglades store a significant amount of carbon, particularly belowground, because of their considerable geological age. The low direct human impacts as a result of high levels of management and conservation enforcement in the protected areas of ENP make these mangrove forests 
a natural $\mathrm{C}$ sink. The economic value of the stored $\mathrm{C}$ in mangrove wetlands per unit area is expected to be significantly higher relative to other types of forests (Donato et al., 2011). The economic valuation of $C$ sequestration varies with valuation methodologies; carbon prices are influenced by several technological, regulatory, economic and social factors, and vary across countries and markets. An estimation of the total C (aboveground, belowground and soil carbon) stored in the mangroves of ENP has not been previously attempted. Global estimates of mangrove C storage or estimates derived from mangroves in tropical areas cannot be transferred to this study site because of its distinct geographical location, ecological characteristics, and the nature of the presses and pulses that influence the mangroves of Everglades. Additionally, climate change in the form of sea level rise, alteration in fresh water flow or other land-use changes can alter the C storage capacity of ENP mangroves, affecting the economic value of the ecosystem service. This study will estimate the economic value of the total $\mathrm{C}$ stored in the mangrove wetland forests of the Everglades National Park and perform an incremental economic analysis of potential changes in the stored carbon as a result of sea level rise.

The specific objectives of this study are to:

(1) Quantify the total carbon (aboveground and belowground biomass, and sediments) stored in the mangroves of ENP from current literature and available data;

(2) Identify appropriate methods of economic valuation in order to estimate the economic value of the stored carbon in the mangroves of ENP; and 
(3) Estimate the incremental value of carbon sequestration and storage service by ENP mangroves in response to sea level rise.

The existing literature on valuation of carbon sequestration by mangroves is mostly limited to aboveground carbon storage. A recent study by Donato et al. (2011) has quantified the whole-ecosystem carbon storage in the mangrove forests of the IndoPacific region. Most valuation studies have not included an exhaustive review of economic valuation methodologies to estimate the price for carbon relevant to the social, economic and political milieu of the study site, its status as a protected area, and the biological attributes influencing the status of the mangrove forest as a $\mathrm{C}$ sink. This study will offer a unique perspective on how we can view the total carbon stored in the ENP mangroves in terms of various valuation methodologies in addition to market prices. The value of carbon calculated in this study can act as a tipping price, encourage other countries to lower the rates of deforestation of mangroves, and improve the status of their natural carbon sinks. In the United States, it can stimulate relevant debates among stakeholders and influence policymakers to arrive at a price for carbon stored in protected areas. 


\section{Chapter 2}

\subsection{Carbon Sequestration in Mangroves}

\subsubsection{Mangroves and Ecosystem Services}

Mangroves are salt tolerant plant species that grow in intertidal regions of the tropics and subtropics. Mangrove ecosystems are a significant ecological and socio-economic resource occupying less than $1 \%$ of the earth's surface (FAO, 2007, Alongi, 2008). The Millennium Ecosystem Assessment (2000), a comprehensive report on the status of ecosystems worldwide, describes ecosystem services as benefits provided by ecosystems to human well-being, and categorizes them as provisioning (e.g., food, water), cultural (e.g., spiritual values, recreation), supporting (e.g., nutrient retention, soil accretion) and regulating (e.g., climate regulation, soil stabilization). Mangroves provide a wide array of essential ecosystem services like provision of nursery grounds for fish, birds, and mammals, sediment and nutrient retention, storm protection (Alongi, 2008), and carbon storage (Twilley et al., 1992; Alongi, 2002). Table 2.1 summarizes the different ecosystem services provided by mangroves. 
Table 2.1: Mangroves and Ecosystem Services

\begin{tabular}{ll}
\hline Type of ecosystem service & Mangrove ecosystem service \\
\hline Provisioning & Food (fish, seafood); fuel, wood, charcoal; timber; paper products, \\
medicine & Climate regulation, carbon sequestration and storage; soil stabilization; \\
Regulatory & flood mitigation; storm protection, protection from strong winds and \\
& waves; erosion control \\
Cultural & Aesthetic, spiritual, educational, recreational values \\
Supporting & $\begin{array}{l}\text { Sediment and nutrient retention; soil formation, soil accretion; primary } \\
\text { production; water quality improvement through filtration of sediments and } \\
\text { pollutants, protection of fresh water resources from salt water intrusion; } \\
\text { nursery grounds and breeding sites for birds, mammals, fish, crustaceans, } \\
\text { shellfish, and reptiles. }\end{array}$ \\
\hline
\end{tabular}

Sources: Badola \& Hussain, 2008; FAO, 2007; Alongi, 2008; Barbier et al., 2011

The regulating ecosystem service of carbon sequestration and storage provides an important link between forests and global warming in the global carbon cycle. Human activities like the burning of fossil fuels and deforestation increase the levels of the greenhouse gas carbon dioxide in the atmosphere which leads to increased global warming. Forests play an important role in removing the atmospheric carbon through the process photosynthesis. The storage of organic carbon in the biomass and sediments by plants is referred to as carbon sequestration and storage. Conventional efforts to mitigate the effects of global warming have largely focused on tropical and temperate forests. But recent studies have underscored the importance of coastal and marine ecosystems, and particularly of mangroves, as carbon sinks (Bouillon et al., 2009). 


\subsubsection{Carbon Sinks in Mangroves and Terrestrial Forests}

Mangrove forests are highly productive (Bouillon et al., 2008) and play a significant role in storing organic carbon. Primary production is the measure of the ability of forest ecosystems to store organic carbon. Mangroves absorb atmospheric carbon dioxide and sequester it into organic compounds in their biomass through the process of photosynthesis (Figure 2.1). The aboveground pools of biomass consist of leaves, stem and wood while the belowground biomass includes fine and coarse roots. The biomass can be later consumed by local fauna, exported to adjacent ecosystems, remineralized back into the atmosphere or stored in sediments (Bouillon et al., 2008). The two significant pools of carbon in mangrove ecosystems are: (a) the net growth of forest biomass which serves as a shorter term carbon sink (decennial), and (b) the carbon stored in mangrove soils which is a long-term carbon sink (millennial) (Bouillon et al., 2009).

As mangroves are present at the interface of land, coasts and watersheds, they produce cumulative benefits of carbon storage, which can be more significant than other ecosystems (Barbier et al., 2011). In the Furo de Meio mangrove forest in Brazil, the carbon in the top $1.5 \mathrm{~m}$ of soil dates back 400 to 770 years. A comparison of soil carbon accumulation rates of mangroves $\left(139 \mathrm{~g} \mathrm{C} \mathrm{m}^{-2}\right.$ year $^{-1}$ or $0.00139 \mathrm{Mg} \mathrm{C} \mathrm{m}^{-2}$ year $^{-1)}$ are ten to one hundred times that of temperate forests $\left(1.4-12 \mathrm{~g} \mathrm{C} \mathrm{m}^{-2} \mathrm{year}^{-1}\right.$ or $1.4 \times 10^{-6}-1.2$ $\mathrm{x} 10^{-5} \mathrm{Mg} \mathrm{C} \mathrm{m}^{-2}$ year $\left.^{-1}\right)$ and 50 times that of tropical forests $\left(2.3-2.5 \mathrm{~g} \mathrm{C} \mathrm{m}^{-2}\right.$ year $^{-1}$ or 2.3 $\times 10^{-6}-2.5 \times 10^{-6} \mathrm{Mg} \mathrm{C} \mathrm{m}^{-2}$ year $\left.^{-1}\right)$. Thus, management of the carbon stored in the coastal and marine ecosystems such as mangroves known as "blue carbon" can be a significant method in combating the effects of global climate change (Yee, 2010). 


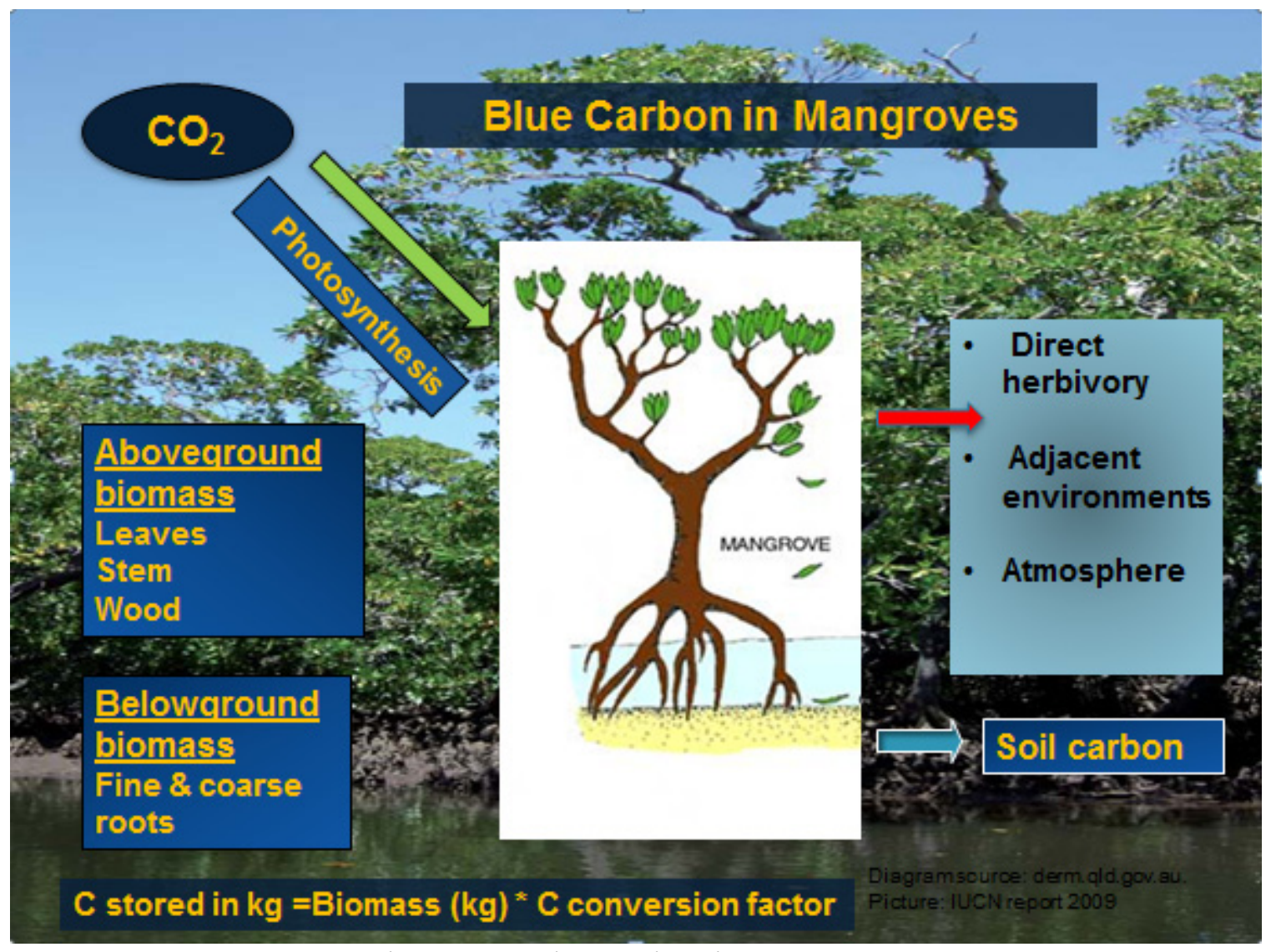

Figure 2.1: Blue Carbon in Mangroves

Twilley et al. (1992) estimated the global carbon storage in mangroves to be $4 \times 10^{9} \mathrm{Mg}$ C. In an assessment of global primary production from literature and using a global area of $160,000 \mathrm{~km}^{2}$, Bouillon et al. (2008) estimated the net primary production of

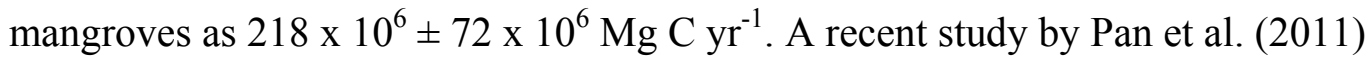
estimated the net global terrestrial forest sink of carbon as $1.1 \times 10^{9} \pm 0.8 \times 10^{9}{\mathrm{Mg} \mathrm{C} \mathrm{yr}^{-}}^{-}$ ${ }^{1}$. A comparative analysis of standing plant carbon stock with other key terrestrial and coastal ecosystems shows that mangroves $\left(7.99 \times 10^{-3} \mathrm{Mg} \mathrm{C} \mathrm{m}^{-2}\right)$ are second only to tropical forests $\left(1.2045 \times 10^{-2} \mathrm{Mg} \mathrm{C} \mathrm{m}^{-2}\right.$ ) (Laffoley \& Grimsditch, 2009). Bouillon et al., 
(2009) report that different global estimates for carbon burial in mangrove systems

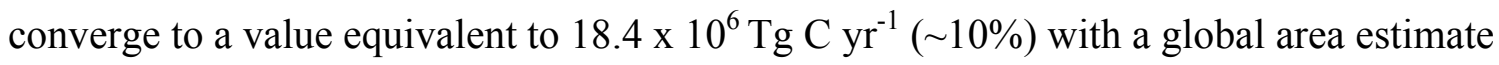
of $160,000 \mathrm{~km}^{2}$. In a recent study, Donato et al. (2011) quantified the total carbon storage in tropical mangrove forests in the Indo-Pacific region and found them to be the most carbon-rich forests in the tropics with an average of $1023 \mathrm{Mg} \mathrm{C}( \pm 88$ s.e.m. $)$ per hectare. In comparison, the mean carbon storage in tropical upland, temperate and boreal forests lies between $200-400 \mathrm{Mg} \mathrm{C}$ per hectare. Data and studies indicate that high mangrove productivity and carbon flux rates translate into high carbon storage, especially below ground (Donato et al., 2011). Conservation and sustainable management of mangrove ecosystems can contribute significantly in reducing greenhouse gas emission reductions.

\subsubsection{Mangrove Production and Biomass}

In order to measure the carbon stored in mangrove ecosystems, two pools of carbon are considered: the carbon present in the biomass and the carbon stored in the soil of the forest. The carbon stored in the biomass as a result of primary production remains in the mangrove ecosystem for decades or hundreds of years, while the reserves of geological carbon in sediments can be preserved for several million years (Bouillon et al., 2009).

Overall, the biomass of mangroves depends on the age of the forest, dominant species and geographical location (Komiyama et al., 2008). Mature mangrove forests with several species may have larger stores of carbon because of the interconnectivity, functional redundancy and an array of more complete services they provide than younger forests (Nickelson, 1999; Alongi, 2011). As established in terrestrial ecosystems, most authors concur that the biomass of mature mangroves in equatorial regions is greater than 
the biomass of mangroves in higher latitudes (Saenger \& Snedaker, 1993; Fromard et al., 1998). Ecological factors like low temperature, low rainfall, excess salinity and occurrence of hurricanes can often restrict biomass of mangroves to low levels (Fromard et al., 1998).

In general, mangroves allocate larger amounts of biomass to their roots, an adaptation which allows them to gain mechanical support in the soft sediments in which they stand. Increased allocation of biomass to roots may also be attributed to soil moisture that increases cambial activity under submerged conditions (Komiyama et al., 2008). Conditions of stress and resource limitation affect biomass allocation and patterns of carbon storage in forest ecosystems. Plants tend to allocate more biomass to roots in nutrient poor soils, an adaptation which also affects soil formation and vertical accretion rates (Chen \& Twilley 1999a; Castañeda-Moya et al., 2011). Root production in mangroves controls the accumulation of organic matter and distribution of soils in the neotropics (Chen \& Twilley, 1999a). Mangroves allocate as much as $40-60 \%$ of their total biomass to roots under conditions of nutrient limitation. Scrub forests in particular have a higher root/shoot ratio when in nutrient-poor and anaerobic soils (CastañedaMoya et al., 2011). Primary or mature forests and forests in lower latitudes have higher aboveground biomass than forests in temperate regions where the aboveground biomass is lower as a result of climatic conditions like temperature, solar radiation, precipitation and frequency of storms (Komiyama et al., 2008).

Mangroves forests are well known for their contribution to organic carbon reserves in their soils through direct deposition as a result of mangrove production and also by 
increasing sedimentation rates. Soil formation in mangroves results from several ecological processes like production, export, decomposition and burial of organic matter along with sedimentation of allochthonous inorganic matter (Chen \& Twilley, 1999a; Twilley \& Rivera-Monroy 2009). Distance from the sea, the geomorphic setting, tidal regimes and the varying inputs of sediments from autochthonous and allochthonous sources determine carbon dynamics in mangrove soils (Donato et al., 2011).

Carbon accumulation in mangrove sediments is sourced in autochthonous (mangrove derived production) and allochthonous (from rivers or adjacent coastal ecosystems) mineral inputs. Mangrove roots attenuate and dissipate wave energy thereby helping the system to trap the incoming sediments and increase the rate of sedimentation. The sequestration of carbon in sediments of mangrove ecosystems is reduced by export of organic matter from the site or its decomposition. The amount of carbon that gets buried is influenced by several factors (Chmura et al., 2003; Komiyama et al., 2008; Bouillon et al., 2009; Yee, 2010):

(a) The tidal signature in the mangrove coastal system: mangrove shorelines with low tidal amplitude have higher carbon accumulation and vice versa.

(b) Topography of the mangrove shoreline: higher shorelines tend to have more carbon accumulation as they are unable to export the organic material produced locally.

(c) Biotic factors: marine invertebrates like crabs increase leaf litter retention thus reducing export or decomposition of the organic matter. 
(d) Abiotic factors: climate conditions like wetness and high temperature increase decomposition rates, increasing the amount of carbon that is released by the mangrove ecosystem.

(e) Rate of soil respiration: low rate of soil respiration, possibly attributable to anaerobic conditions, may be responsible for increased carbon burial.

\subsubsection{Mangroves are Non-linear, Dynamic Ecosystems}

Owing to their unique location at the interface of land and sea, mangrove ecosystems are subject to a plethora of environmental disturbances that vary across spatial and temporal scales. Consequently their responses to environmental disturbances that act at local and global scales are also dynamic and varied. Mangroves are able to withstand a daily exposure to changes in tides, temperature, and anoxic conditions in waterlogged saline soils, possible because of the inherent adaptability of the mangrove ecosystems towards changing environmental conditions. Several characteristics of mangrove ecosystems allow them to exhibit ecological resilience and persistence to environmental disturbances. These include (a) the presence of a significant reservoir of nutrients in the soil which help overcome periods of nutrient loss; (b) rapid biotic turnover as a result of rapid rates of nutrient flux and microbial decomposition; (c) inherent ability to physically reconstruct and rehabilitate the forest post disturbance events; (d) redundancy of keystone species which restores ecological functions of the forest; and (e) presence of positive and negative feedback pathways that ease the path of recovery to a stable state (Alongi, 2008). 
The inherent adaptability and resilience makes mangroves dynamic and non-static ecosystems that constantly respond and adapt to the nonlinear and non-equilibrium conditions produced as a result of environmental disturbances. These dynamic and complex ecosystems exhibit natural spatial and temporal variability that results in nonlinear ecosystem functions and services. This implies that the ecosystem functions like mangrove production, and ecosystem services like carbon sequestration and storage also vary across space and time (Koch et al., 2009; Alongi, 2011).

\subsubsection{Uncertainties in Estimates of Carbon Storage in Mangroves}

Despite being well known for the high carbon accumulation rates as indicated above, there are several reasons why coastal ecosystems and especially the mangroves, have mostly been overlooked for their contribution as carbon sinks in comparison to terrestrial forests. Large uncertainties complicate the status of mangrove ecosystems as sinks or sources of carbon.

(a) Studies that quantify the carbon in mangrove forests report the carbon present in the aboveground biomass but lack information on belowground biomass and soil carbon. Such estimates are incomplete and conservative as mangrove soils are rich in organic matter and contain moderate to high carbon concentration (Donato et al., 2011).

(b) Methodologies for estimation of carbon sequestration vary considerably, adding to the uncertainties (Bouillon et al., 2008, Alongi, 2008). The rates of gross and net primary production are used to determine the sequestration capabilities of mangroves. But large uncertainties exist as carbon storage in the soil and organic carbon export 
and $\mathrm{CO}_{2}$ emission from sediments and the water column account for less than $50 \%$ of the mangrove production. More than 50\% of the carbon fixed by mangroves is still unaccounted for in carbon budgets (Bouillon et al., 2008).

(c) While estimating the economic value of carbon sequestered by mangroves, the natural spatial and temporal variability of this ecosystem, which results in nonlinear functions and services, must be kept in mind. The variability in mangrove production and carbon accumulation through space and time greatly influences the economic valuation of the ecosystem service. The sequestration abilities of mangroves vary at human and geological timescales making them dynamic, nonlinear and nonequilibrium ecosystems. Small scale studies that use short term measurements are unable to capture the accurate picture of sequestration services provided by mangroves (Koch et al., 2009; Alongi, 2011).

(d) As information regarding mangroves is limited, many studies transfer estimates from other regions to study sites. Such projections may be biased as the geomorphology, climate, hydrological conditions, tidal amplitude and biotic factors vary among different mangroves sites (Bouillon et al., 2008).

All such uncertainties make it difficult to categorize a mangrove forest as a sink or source of carbon. Estimates for carbon stored in mangrove ecosystems must, as far as possible, be based on comprehensive data with long temporal records of the actual site in question (Alongi, 2011; Donato et al., 2011). A reliable quantification of these repositories of carbon is difficult as thousands of years of variable deposition, transformation and 
erosion dynamics associated with the fluctuating sea levels and pulse events must be accounted for (Donato et al., 2011).

\subsubsection{Press and Pulse Stressors of Mangrove Forests}

Globally, mangroves are affected by presses like climate change, altered hydrology, land use change, nutrient loading and pollution along with pulses like hurricanes and storms. The response of mangrove ecosystems to large scale events in the form of presses and pulses will be dynamic and uncertain. These presses and pulses influence a variety of ecosystem functions and services including mangrove production and carbon sequestration.

Mangrove forests have been able to persist in the face of sea level rise because of landward migration, and accretion of mangrove soil surface through increased rates of belowground production of organic matter and/ or sedimentation. Under the projected average rate of sea level rise of 1.8 to $7.9 \mathrm{~mm}$ per year, it is difficult to predict the response of mangroves to future changes in sea level. Current data indicate that overall, mangroves are keeping pace with sea level rise although it may be noted that some forests are accreting and some are not. Small-scale and short-term measurements are unable to convey an accurate picture of long term mangrove forest transitions in terms of accretion (Alongi, 2008).

Anthropogenic influences like land-use changes can disturb the reservoirs of carbon in mangrove forests and lead to significant emissions. Clearing of mangrove forests, their drainage, and/or conversion to aquaculture destroys the standing vegetation and leads to 
significant decreases in soil carbon. The top $30 \mathrm{~cm}$ of soil in upland forests is considered most vulnerable to carbon emissions but deeper layers of soil, too, may be affected in wetland forests as a result of drainage and oxidation of suboxic soils. Deforestation of mangroves is responsible for $10 \%(0.02-0.12 \mathrm{Pg} \mathrm{C}$ per year) of global emissions from deforestation (Donato et al., 2011). Deforestation leads to significant reduction of soil carbon reserves (up to $50 \%$ in 8 years), underscoring the links between mangrove carbon reserves, land-use and climate change (Bouillon et al., 2009).

\subsubsection{Patterns of Biomass Production in Mangrove Forests of Everglades National Park}

The mangrove forests of the Everglades National Park lie on a karstic (limestone) platform at the interface of the Everglades freshwater marsh and the marine waters of the Gulf of Mexico and Florida Bay (Figure 1.1). They have unique ecological attributes that do not conform to several trends observed in mangrove forests worldwide. In contrast to the nutrient rich characteristic of most estuaries, the ENP mangroves are fed by highly oligotrophic and phosphorus-limited freshwaters of the Everglades marsh from the north. The limiting nutrient phosphorus $(\mathrm{P})$ is supplied by the marine waters of the Gulf of Mexico rather than the upper Everglades watershed, making the ENP mangroves function as an upside-down estuary (Childers et al., 2006). In the ENP mangroves, there is a distinct variance in the morphological and physiological attributes across spatial scales in response to gradients in hydroperiod, resources (phosphorus, nitrogen) and regulators (salinity and sulfide). Consequently, the interactions among gradients affect the structure, function and productivity of the mangroves. Despite the considerable body of research that supports the Everglades region, the nature of the effects of such environmental 
gradients on the productivity patterns of the Everglades mangroves is not completely understood as yet (Twilley \& Rivera-Monroy, 2009; Rivera-Monroy et al., 2011).

The three mangrove species found in the Everglades are the red mangrove (Rhizophora mangle), the black mangrove (Avicennia germinans) and the white mangrove (Laguncularia racemosa). Conocarpus erectus or the buttonwood is also found in these forests and is not a true mangrove. Variations in hydroperiod and soil nutrient concentrations determine the dominance of mangrove communities which can be grouped into two main categories, forests and scrub. Mangrove forests are high density areas of trees with heights greater than $5 \mathrm{~m}$ and the scrub category are low density areas of trees and shrubs with heights less than $5 \mathrm{~m}$ (Welch et al., 1999; Doren et al., 1999; RiveraMonroy et al., 2011).

Two drainage basins, Shark River Slough (SRS) and Taylor Slough (TS) flow through the western and eastern regions of the Everglades, respectively. Study sites are located along the paths of the SRS and TS estuaries, and are part of a comprehensive research program under the aegis of Florida Coastal Everglades Long-Term Ecological Research (FCE LTER) since 2000 (Figure 2.2). SRS-4, SRS-5 and SRS-6 are located along the Shark River from upstream to downstream along the southwest coast of ENP. The Taylor Slough/Panhandle (TS/Ph) transects follows two flow paths, one that flows into eastcentral Florida Bay and the other that flows into the eastern Florida Bay (Rivera-Monroy et al., 2011). 


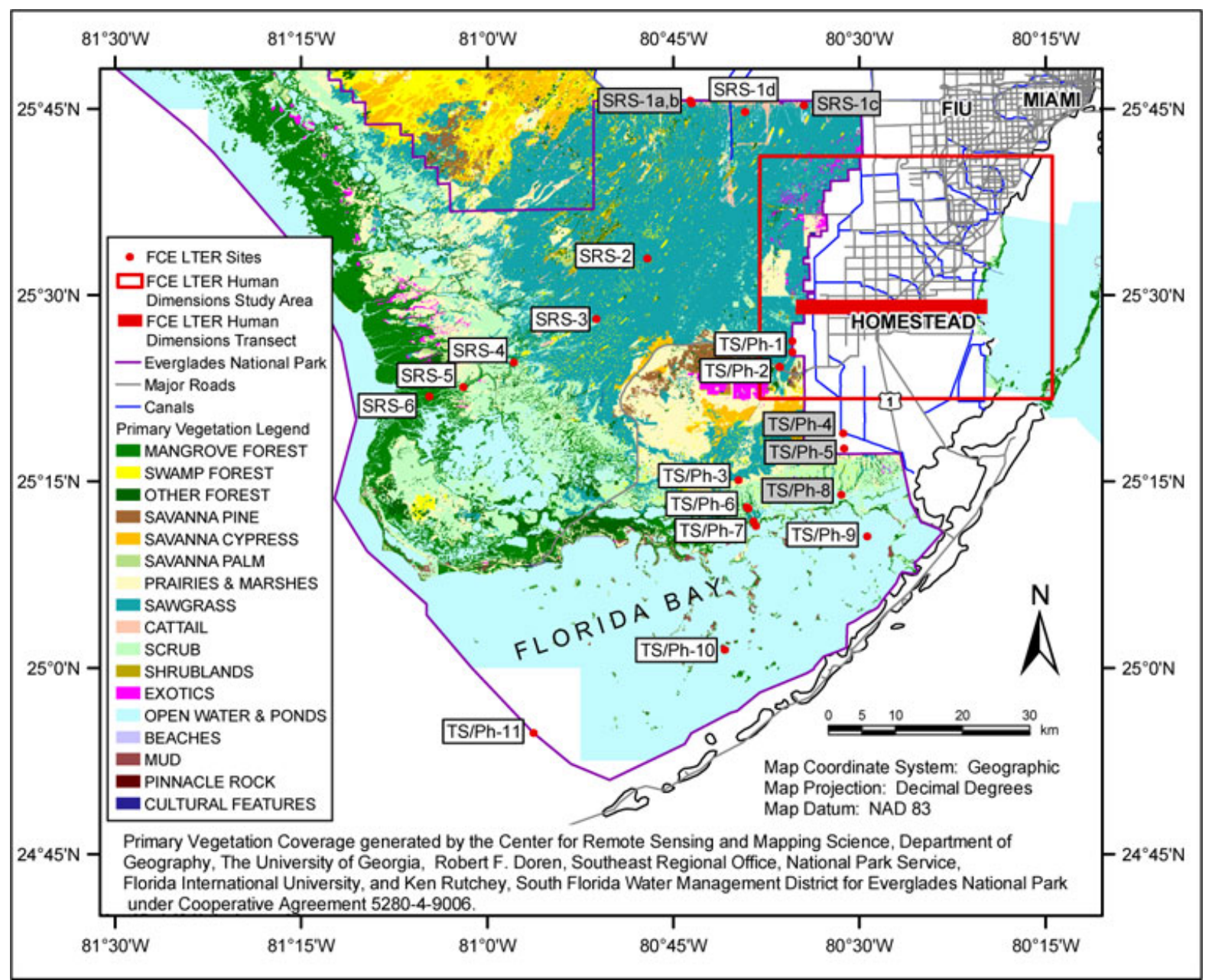

SRS $=$ Shark River Slough, TS/Ph = Taylor Slough/Panhandle

Figure 2.2: Location of the Florida Coastal Everglades (FCE) LTER Study Sites in Everglades National Park, South Florida.

Shark River and Taylor River sloughs have contrasting hydrogeomorphological characteristics. The contrasting gradients in hydroperiod, resources (soil P fertility) and regulators (salinity and sulfide concentrations) give rise to contrasting landscape patterns of productivity and biomass allocation across the two basins. The interactions of the various environmental gradients have resulted in a distinct gradient of scrub to fringing mangroves in the Everglades. The SRS with tall, riverine mangroves and TS, dominated 
with dwarf, scrub forests are therefore analyzed separately to finely portray the distinct continuum of processes in the Everglades mangrove forests (Rivera-Monroy et al., 2011).

Hydroperiod refers to the temporal patterns of water level in a wetland and is characterized by the depth, duration and frequency of flooding of the soil. Hydrological conditions in the Everglades mangroves are defined by the dry (November to May) and wet (June to October) seasons, tropical storms and the winter frontal passages in south Florida. Hydrological conditions in both Shark River Slough (SRS) and Taylor River Slough (TS) in the Everglades' mangrove forests are influenced by local rainfall, evaporation and water management upstream. Climate plays a significant role in influencing rainfall, nutrient exchange, phosphate inputs into the mangroves, and salinity patterns along the rivers (Rivera-Monroy et al., 2011).

\subsubsection{Aboveground Biomass}

The tall, riverine mangroves seen along the Shark River Slough are indicative of the high aboveground productivity seen in this region, with the highest aboveground biomass values observed close to the mouth of the estuary. The high aboveground productivity of the mangroves of SRS is attributed to the dominant tidal hydrology and higher P availability in the soil. The mangroves in SRS are tide-dominated and subject to a high frequency, duration and depth of flooding in regions close to the mouth of the estuary (SRS-6) (Chen \& Twilley, 1999b; Castañeda-Moya et al. 2010; Rivera-Monroy et al., 2011). Tides in SRS are semidiurnal with a mean tidal range of $1 \mathrm{~m}$. Surface flooding is more common in wet season than dry. The tidal influence in SRS-4 is lower than that in the downstream SRS-6 and is reflected in the lower salinity levels (Rivera-Monroy et al., 
2011). Hurricane activity also controls patterns of mangrove structure and productivity along the SRS. The allochthonous mineral inputs in the form of calcium-bound P carried by the sediments during the storm events are deposited near the mouth of the Shark River estuary near the Gulf of Mexico during pulse events like storms and hurricanes (Chen \& Twilley, 1999a, b). This deposition leads to increase in the concentration of the limiting nutrient $\mathrm{P}$ and lower N/P ratios at the mouth of the estuary (SRS-6). The availability of $\mathrm{P}$ deposits decreases with distance from the mouth of the estuary as upstream sites (SRS-4 and 5) do not receive the same mineral and sediment inputs. As a result, the highest tree height values $(18-20 \mathrm{~m})$ and higher biomass values $\left(150-200 \mathrm{Mg} \mathrm{ha}^{-1}\right)$ are observed at the mouth of the estuary as compared to upstream sites of SRS and other regions in the southeastern part of the forest. As the dominance of tides and availability of $\mathrm{P}$ decreases with distance away from the mouth of the estuary, SRS-5 and SRS-4 exhibit lower aboveground productivity. In comparison to the scrub mangroves of TS, SRS mangroves allocate 3.5 times more biomass in their aboveground portions than to their roots (Castañeda-Moya, 2010).

The mangrove forests along the Taylor Slough have lower aboveground productivity as seen by the dwarf, scrub mangroves that grow in this forest. The scrub mangroves have an average height of less than $5 \mathrm{~m}$ and biomass of less than $50 \mathrm{Mg} \mathrm{ha}^{-1}$ (Simard et al., 2006; Castañeda-Moya, 2010). The mangroves in TS are permanently flooded with negligible tidal frequency, and a tidal range of less than $0.5 \mathrm{~m}$ (Castañeda-Moya et al. 2011; Rivera-Monroy et al., 2011). Storm deposits from the Florida Bay are prevented from reaching the TS mangroves because of the presence of a geologic barrier called the 
Buttonwood Ridge. Thus, TS mangroves do not receive the same deposition of allochthonous mineral inputs during storm events as the mangroves of SRS, resulting in lower P concentrations in the soil. The lower aboveground productivity in TS mangroves is attributed to a strong P limitation in the soils and the absence of tidal dominance and permanent flooding of the soils (Castañeda-Moya et al. 2011).

\subsubsection{Belowground Biomass}

The same factors that result in low aboveground productivity are responsible for a higher fine root biomass in Taylor Slough mangroves. Mangroves along Taylor River allocate more biomass to fine roots with corresponding increase in $\mathrm{P}$ limitation and permanence of flooding (lower tidal frequency) (Ewe et al., 2006; Castañeda-Moya, 2010) . Taylor River mangroves allocate 3.8 times more biomass to their roots in comparison to aboveground biomass (Castañeda-Moya et al. 2011). The total belowground biomass ( 0 $-90 \mathrm{~cm}$ ) among all the FCE LTER sites in SRS and TS ranges from $2404 \pm 329 \mathrm{~g} \mathrm{~m}^{-2}$ to

$4673 \pm 401 \mathrm{~g} \mathrm{~m}^{-2}$. The estimates for belowground biomass were highest in TS/Ph-7, followed in decreasing order by SRS-5, TS/Ph-8, SRS-4, SRS-6 and TS/Ph-6. The root/shoot ratio in Taylor River sites was found to be 17 times higher when compared to Shark River Slough sites. The increased allocation of biomass belowground in TS when compared to SRS is attributed to P limitation and flooded soil conditions (CastañedaMoya et al., 2011). Castañeda-Moya et al. (2010) observed root/shoot ratios increased with the stress of increasing sulfide concentrations in TS as a result of permanent flooding. Such increase in root biomass allocation enables the plants to adapt towards nutrient limitation and soil stress conditions (Krauss et al., 2006). 
In addition, pulse disturbances like hurricanes have an impact on the distribution of minerals and sediments across the mangrove forest of the Everglades. Allochthonous mineral inputs of calcium-bound P from Hurricane Wilma were found to be highest at areas close to the mouth of the SRS estuary and decreased with distance away from it. The same mineral and sediment inputs were prevented from reaching Taylor Slough because of the presence of the geographical barrier called the Buttonwood Ridge, resulting in increased $\mathrm{P}$ limitation in this area (Castañeda-Moya et al., 2010). As a result, regions like the mouth of Shark River estuary that receive hurricane-derived P subsidies have greater soil P fertility. Areas at a distance from the mouth of the Shark River estuary and mangroves of Taylor Slough have lower soil P fertility as they do not lie under the influence of pulse events like storms and hurricanes (Castañeda-Moya et al., 2010). The variations observed in the hurricane-induced sediment and nutrient deposition correspond with the gradients in productivity and biomass in the Everglades mangroves (Chen \& Twilley, 1999a; Ewe et al., 2006; Simard et al., 2006).

Thus, the biomass of mangroves is distributed differentially across spatial scales in the Everglades' mangroves, varying in response to the interaction of distinct environmental gradients that operate in this region. Gradients in hydroperiod, resource nutrients like phosphorous, and regulators like sulfide interact with each other and produce a conspicuous gradient of biomass of scrub to fringing mangroves in the Everglades landscape (Rivera-Monroy et al., 2011). In addition, pulse events like hurricanes influence the inputs of nutrients and contribute to the vertical accretion of mangrove soils (Castañeda-Moya, 2010). A combination of all these factors and influences results in a 
non-uniform allocation of aboveground and belowground biomass across spatial scales of the mangrove forests in ENP. The incremental deposition of sediments during pulse events contributes to vertical soil accretion and may be an adaptive response to sea level rise (Castañeda-Moya, 2010). The vertical accretion resulting from Hurricane Wilma was 8 to 17 times greater than the annual vertical accretion rate $(0.30 \pm 0.03 \mathrm{~cm} /$ year $)$ averaged over the past 50 years (Castañeda-Moya et al., 2010).

\subsection{Economic Valuation of Carbon Sequestration}

The economic value of any resource-environment system lies in the contribution of its ecosystem services and functions to human well-being. Consequently, the economic value of the change in ecosystem service flow can be derived by measurement of the effect on changes in human welfare. Effect on human welfare is measured by people's willingness to pay (WTP) for changes that have a positive welfare impact or the willingness to accept (WTA) compensation to avoid negative impacts. To assess the welfare contribution of ecosystem services, economists use environmental valuation methodologies (Freeman, 2003). The economic value of private goods in a conventional market is a sum of the producer and consumer surplus as indicated by the supply and demand curves of commonly marketed goods. The total economic value (TEV) of ecosystem services, harder to constrain within the framework designed for private goods, is determined by the sum of their use values and non-use values. However, this valuation can only be done upon the characterization of the changes in ecosystem structure, function and processes that result in the change in ecosystem services. In addition, it is important to understand how the changes in ecosystem structure and function influence 
the quantity and quality of the flow of an ecosystem service to human beings (Barbier et al., 2011).

The carbon stored within mangrove forest ecosystems has begun to take significant economic value as seen with the emergence of carbon markets. Its economic value arises from the knowledge that $\mathrm{CO}_{2}$, a major greenhouse gas, is sequestered by forest ecosystems including mangrove forests, thus reducing the effects of global climate change. However, no single valuation method can encompass the value of carbon sequestration service to society and human welfare. Each methodology depends on the context of the study and carbon sequestration project in question, availability of data, and certain theoretical considerations. A detailed analysis of appropriate methodologies for pricing carbon is necessary to estimate a suitable price range that would be scientifically justified and socially acceptable. A review of four different approaches is considered appropriate for carbon sequestration: (a) damage cost assessment (b) damage avoidance method, (c) market price analysis, and (d) stated preference approach.

\subsubsection{The Damage Cost Approach}

Several authors have estimated the economic costs of climate change in terms of reduction in welfare below its reference levels. Cost estimates for doubling of $\mathrm{CO}_{2}$ concentration in the atmosphere roughly lie in the range of 1 to $2 \%$ of the GDP of the world in many studies (such as Nordhaus,1994a; Fankhauser, 1994; Tol 1995; Nordhaus and Yang, 1996) but estimates as low as $0.1 \%$ and as high as $4.8 \%$ also exist (such as Maddison, 2003; Nordhaus, 2006). In contrast, Tol (2002) and Hope (2006) have estimated that the net effects of global warming could be positive. These studies show 
that the aggregate benefit for the doubling of $\mathrm{CO}_{2}$ in the atmosphere could be as high as $2.3 \%$. The studies indicate initial benefits derived from small increases in temperature followed by losses with larger increases (Tol, 2009).

Two basic approaches are used to carry out these studies. The enumerative method used by Nordhaus (1994a), Fankhauser $(1994)$ and Tol $(1995,2002)$ uses the physical effects of climate change based on climate and impact models and laboratory experiments and data. The physical impacts are then allocated a suitable price. For example, the cost of building levees for coastal protection and the value of the loss of land with rise in sea level can be estimated through scientific and economic data. All such effects of climate change are then added up to arrive at final cost estimates. Valuation of nonmarket goods and services may require the benefit transfer approach to attach economic values to effects of climate change by using research in epidemiology of effects on health and environment. There is a fair degree of extrapolation used in the enumerative approach in terms of time scale, level of development, geographic scope and transfer of values from one area to another. On the other hand the statistical approach uses direct estimates of welfare impacts based on observed variations in price and expenditures over space and time in order to quantify effects of climate change (Tol, 2009).

Marginal damage costs are the net present value of the incremental damage caused by a small increase in emissions (Tol, 2006). The damage cost associated with the marginal increase in the atmospheric content of carbon equals the damage inflicted by that carbon emission on the environment and society. Marginal damage cost of carbon is also referred to as the social cost of carbon (SCC) which is defined as the incremental cost to society 
of a one-metric-ton increase in carbon emissions (Yohe et al., 2007). SCC reflects what a society should, in theory, be willing to pay now to avoid the future damage caused by incremental increase in carbon emissions (Price et al., 2007). The concept of marginal benefits is appropriate for climate policy as it provides a practical solution in the form of small contributions to a global problem that scales several centuries (Tol, 2011). Marginal damage cost may be considered equal to the Pigouvian tax on carbon for policy purposes in order to make for an efficient market by internalizing the externalities (Tol, 2009).

To offset the uncertainties in the calculation of damage costs a sizeable amount of research has been carried out on the economic modeling for the estimation of socioeconomic damage costs of climate change. These models like MERGE ${ }^{1}, \mathrm{IMAGE}^{2}$, $\mathrm{CASES}^{3}, \mathrm{FUND}^{4}$, and DICE ${ }^{5}$ are called Integrated Assessment Models (IAMs). They combine the socio-economic aspects of global economic growth with the scientific aspects of geophysical climate dynamics and aim to set a dynamic approach for assessing policy options for climate change control (Ding et al., 2010).

Ding et al. (2010) have used the values of SCC derived from the Cost Assessment for Sustainable Energy Systems (CASES) project, a worldwide study funded by the

\footnotetext{
${ }^{1}$ MERGE - the Model for Estimating the Regional and Global Effects of GHG policies

${ }^{2}$ IMAGE - the Integrated Model to Assess the Greenhouse Effect

${ }^{3}$ CASES - the Cost Assessment for Sustainable Energy Systems

${ }^{4}$ FUND - the Climate Framework for Uncertainty Negotiation and Distribution model

${ }^{5}$ DICE - the Dynamic Integrated Climate Economy model
} 
European Union. The central estimate range for the SCC was $\$ 119.86 / \mathrm{tC}$ in 2000 to $\$$ 213.70/tC in 2030. A survey of Tol (2005) of the literature's SCC estimates reports a mean estimate of $\$ 50 / \mathrm{tC}$. Nordhaus (2007) estimated the SCC with no emission limitations, using the Dynamic Integrated model of Climate and the Economy (DICE), to be about $\$ 28$ per metric ton of carbon in 2005. Another study by Chiabai et al. (2009) has used the lower marginal damage costs estimates, $\$ 9 / \mathrm{tC}$ for the year 2007 and $\$ 32.4 / \mathrm{tC}$ for the year 2050 . The values are taken from CASES assuming a $30 \%$ reduction in emissions in 2020. This study has provided conservative estimates for carbon sequestration of the world's biomes using lower bound values in terms of annual per hectare values.

Tol (2011) carried out a meta-analysis of 311 published estimates of SCC confirms the large uncertainty in estimates. The mean estimate of all studies was $\$ 177 / \mathrm{tC}$ with a modal estimate of $\$ 49 / \mathrm{tC}$. The mean estimate for SCC in peer reviewed studies in this metaanalysis was $\$ 80 / \mathrm{tC}$ (mode - $\$ 26 / \mathrm{tC}$ ). Some authors who have significantly contributed to the large body of SCC estimates are William Nordhaus, Chris Hope and Richard Tol. The average mean estimates of SCC in by these authors are $\$ 35 / \mathrm{tC}$ (Nordhaus), $\$ 59 / \mathrm{tC}$ (Tol), and \$77/tC (Hope). The large differences in SCC values are attributed to the different pure rates of time preference or discount rates used in the studies. A higher discount rate implies a lower present value of costs for climate change incurred in the future.

The social cost of carbon for regulatory impact analysis has been estimated by an Interagency Working Group of the United States government (Technical support 
document under executive order 12866). The SCC is estimated at $\$ 77 / \mathrm{tC}$ for 2010 and $\$ 87 / \mathrm{tC}$ for 2015 at 3\% discount rate. The SCC were calculated so that US government agencies can incorporate the social benefits of reducing carbon emissions into costbenefit analyses of regulatory actions that have marginal impacts on cumulative global emissions.

\subsubsection{The Cost of Damage Avoidance Approach}

Any project that lowers greenhouse gas emissions and avoids attendant environmental damage by investing in less carbon-intensive technology or sequestration measures entails certain opportunity costs. These costs are the benefits forgone when scarce resources are used to avoid the chances of negative impacts of emissions instead of being used in alternative activities. Estimation of such opportunity costs is referred to as damage avoidance approach (Dieter \& Elsasser, 2002). More specifically, opportunity cost is the net benefit sacrificed in order to prevent or reduce the chances of a negative environmental impact. Marginal avoidance costs increase with increased amounts of reduction, and inter-sectoral and emissions trading lowers them as trading leads to growth in technology. These costs encompass all explicit and implicit costs and are not a mere reflection of monetary accounting (Stavins \& Richards, 2005).

Forest-based sequestration has emerged as a powerful concept in mitigating the effects of climate change as forests being highly productive ecosystems, can sequester $\mathrm{CO}_{2}$ from the atmosphere and become long-term carbon sinks. Based on this concept, Stavins and Richards (2005) analyzed eleven previous studies that have estimated the likely costs of large scale, hypothetical forest carbon sequestration programs based on modified 
management of existing forests or conversion of agricultural land to forests or agroforestry in the U.S. The costs for carbon sequestration in these eleven studies were mainly derived from "engineering" cost methods and some studies relied on the revealed preference approach. Stavins and Richards (2005) analyzed these previous studies for opportunity costs of using vast amounts of land in the United States for sequestration and the factors that influence the economics of a long-term sequestration project. As noted by the authors, the cost of forest carbon sequestration is influenced by several factors: (a) forest management practices, the species of trees used, related rates of carbon uptake over time and geographic location of the area selected; (b) disposition of the biomass through burning, harvesting, and forest product sinks; (c) opportunity costs of the land; (d) anticipated changes in forest and agricultural product prices over time; (e) the analytical methods used to account for carbon flows over time; (f) the discount rate applied; and (g) the policy instruments used to achieve a given carbon sequestration target. Upon normalization of results from relevant studies, the marginal cost of supplying 500 million tons of forest-based carbon sequestration in the United States was found to be $\$ 70$ per ton of carbon (using a discount rate of 5\%).

Marginal abatement costs (MAC) are the costs of eliminating an additional unit of carbon emissions and a MAC curve can be constructed by plotting $\mathrm{CO}_{2}$ prices against a corresponding reduction amount for a specific time and region (Ellerman \& Decaux, 1998). MACs are used to demonstrate the benefits of emissions trading. Computer based economic models are developed to calculate MACs with respect to long-term policy targets. Varying estimates are produced depending on the models used which differ in the 
assumptions and specifications provided and the stabilization targets used. Most models equalize MACs across all sources and MACs of different GHGs are also equalized with respect to their warming potentials and lifetimes in the atmosphere. A meta-analysis of MAC estimates was carried out by Kuik et al. (2008) by synthesizing the results from multiple sources using statistical techniques. The MACs from these studies were based on the level of stabilization target, the baseline of emissions used, intertemporal optimization, the choice of control variable and assumptions on future technological options. Normalization of results was done using the consumer price index from OECD (Organization for Economic Co-operation and Development) to convert all prices to a common year of 2005, market exchange rates from OECD were used to arrive at a common currency (Euros) and molecular weights were used to convert all physical dimensions to that of $\mathrm{CO}_{2}$ (Kuik et al., 2008). The resulting MAC from this meta-analysis is labeled an "idealized global MAC" as it strives to equate MAC across all sources of emissions at each point in time and is designed to result in an optimal trajectory of MAC over time (Kuik et al., 2008). The range of values of the globalized MAC is $€ 13-$ $€ 119 / \mathrm{tCO}_{2}$ for the year 2025 and $€ 34-212 / \mathrm{tCO}_{2}$ for the year 2050 (average value of $\$ 204 / \mathrm{tC}$ for 2010). This estimation is calculated for a target range of 550-350 ppmv. It can be considered as the carbon permit price in an idealized global emissions trading system (Kuik et al., 2008).

Tol (2006) estimated the avoidance costs for $\mathrm{CO}_{2}$ and other GHGs with the 2.9 version of the model, Climate Framework for Uncertainty, Negotiation and Distribution (FUND). Marginal abatement costs in this study were considered equal between regions and gases 
although differential global warming potentials have been taken into account. The marginal abatement cost for $\mathrm{CO}_{2}$ in 2050 was estimated to $\$ 95.2 / \mathrm{tC}(\$ 14 / \mathrm{tC}$ for 2010) for a target of $500 \mathrm{ppm}$.

Fisher \& Nakicenovic et al. (2007) in the fourth assessment report of the IPCC 2007 estimate that the MAC was an average of $\$ 125 / \mathrm{tC}$ (calculated for the year 2010).

\subsubsection{The Market Price Method}

Carbon markets, based on the current and future demand and supply of carbon credits, determine the market price and generate payments for storage and sequestration of carbon. The price per ton of carbon in markets represents the price investors are willing to pay to store one ton of carbon (Yee, 2010). Carbon markets can be regulatory like the European Union's Emission Trading Scheme (EU ETS) and the Regional Greenhouse Gas Initiative (RGGI) in the U.S or voluntary like the European Climate Exchange (ECX) and the now defunct Chicago Climate Exchange (CCX).

\subsubsection{Regulatory Carbon Markets}

Carbon markets have been in the process of evolution since the beginning of the EU ETS. Regulatory markets like the EU ETS are a classic cap-and-trade system as (a) an absolute quantity limit (cap) on $\mathrm{CO}_{2}$ emissions is set on the installations and factories; (b) tradable allowances (called EUAs or European Union Allowances in EU ETS) equal to the cap are given to these installations; and (c) the installations have to measure and report the $\mathrm{CO}_{2}$ emissions every year and then surrender allowances to cover the emissions. A company that has more emissions than allowances will have to purchase additional allowances and 
a company that has surplus allowances can sell them. In such a regulatory or compliance market, parties and installations are required to meet an emission reduction commitment which raises the demand for credits. Along with the higher demand, strict standards for verification of validity of emission reductions result in a higher price per metric ton of $\mathrm{CO}_{2}$ emissions. Emission trading occurs among the 30 countries with binding targets under the Kyoto Protocol. The targets for each country with the commitment are the "allowed emissions" and are divided into "assigned amount units" (AAUs). Countries with excess emission units to spare can sell them to countries that are over their targets so they can meet their commitments. In addition to AAUs, other units that can be traded are (a) Certified emission reductions or CERs generated from Clean Development Mechanism (CDM) projects; (b) Emission reduction units or ERUs generated from Joint Implementation (JI) projects; and (c) Removal units on the basis of land use, land use change and forestry (LULUCF) activities. All these are equal to one ton of $\mathrm{CO}_{2}$.

The Regional Greenhouse Gas Initiative (RGGI) is the first market based regulatory program for greenhouse gas emissions in the United States in which ten Northeastern and Mid-Atlantic States aim to reduce their emissions by 10\% from the power sector by 2018 . Emission allowances are sold through quarterly auctions in the primary market and the revenues are invested in clean energy technologies, energy efficiency and renewable energy programs. $\mathrm{CO}_{2}$ emission allowances are distributed in the market through auctions, and 319 million $\mathrm{CO}_{2}$ allowances have been sold for $\$ 777$ million since the inception of the program in January 2009 through December 2010. The allowances can also be traded any time in a secondary market in between auctions. This allows protection 
to firms against potential volatility of future auction clearing prices and also provides price signals to affected firms that help in making investment decisions in markets (RGGI annual report, 2010).

In 2010, the international carbon markets transacted $6,692 \mathrm{MtCO}_{2} \mathrm{e}$ and were valued at $\$ 124$ billion. The EU ETS dominated the market with a value at $\$ 106$ billion (PetersStanley et al., 2011). The RGGI had seen promising growth in its first year but problems of over-allocation coupled with the failure of a federal US climate legislation dampened the momentum of the United States' first carbon market. The average trading price of a metric ton of $\mathrm{CO}_{2} \mathrm{e}$ is $\$ 18-23$ in the EU ETS and $\$ 9-16$ in the Clean Development Mechanism (CDM) market (Yee, 2010). For December 2011, the closing price of European Union Allowances (EUAs) was predicted from the average values as $€ 10.78$ or \$15.37 as reported by Point Carbon (http://www.pointcarbon.com/, date of last access August 5,2011 ). The price assessment for secondary CERs was $€ 7.60$ or $\$ 10.83$ (http://www.pointcarbon.com/, date of last access August 5, 2011). In December 2010, the $\mathrm{CO}_{2}$ allowance prices in the RGGI market fell to $\$ 1.87$ from $\$ 2.24$ in January 2010 (RGGI annual report, 2010).

\subsubsection{Voluntary Carbon Markets}

Voluntary carbon markets (VCMs) are not guided by regulatory obligations. The volume of credits transacted in this sector is small and formed $0.1 \%$ of the global carbon markets share in 2010 (Peters-Stanley et al., 2011). The demand for offsets is low and the standards for verification of credits are less strict, resulting in lower price range of $\mathrm{CO}_{2}$ emissions from $\$ 5-10$ (Yee, 2010). Transactions are driven by individuals and companies 
that take responsibility for offsetting their own emissions or by pre-compliance buyers. Pre-compliance buyers are those that purchase offsets at a lower price as they anticipate a future regulatory system. ECX is a formal exchange, a cap and trade system that is legally binding for members that sign up for it voluntarily. A formal, public exchange offers a straight forward method of trading, eliminating risks of default by counter parties due to the monitoring facilities offered by the exchange (RGGI annual report, 2010). Most voluntary offset transactions take place in the decentralized over-the-counter (OTC) market where buyers and sellers engage directly, allowing them to create contracts that suit their purpose and needs. The credits generated through OTC markets are referred to as Verified or Voluntary Emissions Reductions (VERs) or carbon offsets. Investors in OTC can also purchase and retire allowances from compliance markets like RGGI or CDM. Voluntary markets guide and inform regulatory markets through innovative experiments in project finance, monitoring and methodologies (Peters-Stanley et al., 2011).

\subsubsection{Reducing Emissions from Deforestation and Forest Degradation-Plus (REDD+)}

The carbon related to land use projects traded in voluntary markets provides the best indication of the potential value for carbon stored in ecosystems (Campbell et al., 2008). In 1997, the Kyoto Protocol only allowed project based incentives for afforestation and deforestation. The current carbon market therefore uses credits from afforestation and reforestation projects. Comprehensive greenhouse gas reductions can only be achieved by including avoided deforestation efforts that protect existing carbon sinks along with reforestation and afforestation projects. The 2005 UNFCCC Montreal Conference of 
Parties (COP) proposed a carbon credit system for avoided deforestation and transformed the original Reducing Emissions from Deforestation and Forest Degradation (REDD) mechanism to Reducing Emissions from Deforestation and Forest Degradation-Plus (REDD+). The goals of REDD+ include the added benefits of biodiversity conservation and poverty alleviation (Yee, 2010).

The market share of REDD grew last year due to the formal international recognition in the 2010 UNFCCC Cancun COP for REDD and REDD+ as significant tools for climate change mitigation. REDD + has also been recognized by California's upcoming cap-andtrade program in 2012. The COP 16 decision at Cancun recognized the significance of tropical forests in mitigating global climate change. Developing countries not covered by the global emissions commitment can now receive financial incentives through the following REDD + activities by: (a) reducing emissions from deforestation by slowing the process and measuring against reference levels; (b) reducing emissions from forest degradation; (c) conservation through continued practice of good management techniques; (d) sustainable management of forests by lowering impacts through sustainable harvestation methods; (e) enhancement of carbon stocks in forests. These reductions are subject to verification and validation based on conditions of additionality, permanence of credits and spatial leakage. Credits for REDD+ will require protection of rights and participation of indigenous people and local communities (Linacre et al., 2011).

The average credit price for REDD and avoided conversion projects rose to $\$ 5 / \mathrm{tCO}_{2} \mathrm{e}$ and these projects contributed $29 \%$ of credits transacted in the voluntary market in 2010 
(Peters-Stanley et al., 2011). This increase was attributed to private sector finance injected into forest conservation and sustainable development projects in developing countries. REDD+ projects have gained further standing in the voluntary market following the approval of project methodologies by Verified Carbon Standard (VCS) which is a greenhouse gas accounting program used by projects to verify and issue carbon credits in voluntary markets.

In sum, the 2010 voluntary carbon markets transacted $131 \mathrm{MtCO}_{2} \mathrm{e}$, higher than the previous year by $34 \%$. This rise is mostly attributed to the single bilateral OTC transaction of allowances called Carbon Financial Instruments (CFIs) worth $59 \mathrm{MtCO}_{2} \mathrm{e}$ following the demise of Chicago Climate Exchange. Despite this statistical outlier, the volume of OTC transaction was higher than previous years. The volume-weighted average price of credits transacted in the voluntary OTC market fell from $\$ 6.5 / \mathrm{tCO}_{2} \mathrm{e}$ in 2009 to $\$ 6 / \mathrm{tCO}_{2} \mathrm{e}$ in 2010 . The value of the voluntary carbon markets for 2010 is estimated to be $\$ 424$ million (Peters-Stanley et al., 2011).

\subsubsection{Stated Valuation Approach}

Tsang and Burge (2011) in a report titled "Paying for carbon emissions reductions" based their research on people's willingness to pay using four stated choice studies in the water sector in order to apply the resulting values for climate change policy. The study found that households were willing to pay $£ 1.45$ to $£ 2.97$ per year on their water bill in exchange for climate change related improvement. This premium translates to a willingness to pay of $£ 135-£ 333$ per ton of $\mathrm{CO}_{2}$ with a potential saving of 0.01 ton of $\mathrm{CO}_{2}$ per household per year. The studies carried out on behalf of four water companies 
quantified the WTP of customers through service improvements like availability of water meters, frequency of hosepipe bans and leakage in water mains along with the environmental attributes.

\subsubsection{Shadow Price of Carbon}

Shadow price of carbon (SPC) is the price adopted by governments based on scientific and economic estimates and is modified to reflect policy requirements and technological advancements. The SCC for a given target is modified with respect to a globalized MAC based on stabilization goals and the final SPC calculated reflects the climate change commitment goals set by environmental policy of that particular country. Shadow price of carbon is an effective price for carbon that evolves within a strong policy framework. The need for valuing carbon in policy appraisal is obvious. Government policies have potential impacts on carbon and GHG emissions. Assigning a value to carbon or GHG emissions helps to evaluate the cost effectiveness of government policies that ultimately affect the welfare of society. In 2007, the United Kingdom recommended a shadow price for carbon valued at $£ 25.5 / \mathrm{tCO}_{2}$ (2007 prices) based on SCC estimates. This strategy was strongly influenced by the recommendations of the Stern Review (2007) (Price et al., 2007). In July 2012, the Australian government will implement a fixed a price on carbon as tax at $\$ 87 / \mathrm{tC}\left(\$ 23 / \mathrm{tCO}_{2}\right)$ which will transition to an emissions trading scheme from July 2015. The carbon price will rise at $2.5 \%$ per year in real terms. The tax is targeted for approximately 500 of the biggest polluters in Australia (http://www.cleanenergyfuture.gov.au). 


\section{Chapter 3}

\section{Methodology}

As discussed in chapter 2, mangrove production and biomass are major inputs to the total Everglades National Park (ENP) ecosystem productivity, particularly due to their spatial extent and conspicuous patchiness across the landscape (Ross et al., 2000; Simard et al., 2006; Rivera-Monroy et al., 2011). Because of the potential carbon storage of mangrove forests in the region, there is not only a critical need to determine the value of this ecosystem service, but also to assess the applicability of current valuation methodologies to determine how different pulsing (e.g., hurricanes) and pressure (e.g., sea level rise) drivers (Collins et al., 2010) influence the economic value of carbon storage capacity of this productive forested wetlands. In this chapter, I describe and discuss the main research questions, hypotheses, characteristics of the study area, and methodology.

\subsection{Research Aim and Specific Objectives}

The aim of this research is to provide an estimate of the economic valuation of the total carbon sequestered (belowground and aboveground) in the mangroves wetlands of Everglades National Park, and how these values can be considered a potential ecosystem service. The study is also an attempt to evaluate the economic implications of potential changes in the stored carbon in the ENP mangroves caused by rising sea level in the next century. The specific objectives of the study are:

(1) Quantify the total carbon (aboveground and belowground biomass, and sediments) stored in the mangroves of ENP from current literature and available data; 
(2) Identify appropriate methods of economic valuation in order to estimate the economic value of the stored carbon in the mangroves of ENP; and

(3) Estimate the incremental value of $\mathrm{C}$ sequestration and storage service by ENP mangroves with respect to sea level rise.

\subsection{Central Research Hypothesis}

The research addresses the central hypothesis that mangrove forests in the Everglades store a significant amount of carbon, particularly belowground, because of their geological age, low direct human impacts (e.g., deforestation), and the level of management and conservation enforcement in the protected areas of ENP. The economic value of the stored carbon in mangrove wetlands is expected to be significantly higher relative to other types of forests (Donato et al., 2011). The economic valuation of carbon sequestration varies with valuation methodologies. Carbon prices so generated are influenced by several technological, regulatory, economic and social factors, and vary across countries and markets. The economic value of the carbon stored in the mangrove wetlands of ENP will likely vary as the salt-tolerant mangroves migrate inland in response to rise in sea level over the next centuries. The rate and extent of landward transgression of ENP mangroves will depend on the rate and amount of sea level rise, alterations in amount of water inflow from upland sources and hurricane effects (Engel, 2010). For instance, mangroves in the southeast Everglades have shifted inland by $1.5-$ $3.3 \mathrm{~km}$ since the mid-1940s under a regime of seal level rise of approximately $2 \mathrm{~mm} / \mathrm{year}$ (Ross et al., 2000). 


\subsection{Research Questions}

This research addresses the following questions:

(1) What is the quantity of the total carbon stored in the mangrove ecotone regions of the Everglades National Park?

Hypothesis: The carbon stock in the undisturbed mangrove forests of the Everglades is significantly higher and comparable to other forests in tropical latitudes.

(2) Does the carbon stored in the mangrove ecotone regions of the Everglades National Park differ significantly across the landscape?

Hypothesis: The large spatial variability in biomass values in Shark River and Taylor River Slough basins indicates a significant gradient of carbon storage, with higher values in the western regions of the ENP as a result of higher nutrient $(\mathrm{P})$ availability.

(3) What is the economic value of the total carbon stored in the mangrove forests of the Everglades National Park in terms of relevant valuation methodologies? Hypothesis: The economic valuation of carbon sequestration varies with valuation methodologies. Carbon prices are influenced by several technological, regulatory, economic and social factors, and vary across countries and markets.

(4) What are the likely effects of rise in sea level on the total amount of carbon stored in the ENP mangroves and its economic value in the long-term?

Hypothesis: The change in value carbon and growth of carbon markets will likely increase the value of carbon stored in ENP mangroves. 


\subsection{Characterization of Study Area}

The mangrove forests of south Florida are located mainly within the protected areas of Everglades National Park, Florida ( $\left.25^{\circ} 19^{\prime} 0^{\prime \prime} \mathrm{N}, 80^{\circ} 56^{\prime} 0^{\prime \prime} \mathrm{W}\right)$ (Figure 1.1). The mangroves of ENP are located on the coastal margins of the greater Everglades ecosystem, occupying an estimated area of 144, 447 hectares (Simard et al., 2006). The ENP mangroves lie on a carbonate platform between freshwater marshes of the Everglades and marine waters of the Gulf of Mexico and Florida Bay. A thick layer of peat soil $(0.5-6.5 \mathrm{~m})$ lays the foundation of these mangrove forests (Wanless et al., 1994; Ewe et al., 2006). The fresh water-estuarine landscape is an oligotrophic phosphorus (P) limited ecosystem (Noe et al., 2001). The limiting nutrient $\mathrm{P}$ is supplied by the marine waters of the Gulf of Mexico rather than the freshwaters of the upper watershed, making the mangroves of the Everglades function as an upside down estuary (Childers et al., 2006).

The Shark River Slough (SRS) and Taylor Slough (TS) are located in the western and eastern parts of the Everglades' mangroves, respectively (Figure 2.2). Variations in hydroperiod, soil nutrient concentrations and salinity result in a gradient of scrub to fringing mangroves across the Everglades landscape. Tall, riverine mangroves dominate the Shark River Slough and scrub mangroves are present along Taylor River basin. The three mangrove species found in the Everglades are the red mangrove (Rhizophora mangle), the black mangrove (Avicennia germinans) and the white mangrove (Laguncularia racemosa). Conocarpus erectus or the buttonwood is also found in these 
forests and is not a true mangrove (Castañeda-Moya et al., 2011; Rivera-Monroy et al., 2011).

The mangrove forests of Everglades National Park lie juxtaposed between the Everglades drainage basin and the sea waters of Gulf of Mexico and Florida Bay, making them particularly vulnerable to changes in water inflow on one hand and sea level rise on the other (Davis et al., 2006). Sea level rise caused by global warming and alterations in water inflow from the upper Everglades are the two major hydrological press events that affect the mangrove wetlands of ENP. The mangroves are also affected by pulse events such as hurricanes and tropical storms, making them an ideal site to study the effects of different presses and pulses that operate upon them.

\subsubsection{Fresh Water Flow and Water Management}

The fresh water inflows from the upper Everglades watershed bring in nutrients to aid mangrove productivity and sediments to support soil accretion. The incoming fresh water moderates the high salinity associated with dry periods and the accumulation of toxins as a result of sulfate reduction in anaerobic soils (Engel, 2010). However, human interference in the form of extensive hydrological changes in the past 100 years have vastly altered drainage patterns and reduced fresh water flows into Everglades' estuaries by more than $50 \%$ (Smith \& Whelan, 2006). The freshwater wetlands of the Everglades were extensively ditched, diked, and drained for the purpose of agricultural development, urban water supply and flood protection (Light \& Dineen, 1994; Smith \& Whelan, 2006). The altered timing and distribution of the fresh water inflow have affected the hydrology and salinity of the region, which in turn influence the ecological and processes in the 
mangrove wetlands (Davis et al., 2005) like mangrove production and biomass. Altered hydrology has led to extensive habitat loss, disruption of the characteristic sheet flow, increased salinity, and loss of native plant communities and altered vegetation patterns in the Everglades wetland ecosystem.

Wetlands maintain elevation through a dynamic balance between peat accretion and oxidation. The drainage, lowering of water tables and the consequent drought conditions along with the compartmentalization of the landscape have upset this balance by increasing microbial oxidation of soils and frequency of peat fires. This has led to peat subsidence and lowered ground level elevations in northern Everglades with severe peat losses along the eastern edges of the Everglades. Accretion rates are lowest in areas of reduced hydroperiod (Sklar et al., 2002).

The Everglades are currently under a massive restoration program under the Comprehensive Everglades Restoration Project (CERP) and the U.S. government has allocated 7.8 billion dollars towards this effort (CERP, 2000). While the Everglades cannot be restored to their original condition, the restoration under CERP is expected to increase the quantity, quality, and timing of fresh water reaching the Florida coast. The plan includes the capture and storage of freshwater presently discharged into the Atlantic Ocean and thereafter releasing $80 \%$ of the captured water into the natural system, and using $20 \%$ of it for agricultural and urban needs. Among other objectives, the plan may slow down or even reverse the landward migration of the mangroves in some locations (Simard et al., 2006; Rivera-Monroy et al., 2011). The impact of the restoration of water 
depths and hydroperiod in the inland water marshes and on the mangrove production, biomass and carbon storage capacity is still uncertain.

\subsubsection{Sea level Rise}

Accelerated sea level rise as a result of global warming is a major press event operating on south Florida mangroves. Since 1930, south Florida has faced a $23 \mathrm{~cm}$ rise in sea levels that amounts to a rate of $30 \mathrm{~cm}$ of sea level rise per century $(2-3 \mathrm{~mm} / \mathrm{year})$. It is predicted that accelerated global warming will result in a sea level rise of $60 \mathrm{~cm}$ in the next century leading to significant alteration in the geomorphology and in ecological processes of the Everglades coastal ecosystem (Wanless et al., 1994; Davis et al., 2005) that will eventually alter the carbon sequestration and storage capacity of ENP mangroves. In response to sea level rise, mangrove communities migrate inland, and mangrove soil accretion rates increase in order to maintain mangrove coverage by raising the forest floor relative to seal level (Alongi, 2008). The concomitant rise in saline intrusion along with rise in sea level can erode mangroves along the coastline, and decrease and segment upstream mangrove communities in south Florida (Wanless et al, 1997, 2000). The expected landward transgression of ENP mangroves will depend on the rate and amount of sea level rise and changes in the fresh water inputs among other factors in south Florida. The landward transgression may be hampered by the pressures of aggressive coastal development in southeast Florida, and other land uses that impede sediment accretion rates (Engel, 2010; Donato et al. 2011). Anthropogenic activities that reduce the water, nutrient and sediment inputs into the mangrove forests will slow down the process of organic matter production and sediment accretion by the Everglades 
mangroves. Landward transgression may increase the coverage of mangroves in south Florida at the expense of fresh water ecosystems upland, while increasing salinity along with lowering of soil accretion capabilities of the coastal communities can hamper the carbon storage capacity of ENP mangroves.

A $3.5 \mathrm{~km}$ inland migration of mangroves has been observed during the past 50 years in the southeastern region of the Everglades in response to the average annual sea level rise of $2.0 \mathrm{~mm}$ along with fresh water reduction (Ross et al., 2000; Simard et al., 2006). The migration of the "white zone', which appears white in color or black and white aerial photos, in the southeast Everglades is maximum in regions where fresh water inflow was reduced and minimum where water flow was unchanged by water management practices. It is thus assumed that fresh water inflow counters the landward transgression of mangroves in this region (Davis et al., 2005). Meeder et al. (1996) observed an inland movement of $1.9 \mathrm{~km}$ of the white zone along its interior boundary in the period between 1990 and 1994, accompanied by a $13 \mathrm{~cm}$ vertical shift in response to $11 \mathrm{~cm}$ of sea level rise.

Thus, sea level rise presents a significant risk to the mangrove forests of ENP. Land-use changes upland, ground water influence, agriculture and coastal development in southeast Florida are anthropogenic factors that influence the survival of mangrove communities in the face of sea level rise. ENP mangroves in south east Florida may not be able to keep pace with the rising sea level and may suffer a net loss in area. The restoration of fresh water inflow as a result of water management upstream may slow the landward 
transgression of mangroves but will not affecting the rate of erosion along the coastline (Davis et al., 2005).

\subsubsection{Hurricanes and Tropical Storms}

The Everglades' mangroves are subject to high recurrence of hurricanes and storm events of significant magnitude. These pulse events destroy mangrove biomass and are responsible for periodic redistribution of vast amounts of sediments across the landscape in the mangroves of the Everglades (Smith et al., 1994 as cited in Chen \& Twilley, 1999a). Between 1871 and 2003, the south Florida region was struck by 40 storms, at an average of about one storm every three years (Lodge, 2005). The large scale sediment deposition and distribution caused by storm surge aids soil vertical accretion in mangrove forests. Hurricanes influence the nutrient biogeochemistry in mangrove soils which affects the structure and composition of the plant community. The input of Calciumbound P brought in by storm events from the Gulf of Mexico to the mouth of SRS estuary is responsible for the patterns of mangrove biomass and production in this region (Chen \& Twilley, 1999a, b). The storm deposition leads to increase in the concentration of the limiting nutrient $\mathrm{P}$ and lower N/P ratios at the mouth of the estuary (SRS-6). The availability of $\mathrm{P}$ deposits decreases with distance from the mouth of the estuary as upstream sites (SRS-4 and 5) do not receive the same mineral and sediment inputs. As a result, the highest tree height values $(18-20 \mathrm{~m})$ and higher biomass values $(150-200$ $\mathrm{Mg} \mathrm{ha}^{-1}$ ) are observed at the mouth of the estuary as compared to upstream sites of SRS and other regions in the southeastern part of the forest (Castañeda-Moya, 2010). Hurricane Wilma, which struck south Florida, resulted in a gradient of sediment 
deposition across the SRS estuary. The nutrient and sediment deposition were was confined to the mouth of the estuary, while upstream sites like SRS-4 and Taylor River sites did not receive any. The total Calcium-bound P deposited was twice the average soil nutrient $\mathrm{P}$ density $\left(0.19 \mathrm{mg} \mathrm{cm}^{-3}\right)$ and total $\mathrm{N}$ deposited was 0.8 times the average soil nutrient $\mathrm{N}$ density $\left(2.8 \mathrm{mg} \mathrm{cm}^{-3}\right)$. The gradient of $\mathrm{N} / \mathrm{P}$ ratio increased from west to east with the lowest value in the Shark River (12.3) and the highest value in TS/Ph-8 (98) in the west of the Everglades' mangrove forest thereby indicating the significant deposits of P by Hurricane Wilma (Castañeda-Moya, 2010).

Hurricane Wilma resulted in a vertical accretion of one order of magnitude greater than the average rate of the past 50 years, indicating the significant contribution of hurricanes to soil elevation in the mangrove forests of ENP. Thus, pulsing events like hurricanes and storm events significantly influence mangrove productivity and vertical soil elevation in ENP through allochthonous deposits of P and sediment (Castañeda-Moya, 2010).

Thus, press and pulse events influenced by human actions shape the mangrove structure and production patterns in the ENP mangrove forest wetlands, altering the carbon storage and sequestration services. The quantification and economic valuation of the stored carbon in ENP mangroves will help to establish a baseline for future comparison. The maintenance of the natural mangrove $\mathrm{C}$ sink in south Florida can be a key strategy for climate change mitigation. 
In order to answer the research questions, the methodology was implemented in four stages:

(1) Landscape level estimation of total carbon (aboveground and belowground) in the mangrove forests of Everglades National Park.

(2) Comparison of carbon prices based on different valuation methodologies appropriate for mangroves and other coastal ecosystems.

(3) Estimation of a suitable price range for carbon stored and sequestered by mangrove forests in Everglades National Park based on their geological age, status as protected area, and level of direct human impacts, management and conservation enforcement.

(4) Estimation of economic value changes in C stock of ENP mangroves with respect to sea level rise.

\subsection{Estimation of the Total Carbon present in the Mangrove Forests of Everglades National Park}

The estimation of total carbon present in the mangrove forests of the Everglades National Park was performed using data obtained from previous studies that evaluate mangrove tree height spatial distribution and associated biomass in ENP (Simard et al., 2006; Rivera-Monroy et al., 2011). In order to measure the carbon stored in the mangrove forest of ENP, two main pools of carbon were considered: (1) the C present in the biomass (aboveground and belowground), and (2) the C stored in the peat soils. As discussed in Chapter 2, the interactions among environmental gradients regulating mangrove structure 
and the mangrove productivity result in a significant biomass gradient, from scrub mangroves dominating the Taylor Slough to fringing tall mangroves in the Shark River Slough. Similarly, the peat soil deposits vary in thickness from 0.5 to $6.5 \mathrm{~m}$ across the landscape (Wanless et al., 2004; Ewe et al., 2006) and are a significant store of C. Total carbon was estimated using a disaggregated approach by adding $\mathrm{C}$ values in the aboveground (tree biomass) and belowground (fine roots) stocks and $\mathrm{C}$ in the soil.

$$
T C=C_{A G}+C_{B G R}+C_{B G S}
$$

where,

$T C$ is the total carbon stored in the mangrove forest ecosystem,

$C_{A G}$ is the carbon stored in the aboveground biomass,

$C_{B G R}$ is the carbon stored belowground in fine roots, and

$C_{B G S}$ is the carbon stored in the peat soil.

To estimate a first-rate value of total $\mathrm{C}$ present in the entire mangrove forest area, I used published data for belowground biomass (roots) and soil carbon available for the six study sites encompassing the Taylor and Shark River sloughs (SRS-4, 5, 6; TS/Ph-6, 7, \& 8) where mangrove studies have been implemented under the aegis of Florida Coastal Everglades Long Term Ecological Program (FCE-LTER, http://fce.lternet.edu/) since 2000. FCE-LTER sites are located along transects in the freshwater marsh, estuarine mangrove, and seagrass-dominated estuarine ecosystems of the 2,358- $\mathrm{m}^{2}$ Everglades National Park (Childers, 2006) (Figure 2.2). The six study sites are located along the paths of SRS (SRS-4, SRS-5 and SRS-6) and TS (TS/Ph-6, TS/Ph-7 \& and TS/Ph-8) 
estuaries (Fig 2.2). Two $20 \times 20 \mathrm{~m}$ permanent plots $30-50 \mathrm{~m}$ away from the shoreline at each of the sites aid in the study of structural attributes of mangrove trees and biogeochemical properties of the soil. Sites SRS-6, SRS-5 and SRS-4 are located 4.1, 9.9 and $18.2 \mathrm{~km}$ away from the mouth of the estuary. TS/Ph- 6 and TS/Ph-7 are located 4 and $1.5 \mathrm{~km}$ inland from Florida Bay while TS/Ph-8 is located near Snook Creek, a tributary of Joe Bay. Below and aboveground biomass was converted from dry grams biomass $\left(\mathrm{g} \mathrm{m}^{2}\right.$ year $^{-1}$ ) to grams carbon $\left(\mathrm{g} \mathrm{C} \mathrm{m}^{2}\right.$ year $\left.^{1}\right)$ based on plant carbon content of $44 \%$ prior to analysis and based on published data (Ewe et al., 2006).

Each component of (3.1) was obtained from different sources in published literature. Although a comprehensive data from study sites including the entire landscape of the mangrove ecotone region would have been ideal, data at the landscape level was only available for aboveground standing biomass distribution (Simard et al., 2006; RiveraMonroy et al., 2011). Root biomass and soil carbon data was restricted to studies in the six FCE LTER study sites along Shark River and Taylor slough basins. Information on whole-ecosystem biomass and carbon storage across the entire landscape is presently lacking.

\subsubsection{Aboveground Carbon in the Mangrove Forests of Everglades National Park}

\subsubsection{Data Sources}

Simard et al. (2006) produced the first map of mean mangrove tree height in the mangrove ecotone region based on Shuttle Radar Topography Mission (SRTM) and Light Detection and Ranging (LiDAR) data. Tree height, which is a good indicator of forest biomass (Bouillon et al., 2008; Cintron \& Schaeffer-Novelli, 1984; Zhang et al., 
2008), was calibrated using LiDAR data. Ground truthing studies included collection of individual trees diameter-at-breast height (DBH) and tree height data in Shark, Broad and Harney River sites and Biscayne National Park (Simard et al., 2006). Allometric equations are mathematical relationships that are initially developed from the selective sampling and harvesting of trees that are representative of the size-classes found in the forest and then used to estimate the tree biomass relative to metrics like DBH or tree height. Simard et al. (2006) estimated the biomass for ENP mangroves using published allometric equations for neotropical mangroves from Fromard et al. (1998) and Ross et al. (2001) in the absence of ENP site specific allometric equations before the study. Landscape scale estimation of tree height was then related to biomass values obtained at local scales. Field data from ENP and Biscayne Bay was used to derive a relationship for biomass versus stand mean tree height: Biomass $(\mathrm{Mg} / \mathrm{ha})=10 *$ Height $(\mathrm{m})$, with slope $\mathrm{m}$ $=10$ and standard error 1.4. This relationship was applied to the SRTM mean tree height estimates to map the spatial distribution of mangrove biomass with a spatial resolution of $30 \mathrm{~m}$. Thus, Simard et al. (2006) estimated a total standing mangrove biomass of $5.6 \mathrm{x}$ $10^{9} \mathrm{~kg}\left( \pm 0.1 \times 10^{9} \mathrm{~kg}\right)$ for ENP. The spatial distribution indicated that the standing biomass was dominated by the mid-size tree stands $8 \mathrm{~m}$ in height.

Allometric relations differ by species and region and do not follow latitudinal or general area trends. To achieve accuracy of results, allometric equations used must be specific to the geographic region, species and range of DBH class. If the trees being studied do not match the geographic region, ecological conditions or the range of diameter or height that the allometric equations are developed for, then the results may overestimate or underestimate the values for biomass and carbon sequestration (Redondo-Brenes \& 
Montagnini, 2006). In addition, environmental parameters such as salinity, nutrients, hydrological exchange, stem density, net primary productivity, and herbivory of the study area should match those of the site for which the allometric equations were developed (Smith \& Whelan, 2006). In 2006, Smith \& Whelan published allometric equations to forecast aboveground biomass of the three species of mangroves (Rhizophora mangle, Avicennia germinans, and Laguncularia racemosa) in the Everglades National Park. These are the first published site-specific and species-specific allometric equations for the mangrove forests of the Everglades region located at the northern limit of their distribution at $25^{\circ} \mathrm{N}$ latitude. Stem height and DBH were used as predictors for total aboveground biomass for each mangrove species. Using the ENP site and species specific allometric equations obtained by Smith and Whelan (2006) and previous tree height data (Simard et al., 2006), Rivera-Monroy et al. (2011) revised the total mangrove biomass per tree class and updated the spatial distribution map (Figure 3.1).

\subsubsection{Landscape Level Estimation of Aboveground Carbon $\left(C_{A G}\right)$}

A geodatabase was created using the Environmental Systems Research Institute's (ESRI) ArcGIS10, a geographic information system. The map showing standing biomass distribution (Rivera-Monroy et al., 2011) (Figure 3.1) was imported as a layer titled 'Aboveground biomass' in ArcMap 10. The geographic coordinate system was set to the World Geodetic System 1984 and projected to WGS_1984_UTM_Zone_17N. Table 3.1 describes the characteristics of the map. 


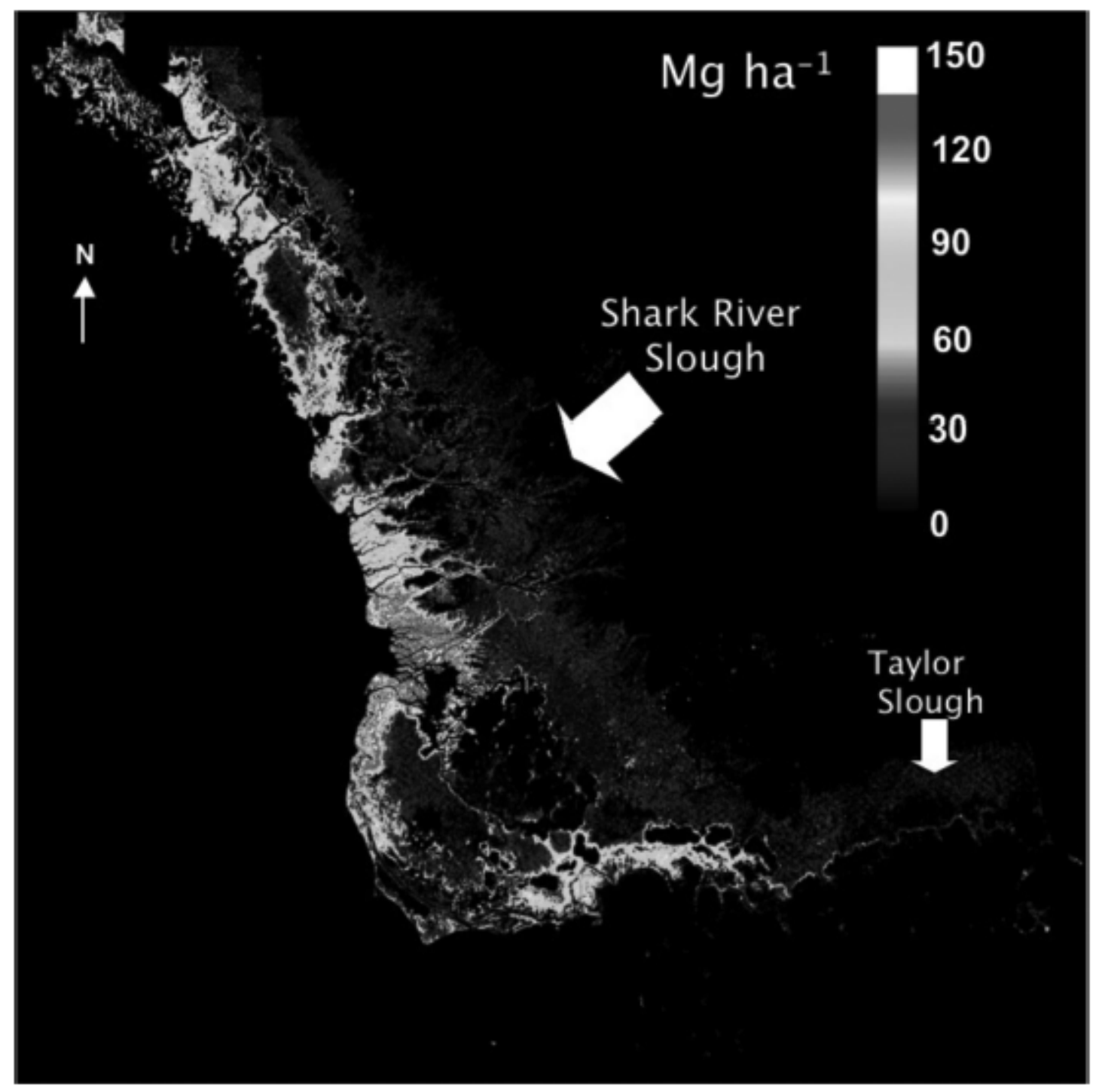

Figure 3.1: Map of Mangrove Standing Biomass Distribution in Everglades National Park, Florida (from Rivera-Monroy et al., 2011) 
Table 3.1: Raster Information for the Map of Mangrove Standing Biomass Distribution in Everglades National Park

\begin{tabular}{ll}
\hline & Raster Information \\
\hline Columns, Rows & 3813,3289 \\
Number of Bands & 1 \\
Cell Size & 30,30 \\
Uncompressed size & $48.05 \mathrm{MB}$ \\
Format & GRID \\
Source Type & Continuous \\
Pixel Type & Floating point \\
Pixel Depth & 32 Bit \\
& \\
Extent & \\
Top & 2863926.75517 \\
Left & 447407.327974 \\
Right & 562097.327974 \\
Bottom & 2765076.75517 \\
& \\
Spatial Reference & WGS_1984_UTM_Zone_17N \\
Total area of mangrove forest & Note: Source: Rivera-Monroy et al., 2011
\end{tabular}

To convert the biomass map to a map depicting the carbon content in the aboveground component of the total $\mathrm{C}$, the raster calculator tool in Spatial Analyst Tool section of ArcGIS 10 was used. To calculate the carbon content, a carbon conversion factor of 0.44 , specific to the Everglades' mangroves (Ewe et al., 2006) was used. A map of aboveground carbon distribution of the mangrove forests in Everglades National Park, South Florida was produced and the layer was given the title Aboveground Carbon.

\subsubsection{Belowground Carbon in Roots of Mangrove Forests of Everglades National Park}

\subsubsection{Data Sources}

There are no published estimates of mangrove root (coarse and fine) biomass at the landscape level for mangrove forests of ENP, except for the six FCE-LTER sites (SRS-4, 
5 and 6 and TS/Ph-6, 7 and 8) mentioned above (Castañeda-Moya et al., 2011).

Castañeda-Moya et al. (2011) estimated belowground biomass $\left(\mathrm{g} \mathrm{m}^{-2}\right)$ of roots less than $20 \mathrm{~mm}(0-90 \mathrm{~cm})$ in diameter in the period 2001-2003 (Table 3.2).

Table 3.2: Information on Aboveground and Belowground Biomass of FCE LTER Sites in the Everglades Mangrove Ecotone.

\begin{tabular}{|c|c|c|c|c|c|c|}
\hline $\begin{array}{l}\text { FCE } \\
\text { LTER } \\
\text { Study } \\
\text { Site }\end{array}$ & $\begin{array}{l}\text { Abovegroun } \\
\mathrm{d} \text { Biomass } \\
(\mathrm{Mg} / \mathrm{ha})\end{array}$ & $\begin{array}{l}\text { Belowground Root } \\
\text { Biomass (Mg/ha) } \\
\text { (Roots < } 20 \mathrm{~mm}) \\
(0-90 \mathrm{~cm})\end{array}$ & $\begin{array}{l}\text { Average } \\
\text { Tree } \\
\text { height }^{c}\end{array}$ & $\begin{array}{l}\text { Aboveground } \\
\text { Carbon }^{\mathrm{d}}(\mathrm{Mg} \\
\mathrm{C} / \mathrm{ha})\end{array}$ & $\begin{array}{l}\text { Belowground } \\
\text { Root Carbon } \\
(\mathrm{Mg} \mathrm{C} / \mathrm{ha})\end{array}$ & $\begin{array}{l}\text { Aboveground: } \\
\text { Belowground } \\
\text { Carbon }^{f}\end{array}$ \\
\hline SRS-4 & $97.72^{\mathrm{a}}$ & $31.98^{b}$ & 6 & 43.00 & 14.1 & 3.1 \\
\hline SRS-5 & $108.79^{\mathrm{a}}$ & $43.89^{b}$ & 8 & 47.87 & 19.3 & 2.5 \\
\hline SRS-6 & $152.07^{\mathrm{a}}$ & $25.32^{\mathrm{b}}$ & 13 & 66.91 & 11.1 & 6.0 \\
\hline TS/Ph-6 & $12.5^{\mathrm{a}}$ & $24.04^{b}$ & 2 & 5.50 & 10.6 & 0.5 \\
\hline TS/Ph-7 & $12.5^{\mathrm{a}}$ & $46.73^{b}$ & 2 & 5.50 & 20.6 & 0.3 \\
\hline TS/Ph-8 & $4.47^{\mathrm{a}}$ & $43.58^{\mathrm{b}}$ & 3 & 1.97 & 19.2 & 0.1 \\
\hline
\end{tabular}

Notes: a: Chen \& Twilley (1999b); Coronado-Molina et al. (2004); b: Castañeda-Moya et al. (2011); c: average tree heights from Rivera-Monroy et al., 2011; $d$ : Aboveground carbon $=0.44 *$ Aboveground biomass; e: Belowground (Root) Carbon $=0.44 *$ Belowground Root Biomass; $f$ : Ratio of Aboveground and Belowground Carbon

\subsubsection{Landscape Level Estimation of Carbon in Fine Roots $\left(C_{B G R}\right)$}

Field estimates of aboveground biomass values measured in the six FCE LTER sites

[Chen \& Twilley, (1999b) and Table 3.2] were used to verify values estimated by Rivera-

Monroy et al., (2011). Both aboveground and belowground biomass of roots (Castañeda-

Moya et al. (2011), Table 3.2), were converted to carbon units. These six points/sites with 
known geographical coordinates in the ArcMap10 layer were used to determine belowground carbon for other locations with no information on belowground carbon. This extrapolation was performed using a ratio between aboveground carbon and belowground carbon based on actual data estimated for those six sites representing different canopy heights (Table 3.2).

Aboveground carbon values in $\mathrm{Mg} / \mathrm{h}$ a for the six study sites are 1.9 (TS/Ph-6), 5.5 (TS/Ph-7), 5.5 (TS/Ph-8), 43 (SRS-4), 47.9 (SRS-5) and 66.9 (SRS-6) with the associated tree heights in meter of 3, 2, 2, 6, 8 and 13, respectively. Most of the ENP mangroves belong to the scrub forests ecotype (sensu Lugo and Snedaker, 1974) with an estimated mean height of $3.2 \pm 1.3 \mathrm{~m}$ (Simard et al, 2006). However, the standing biomass is concentrated around tree heights of approximately $8 \mathrm{~m}$ (Simard et al., 2006). Based on this information, I divided the mangroves into groups according to the observed aboveground carbon values and applied the aboveground to belowground carbon ratio (from Table 3.2) to obtain landscape level estimates.

The aboveground carbon value in the TS/Ph-8 site is $1.97 \mathrm{Mg} \mathrm{C} /$ ha with a corresponding aboveground to belowground ratio of 0.1 . Hence, for all geographical locations in the map layer Aboveground Carbon with biomass values of up to $3.00 \mathrm{Mg} / \mathrm{ha}$ of aboveground carbon, I used the aboveground: belowground ratio 0.1 (Table 3.2) to predict the belowground root carbon for those points lacking belowground information. For example, this extrapolation was performed by dividing the aboveground carbon value at a particular site by the ratio (0.1) to estimate the belowground root carbon for that location on the map. Therefore, map locations with up to $3.0 \mathrm{Mg} \mathrm{C} / \mathrm{ha}$ were grouped 
together (Table 3.3). Similar computations were performed for locations similar to the five known FCE-LTER study sites.

These values assigned per category were included in the map layer, Aboveground Carbon, in ArcMap10 to perform the operations. A map algebraic expression was developed to use in the raster calculator in the Spatial Analyst Toolbox. The map for distribution of belowground carbon (roots) was created and the map layer was titled Belowground Carbon Roots.

Table 3.3: Aboveground:Belowground Carbon Ratios

\begin{tabular}{|c|c|c|c|c|}
\hline \multirow[t]{2}{*}{ Site } & \multicolumn{2}{|c|}{ Geographical Coordinates } & \multirow{2}{*}{$\begin{array}{l}\text { Aboveground Carbon } \\
(\mathrm{Mg} / \mathrm{ha})\end{array}$} & \multirow{2}{*}{$\begin{array}{l}\text { Aboveground: } \\
\text { Belowground Carbon } \\
\text { Ratio } \\
\end{array}$} \\
\hline & Latitude & Longitude & & \\
\hline TS/Ph-8 & 25.23269749 & -80.52455665 & $0.01-3.00$ & 0.1 \\
\hline TS/Ph-6 & 25.21609115 & -80.65101654 & $301 \quad 10$ & 04 \\
\hline$\& 7$ & 25.19676203 & -80.64207766 & $3.01-10$ & 0.4 \\
\hline SRS-4 & 25.40976421 & -80.96431016 & $10.01-44$ & 3.1 \\
\hline SRS-5 & 25.37702258 & -81.03234716 & $44.01-50$ & 2.5 \\
\hline SRS-6 & 25.36462994 & -81.07794623 & $50.01-67$ & 6.0 \\
\hline
\end{tabular}

\subsubsection{Carbon in Sediments of Mangrove Forests of Everglades National Park}

\subsubsection{Data Sources}

As in the case of root carbon allocation, there are no published $\mathrm{C}$ estimates for ENP mangrove soils at the landscape level. Thus, I used information from discrete sampling sites where fine root biomass was also obtained. Carbon values were obtained down to a depth of $0.9 \mathrm{~m}$ (Castañeda-Moya, 2010) and extrapolated to values per area (Mg/ha, Table 3.4) for the entire ENP mangroves region. 
The formation of soil and peat is strongly linked to mangrove production in the Everglades (Chen \& Twilley, 1999a) where peat soil deposits vary in thickness from 0.5 to $6.5 \mathrm{~m}$ across the landscape (Wanless et al., 1994; Ewe et al., 2006). Pollen analysis of $5.25 \mathrm{~m}$ depth soil cores at the mouth of Shark River (4 km from SRS-6 site) (Q. Yao, dissertation in progress), it is estimated that the underlying peat started accumulating about $7500 \mathrm{BP}$, at approximately $5 \mathrm{~m}$ depth. Pollen analysis of $5.25 \mathrm{~m}$ depth soil cores at the mouth of Shark River (4 km from SRS-6 site) (Q. Yao, dissertation in progress), it is estimated that the underlying peat started accumulating about $7500 \mathrm{BP}$, at approximately $5 \mathrm{~m}$ depth. Radiocarbon dating suggests a constant sedimentation rate of $0.5 \mathrm{~mm} /$ year from $7500 \mathrm{BP}$ to $1100 \mathrm{BP}$, when sedimentation rates doubled. Mangrove vegetation started to appear from $4900 \mathrm{BP}$ and became dominant at $2800 \mathrm{BP}$ (at approximately 2.5 $\mathrm{m}$ depth). Prior to this the vegetation was dominated by upland taxa (before $7500 \mathrm{BP}$ ) and marsh vegetation $(7500-2800 \mathrm{BP})$. In contrast, maximum peat depth in the Taylor slough region is less than $1.5 \mathrm{~m}$.

Table 3.4: Soil Carbon Values in FCE LTER Mangrove Sites

\begin{tabular}{ccc}
\hline Site & Soil Carbon $^{\text {a }}(\mathrm{Mg} \mathrm{C} /$ ha) at $0.9 \mathrm{~m}$ & Soil Carbon Estimates (Mg C/ha) \\
\hline SRS-4 & 373.5 & $623^{\mathrm{b}}$ \\
SRS-5 & 476.1 & $794^{\mathrm{b}}$ \\
SRS-6 & 365.4 & $609^{\mathrm{b}}$ \\
TS/Ph-6 & 546.3 & $607^{\mathrm{c}}$ \\
TS/Ph-7 & 450 & $500^{\mathrm{c}}$ \\
TS/Ph-8 & 464.4 & $516^{\mathrm{c}}$ \\
\hline Note: : $:$ Soil carbon values from Castañeda-Moya, 2010; $b=a t 1.5 \mathrm{~m}$ depth; $c=$ at 1 m depth
\end{tabular}




\subsubsection{Landscape Level Estimation of Carbon in Soil $\left(C_{B G S}\right)$}

The raster calculator in ArcMap 10 was used to add the soil carbon value to the map layer Belowground Carbon Roots. Based on the above information, a composite map for belowground carbon which includes belowground carbon of mangrove roots and the carbon present in the soil was produced; the map layer was titled Belowground Carbon Soil. The two layers Belowground Carbon Roots and Belowground Carbon Soil are added to produce a map of total belowground carbon that includes the carbon present in the roots and soil of the ENP mangrove forest. The map layer is titled Belowground Carbon (Roots and Soil).

\subsubsection{Estimation of Total Carbon (TC)}

As a final calculation, the total carbon map of the aboveground and belowground portions of the mangrove forests of ENP was produced by adding the two map layers Aboveground Carbon and Belowground Carbon using the raster calculator.

\subsection{Selection and Development of Carbon Prices Based on Valuation Methodologies Appropriate for Coastal Ecosystems like Mangroves}

The economic value of carbon arises from the knowledge that $\mathrm{CO}_{2}$, a major greenhouse gas, is sequestered by forest ecosystems including mangrove forests, thus reducing the effects of global climate change. Carbon markets reflect the price that investors are willing to pay for storing carbon and avoiding the effects of global warming (Yee, 2010). The location of mangroves at the interface of land, coasts and watersheds produces cumulative benefits of carbon storage, which can be more significant than other 
ecosystems (Barbier et al., 2011). Carbon sequestration and storage by mangroves is a public good with non-rival and non-excludable characteristics. Public goods are not governed by property rights and therefore do not fit into the framework of a conventional market system. The price reflected in the present carbon markets, therefore, is not a reflection of the true value of carbon sequestration and storage services by natural ecosystems. A carbon price that arises from a stable and strong international carbon market can alone be indicative of a true price of carbon. Until the time we have regionally strong carbon markets with extensive global networks, additional valuation methodologies like damage costs and damage avoidance costs can help to define the value of carbon sequestration and storage to society and human welfare.

Upon a careful analysis of appropriate valuation methodologies discussed in Chapter 2, a comparison of carbon prices was performed. Estimates for social costs of carbon (SCCs), marginal abatement costs (MACs), and market prices (regulatory and voluntary markets) were compared. The shadow cost of carbon established by the government of United Kingdom and the carbon tax established by the Australian government in 2011 were included in the comparison. All costs were converted to common units of marginal costs per ton carbon in 2010 U.S. dollars by applying a consistent discount rate of $3 \%$. Carbon prices projected for the future were converted to 2010 prices by discounting back to the present at an interest rate consistent with each study (Dietz \& Fankhauser, 2009).

The mean value of social cost of carbon estimates (all estimates, peer reviewed and at $3 \%$ pure rate of time preference) calculated in the meta-analysis performed by Tol (2011) were used for the comparison. These are the most recent estimates by Richard Tol who 
has published extensively on the subject. The average mean estimate of SCC by another well published author, William Nordhaus, was used for the purpose of comparison. The SCC estimated by the U.S. Interagency report was used as it provided a good estimate of how government agencies in the United States were advised to use carbon prices in costbenefit analyses of regulatory actions. The U.S. Government's SCC was converted to 2010 U.S. dollars and expressed as price per ton carbon (Table 3.5).

The cost of damage avoidance is represented by marginal abatement costs (MACs). The estimation of MACs depends on the target of emissions reduction and the discount rate used. Kuik et al. (2008) estimated the globalized MAC for all regions and the estimates by Fisher \& Nakicenovic et al. (2007) contributed to the Fourth Assessment Report of the IPCC. Uncertainty in MAC estimations increases with stricter emission reductions. The globalized MAC by Kuik et al. was published as costs for the year 2025 in 2005 euros. Assuming an annual growth rate of $3 \%$ for C prices, the central estimate of 2025 costs (€66/ $\left.\mathrm{tCO}_{2}\right)$ was converted for the year $2010(€ 154.44 / \mathrm{tC})$. Next, compounding the cost at $3 \%$ for five years, the cost was expressed in 2010 euros $(€ 179.44 / \mathrm{tC})$ before converting to 2010 U.S. dollars (\$233/tC) (Table 3.6). 
Table 3.5: Comparison of Social Costs of Carbon

\begin{tabular}{|c|c|c|c|c|}
\hline Type of Study & & $\begin{array}{l}\text { Mean } \mathrm{SCC}^{\mathrm{a}} \\
\text { as cited in the } \\
\text { source }\end{array}$ & $\begin{array}{l}\text { Mean estimate } \\
\text { of } S C C^{b} \\
(\$ / t C)\end{array}$ & Source \\
\hline \multirow[t]{5}{*}{ Meta-analysis } & All estimates & $\$ 177 / \mathrm{tC}$ & 177 & \\
\hline & Peer reviewed & $\$ 80 / \mathrm{tC}$ & 80 & \\
\hline & 3\% PRTP & $\$ 19 / \mathrm{tC}$ & 19 & Tol, 2011 \\
\hline & Nordhaus & $\$ 35 / \mathrm{tC}$ & 35 & \\
\hline & Tol & $\$ 35 / \mathrm{tC}$ & 59 & \\
\hline \multirow[t]{2}{*}{ CASES } & $\begin{array}{c}\text { Assuming } 30 \% \text { reduction } \\
\text { in emissions by } 2050 ; 3 \% \\
\text { PRTP }\end{array}$ & $\begin{array}{c}\$ 6.43 / \mathrm{tC} \\
(2007 \$)\end{array}$ & 10 & Chiabai et al., 2007 \\
\hline & 2\% PRTP & $\begin{array}{c}€ 23- \\
41 / \mathrm{tCO}_{2} \text { for } \\
2030\end{array}$ & 133 & Ding et al., 2010 \\
\hline $\begin{array}{l}\text { SCC for } \\
\text { regulatory } \\
\text { impact } \\
\text { analysis, U.S. } \\
\text { Govt. }\end{array}$ & 3\% PRTP & $\begin{array}{c}\$ 21.4 / \mathrm{tCO}_{2} \\
(2007 \$)\end{array}$ & 86 & $\begin{array}{c}\text { United States } \\
\text { Interagency Working } \\
\text { Group, } 2010 . \\
\text { U.S. Government }\end{array}$ \\
\hline
\end{tabular}


Table 3.6: Comparison of Marginal Abatement Costs (MACs)

\begin{tabular}{|c|c|c|c|c|}
\hline Type of Study & Influencing factors & $\begin{array}{l}\text { Cost as cited in } \\
\text { source }\end{array}$ & $\begin{array}{l}\text { Mean estimate }{ }^{a} \\
(\$ / t C)\end{array}$ & Source \\
\hline Globalized MAC & $\begin{array}{l}\text { Target range: } 550- \\
350 \text { ppmv } \mathrm{CO}_{2}\end{array}$ & $\begin{array}{l}€ 13-119 / \mathrm{tCO}_{2} \\
\text { for } 2025 \\
\text { (2005euros) }\end{array}$ & 233 & Kuik et al. 2008 \\
\hline IPCC Report & $3 \%$ PRTP & $\begin{array}{l}\$ 0-150 / \mathrm{tCO}_{2} \text { for } \\
2030\end{array}$ & 129 & $\begin{array}{c}\text { Fisher \& } \\
\text { Nakicenovic et al. } \\
\text { 2007; Dietz \& } \\
\text { Fankhauser (2009) }\end{array}$ \\
\hline $\begin{array}{l}\text { Forest-based } \\
\text { sequestration in U.S. }\end{array}$ & $\begin{array}{l}500 \text { million } \\
\text { ton/year }\end{array}$ & $\begin{array}{l}\$ 70 / \mathrm{tC} \\
(1997 \$)\end{array}$ & 103 & $\begin{array}{c}\text { Stavins \& Richards } \\
2005\end{array}$ \\
\hline
\end{tabular}

Note: a: Mean estimate of MACs in 2010 U.S. dollars

Carbon prices from both regulatory and voluntary markets were included in the comparison. European Union's Emission Trading System (EU ETS) is the long-term and relatively stable carbon market that has been operational since its launch in 2005 . The tradable allowances called EUAs or European Union Allowances are traded among the companies and institutions within the EU ETS. In addition, Certified Emission Reductions or CERs generated from Clean Development Mechanism (CDM) projects, all equal to one ton of $\mathrm{CO}_{2}$ are traded in the market. Barbier et al. (2011) used the CER price of EU ETS to calculate the value of global benefits from carbon sequestration by mangroves. The Regional Greenhouse Gas Initiative or RGGI is the only voluntary market presently operational in the United States and hence offers relevant carbon prices to the region. Reducing Emissions from Deforestation and Forest Degradation (REDD) is UNFCC's carbon credit system for avoided deforestation which now includes the added benefits of biodiversity conservation and poverty alleviation (Yee, 2010). Carbon prices 
from REDD are most widely used by most authors to value ecosystem services arising from various forests (Table 3.7).

Table 3.7: Comparison of Market Prices of Carbon

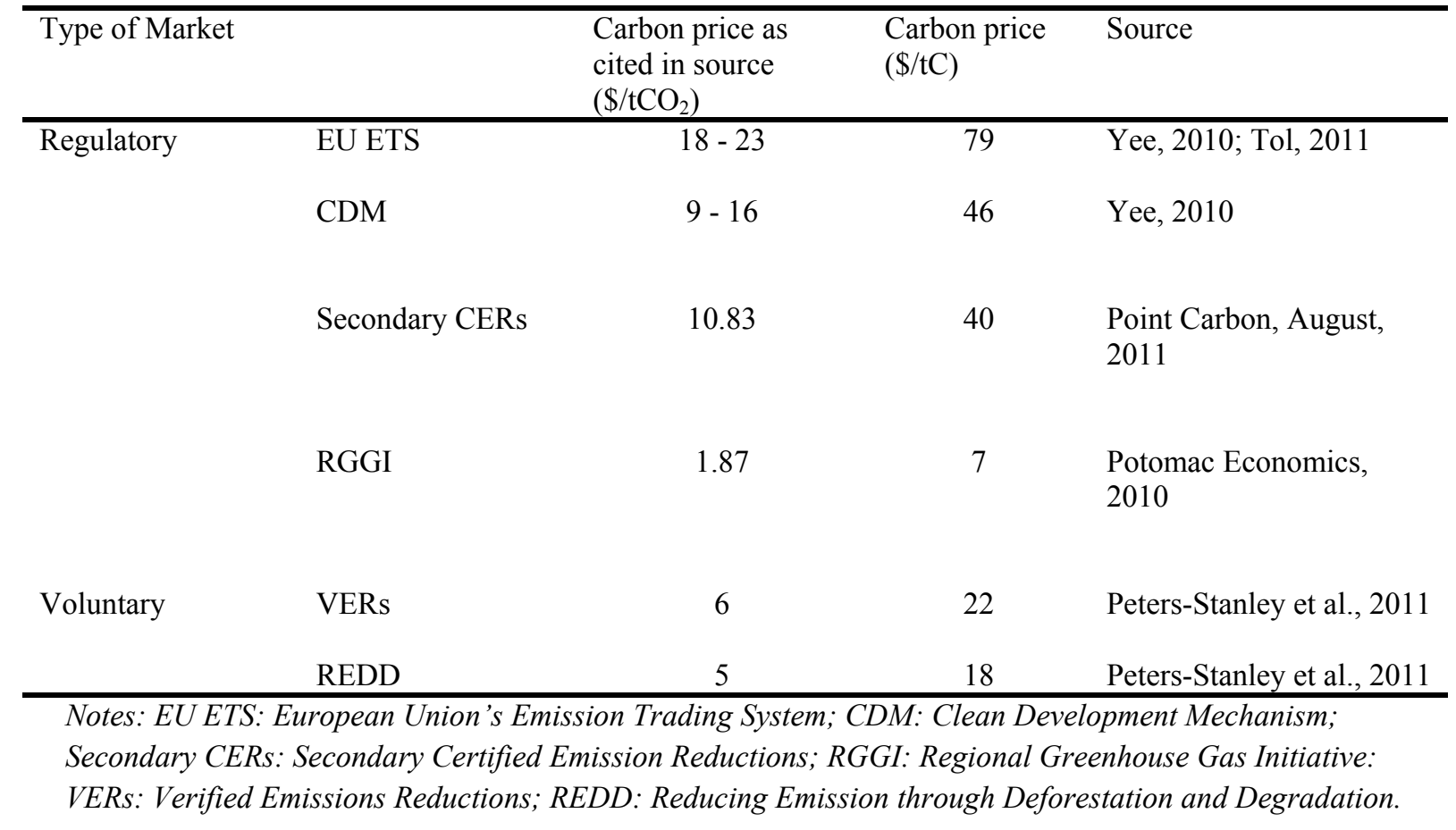

\subsection{Economic Valuation of the Carbon Stored in the Mangrove Forests of} Everglades National Park

Based on the unit carbon value or price $(P)(\$ / \mathrm{tC})$ selected from section 3.6 and the quantity of total carbon (TC) present in the ENP mangroves (section 3.5.5), the economic value $(V)$ of the total carbon can be computed by:

$$
V=T C * P
$$


I calculated a range of estimates for the value of the total carbon using carbon price values from the different valuation methodologies. In this way a range of estimates was produced. To obtain the value of $\mathrm{C}$ present in one hectare, the total economic value $(\mathrm{V})$ was divided by the total area $(A)$ occupied by the mangroves in ENP $(144,447 \mathrm{ha})$.

Therefore, the per hectare carbon value $\left(V_{m}\right)$ is given by:

$$
V_{m}=\left(\frac{T C}{A}\right) * P
$$

\subsection{Estimation of Economic Value Changes in the Carbon Stock of ENP Mangroves in Response to Sea Level Rise}

The change in carbon stock in ENP mangroves in response to the long-term hydrological press event in the form of sea level rise is influenced by several factors (Davis et al., 2005; Alongi, 2008; Engel, 2010).

(1) The rate and extent of the expected landward transgression of ENP mangroves will depend of the rate and amount of sea level rise, alterations in the amount of fresh water inflow from the upper Everglades, and effects of hurricanes and tropical storms (Engel, 2010).

(2) Local factors like nearby coastal development, land surface slope, soil substrates with their ability to withstand changes in water levels and the quality of habitat across the expected path of transgression will influence the landward migration of the Everglades' mangroves. 
(3) South Florida has experienced a rate of sea level rise of $0.2-0.3 \mathrm{~m}$ over the past 100 years $(2-3 \mathrm{~mm} / \mathrm{year})$. Sea level has been recorded to rise at an average rate of 2.24 $\mathrm{mm} \mathrm{yr}^{-1}$ at Key West, Florida since 1913 (Smoak et al., 2012). There are varied predictions for sea level rise for the coming century. According to IPCC, the sea level along the coast of Florida will rise from 0.20 to $0.56 \mathrm{~m}$ by 2100 . Projections based on historical tide gauge data carried out in Key West predict a rise of 0.15 to $0.31 \mathrm{~m}$ by 2080 (Engel, 2010).

(4) Sea level rise is accompanied by saline water intrusion which leads to mangrove erosion along the coastline and progressive dissection of mangrove communities. Evidence suggests that mangroves, at the global level, are keeping pace with mean sea level rise through soil accretion rates. Red mangroves in south Florida have the ability to accrete peat soil at the rate of $2-6 \mathrm{~mm} / \mathrm{year}$. Whether the ENP mangroves will be able to maintain forest floor accretion will depend on their resilience against environmental disturbances like hurricanes, nutrient limitation and salinity stress (Wanless et al., 1997, Davis et al., 2005; Alongi, 2008).

(5) The Everglades' mangroves will require high rates of accretion and OC burial in order to keep pace with the rate of sea level rise. Smoak et al. (2012, in review) examined sediment and organic carbon (OC) burial rates via ${ }^{210} \mathrm{~Pb}$ dating (i.e., 100 year time scale) on sediment cores from two mangrove sites in ENP. An increased level of mass accumulation, accretion and OC burial rates were found in an upper layer that corresponded to the well-documented storm surge deposit from Hurricane Wilma in 2005. The rates of accretion within the storm deposit were 5.9 and $6.5 \mathrm{~mm}$ $\mathrm{yr}^{-1}$ and the overall rates of accretion were 2.5 and $3.6 \mathrm{~mm} \mathrm{yr}^{-1}$. The overall rates 
matched or exceeded the average sea-level rise reported for Key West, Florida. The organic carbon burial rates within the storm deposit were found to be 260 and $393 \mathrm{~g}$ $\mathrm{m}-2 \mathrm{yr}^{-1}$. The overall OC burial rates of 152 and $168 \mathrm{~g} \mathrm{~m}-2 \mathrm{yr}^{-1}$ were found to be similar to global estimates for OC burial in marine wetlands.

The substantial sedimentation at both sites has the potential to raise the forest floor of ENP mangroves, thereby helping the accretion rates keep pace with sea level rise. Hurricane-sourced deposits play an important role in increasing sediment accretion rates in ENP mangroves (Whelan et al., 2009 as cited in Smoak et al., 2012). Between 1901 and 2005, the hurricane return period for southern Florida was every 5 years (Keim et al., as cited in Smoak et al., 2012). Smith et al. (2007) calculated that the storm deposit during Hurricane Wilma supplied enough material to allow the forest floor elevation to keep pace with approximately 10 years of sea level rise at the current rate (Smoak et al., 2012). Climate change can lead to accelerated sea level rise and increase in the intensity of storms. A shoreline retreat of mangroves of approximately $500 \mathrm{~m}$ has been observed between 1888 and 2004 along the mouth of the Shark River by Smith et al. (2010). It is possible that the increase in the magnitude and/or intensity of storms can damage the mangroves along the coastal regions on one hand, while depositing sediments on inland sites leading to their stabilization (Smoak et al., 2012).

(6) The increase in fresh water inflow from upstream sources is expected to slow down the rate at which mangroves migrate landward, thereby controlling the loss of fresh water habitats inland. On the other hand, a resumption of fresh water inflow to 
historic conditions will serve to maintain the oligotrophic conditions that promote peat accretion as seen in the southern Everglades (Davis et al., 2005).

(7) Evidence has been documented that the annual sea level rise of approximately 2.0 $\mathrm{mm}$ along with fresh water reduction has led to inland migration of mangroves into fresh water wetlands during the past 50 years in the southeastern region of the Everglades. Since the mid-1940s the interior boundary of a mixed graminoidmangrove community migrated inland by $3.3 \mathrm{~km}$ while the interior boundary of a low productivity zone called the 'white zone' migrated inland by $1.5 \mathrm{~km}$ on average. The larger encroachment occurred in areas where fresh water inflow had been greatly reduced from upstream sources while the smaller shift occurred where the fresh water flow was unhindered (Ross et al., 2000). In addition, Meeder et al. (1996) demonstrated that that the interior boundary of the white zone moved $1.9 \mathrm{~km}$ into the fresh water wetlands from 1940 - 1994 which is equivalent to a vertical shift of 130 $\mathrm{mm}(13 \mathrm{~cm})$ in in response to a sea level rise of $110 \mathrm{~mm}(11 \mathrm{~cm})$ (Davis et al., 2005). (8) Doyle (2003) (USGS Fact Sheet FS-030-03) developed a high resolution version of SELVA-MANGRO, an integrated landscape ecosystem model, to predict the landward migration of ENP mangroves in response to projected sea level rise scenarios and salt water intrusion along the coastal margins of the forest. The landward encroachment by mangrove communities was based on landward surface slope and elevation with respect to tide range and extent. The results of the simulation model predicted that mangrove encroachment into fresh water habitats will be directly related to the rate of sea level rise. The areal encroachment of mangroves was predicted by the SELVA-MANGRO model in response to rise to projected sea 
level rise scenarios based on historic sea level conditions recorded at Key West, Florida (Table 3.8).

Table 3.8: Landward Migration of ENP Mangroves under selected Sea Level Rise

\begin{tabular}{ccc}
\multicolumn{3}{c}{ Scenarios } \\
\hline Sea Level Rise Scenario $^{\mathrm{a}}$ & \multicolumn{2}{c}{ Habitat Gain $^{\mathrm{b}}$} \\
\hline$(\mathrm{m} / 100$ years $)$ & In square km & In hectares \\
\hline 0.15 & 500 & 50,000 \\
0.33 & 900 & 90,000 \\
0.45 & 1200 & 120,000 \\
0.66 & 1900 & 190,000 \\
0.95 & 2900 & 290,000 \\
1.10 & 3300 & 330,000
\end{tabular}

Note: a: IPCC estimates from Engel, 2010; b: estimates for habitat gain from Doyle, 2003.

3.8.1 Estimation of Total Carbon Sequestered as a Result of Mangrove Transgression into Upland Fresh Water Habitats under 3 Sea Level Rise Scenarios

It was assumed that as the ENP mangroves transgress inland into fresh water habitats in response to sea level rise, they will sequester $\mathrm{C}$ at the global average rate of $2.1 \mathrm{Mg}$ C/ha/year (Chmura et al., 2003). The extent of areal increase of the mangrove transgression for this study is based on the results from the SELVA-MANGRO model (Table 3.8) (Doyle, 2003). This study estimated the total C to be sequestered by the landward transgression of ENP mangroves by the year 2100 .

Predictions in sea level rise for this study are based on IPCC estimates which range from 0.2 to $0.56 \mathrm{~m}$ by the year 2100 . IPCC estimates are based on current knowledge about ice 
sheet dynamics and assumptions in the global carbon cycle regarding $\mathrm{CO}_{2}$ fertilization effect and fossil fuel consumption, all of which are associated with certain uncertainties. However, it is likely that interactive relationships between the atmosphere, oceans and ice sheets will alter as result of the cumulative effect of increased GHG concentrations in the future, making the IPCC estimates fairly conservative (Engel, 2010).

Three scenarios for sea level rise expected by 2100 were selected. They correspond to low $(0.2 \mathrm{~m})$, moderate $(0.38 \mathrm{~m})$ and high $(0.56 \mathrm{~m})$ IPCC estimates scenarios (Table 3.9). The value for the moderate scenario $(0.38 \mathrm{~m})$ is calculated as a midpoint of the predicted range of sea level rise by IPCC. The expected gain in area as a result of transgression for each scenario of sea level rise for this study is estimated using the predictions by Doyle (2003) shown in Table 3.8. The following table shows the estimates used for this study:

Table 3.9: Projected Scenarios for Sea Level Rise and Areal Extent of Mangrove Transgression

\begin{tabular}{|c|c|c|c|c|c|}
\hline Scenario & $\begin{array}{l}\text { Projected sea level } \\
\text { rise }^{\mathrm{a}}\end{array}$ & Extent of man & nigration $^{b}$ & $\begin{array}{l}\text { Length of } \\
\text { landward } \\
\text { boundary of } \\
\text { ENP Mangroves }\end{array}$ & $\begin{array}{l}\text { Landward } \\
\text { distance of } \\
\text { migration }\end{array}$ \\
\hline & $(\mathrm{m} / 100$ years $)$ & Square $\mathrm{km}$ & hectares & $\mathrm{km}$ & $\mathrm{km}$ \\
\hline I & 0.20 & 500 & 50,000 & 120 & 4.17 \\
\hline II & 0.38 & 900 & 90,000 & 120 & 7.5 \\
\hline III & 0.56 & 1500 & 150,000 & 120 & 12.5 \\
\hline
\end{tabular}

Note: a: Projected sea level rise using IPCC estimates from Engel, 2010; b: Estimates for habitat gain from Doyle, 2003.

For the sake of simplicity, I assumed that the ENP mangroves migrate uniformly along their landward boundary and that their areal extent can be represented by a polygon (polygon X) (Figure 3.2). The landward transgression is assumed to begin in the year 
2010, up to the year 2100. The length of the mangrove forest along their landward boundary is represented by two segments $A$ and $B$. Segment $A$ lies parallel to the western Everglades mangroves while segment $B$ is the landward boundary of the southeast ENP mangroves. The approximate lengths of the segments were measured using the Measure tool in ArcGIS $(A=86.281 \mathrm{~km}, B=33.770 \mathrm{~km})$.

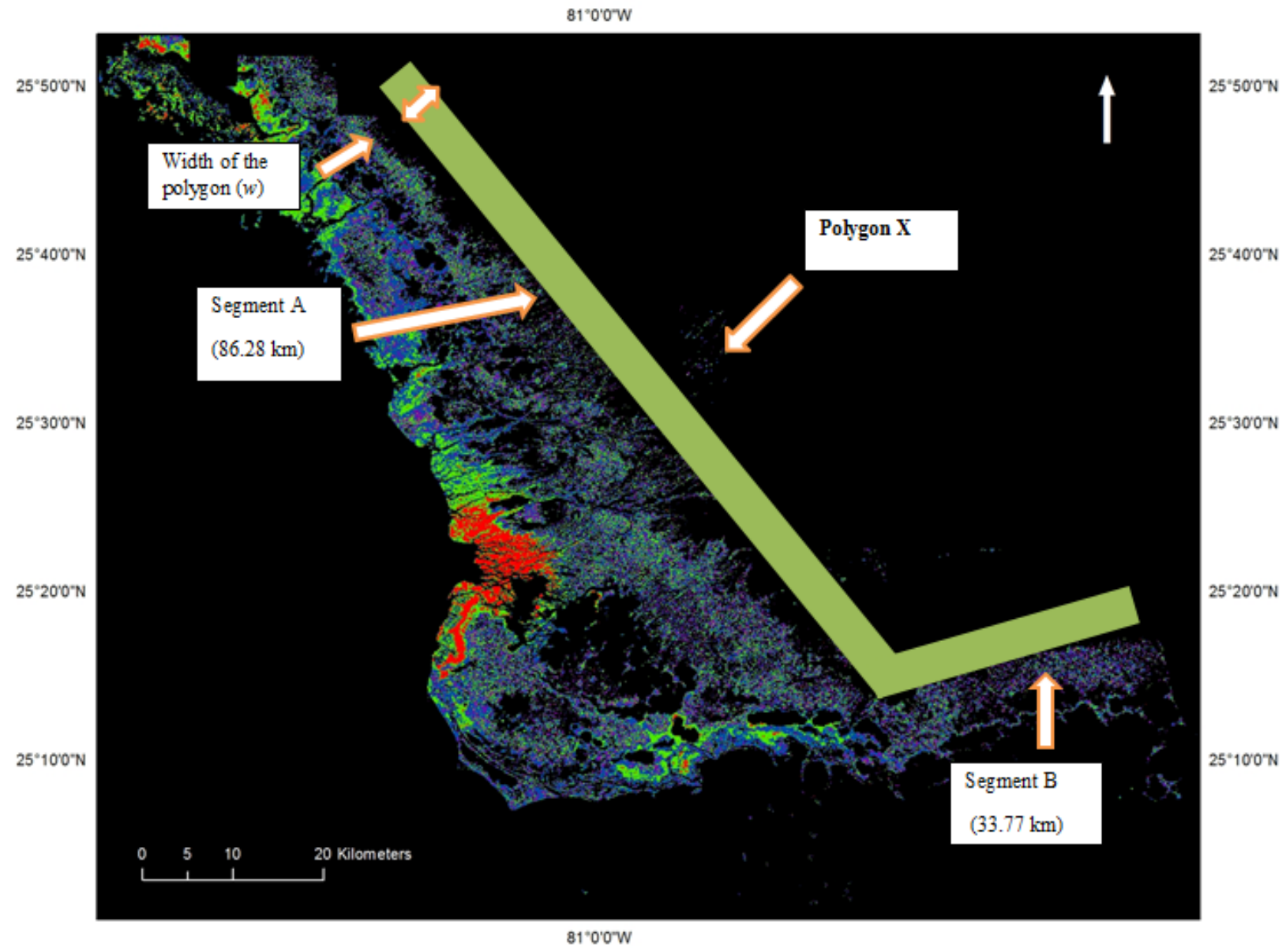

Figure 3.2: Map of Mangrove Forest of Everglades Nation Park, Florida, showing the projected zone of mangrove transgression depicted by Polygon $\mathrm{X}$. 


\subsubsection{Scenario I}

In scenario I, I assumed that sea level will rise $0.2 \mathrm{~m}$ by 2100 and the area of the polygon $\mathrm{X}$ which represents the extent of areal migration by mangroves of $500 \mathrm{~km}^{2}$. If the landward boundary of ENP mangroves (sum of segments $A$ and $B$ ) is approximately $120.051 \mathrm{~km}$, then the width of polygon X $(w)$ represents the landward march of the mangroves into the fresh water habitats of the Everglades. The width of the polygon $\mathrm{X}$ with area $500 \mathrm{~km}^{2}$ and length $120.051 \mathrm{~km}$ is approximately $4.17 \mathrm{~km}$. I assumed that the mangroves will migrate gradually at a constant rate over the next 90 years up to the year 2100 , the baseline year of this study being 2010. For the purpose of the study, a constant rate of $4.17 / 90^{\text {th }}$ kilometer of migration every year for the total expected migration of $4.17 \mathrm{~km}$ was assumed. The $4.17 \mathrm{~km}$ stretch of migration into the upper Everglades results in 90 segments $(S)$ of $0.05 \mathrm{~km}$ each. I assumed that the migration will take place evenly along the current mangrove interface with fresh water habitats equivalent to 120 km (approx.) length.

The carbon accumulated at any location in the zone of transgression was calculated using the following:

$$
C_{a}=C_{r} * a
$$

where,

$C_{a}$ is the carbon accumulated in a unit area $\left(\mathrm{Mg} \mathrm{Cha}^{-1}\right)$ in the zone of transgression of ENP mangroves, 
$C_{a}$ is the rate of carbon sequestration of mangroves, assumed as $2.1 \mathrm{Mg} \mathrm{C}^{-1} \mathrm{year}^{-1}$

(Chmura et al., 2003), and

$a$ is the age of the mangrove at the $90^{\text {th }}$ year.

The first segment S1 represents the first $0.05 \mathrm{~km}$ of mangrove migration to upland Everglades in the first year of the 90 year migration period under study. In S1, the mangroves will sequester $\mathrm{C}$ for the entire 90 years under study and therefore the $\mathrm{C}$ accumulated at each unit hectare area in $\mathrm{S} 1$ will be $189 \mathrm{Mg} \mathrm{C}$ ha $^{-1}$ in 90 years (i.e., 2.1 $\mathrm{Mg} \mathrm{C} \mathrm{ha}{ }^{-1}$ year $^{-1} * 90$ years $)$, by the year 2100 . The total C sequestered in $\mathrm{S} 1\left(C_{s}\right)$ was computed by multiplying the per hectare carbon by total area of mangroves in that segment. Note that the age of the mangroves at the $90^{\text {th }}$ year declined with the inward migration transgression. For instance, in the second segment at the $90^{\text {th }}$ year the mangroves age would be 89 years and so forth. The carbon accumulated in ENP mangroves was also calculated for the year 2050, assuming an increase of 20,000 ha of mangrove transgression.

The total $\mathrm{C}$ sequestered in polygon $\mathrm{X}$ by mangrove transgression under Scenario I was expressed as the sum of the $\mathrm{C}$ sequestered in each of the 90 segments.

$$
C(\text { Scenario } I)=\sum_{s=1}^{90} C s
$$

\subsubsection{Scenarios II and III}

In Scenarios II and III, it was assumed that the sea level will rise $0.38 \mathrm{~m}$ and $0.56 \mathrm{~m}$ respectively by 2100 . In Scenario II, the extent of areal migration of ENP mangroves to upland habitats represented by polygon $\mathrm{X}$ is $900 \mathrm{~km}^{2}$ so that the landward march of the 
mangroves into the fresh water habitats is $7.5 \mathrm{~km}$. The expected stretch of migration into the upper Everglades is divided into 90 segments (S) of $0.08 \mathrm{~km}$ each. The total $\mathrm{C}$ sequestered in $\mathrm{S} 1\left(C_{s}\right)$, for Scenario II was computed by multiplying the per hectare carbon by total area of mangroves in that segment. In Scenario III, the total extent of migration of ENP mangroves is $150 \mathrm{~km}^{2}$, the width of polygon $\mathrm{X}$ is $12.5 \mathrm{~km}$, and each division of the polygon is $0.14 \mathrm{~km}$ each. The total $\mathrm{C}$ sequestered in the zone of mangrove migration in Scenarios II and III was calculated in the same way as in Scenario I (Equation 3.4).

\subsubsection{Estimation of Change in Economic Value of the Carbon Stored in ENP Mangroves}

To estimate the change in total economic value of $\mathrm{C}$ stored in ENP mangroves in response to sea level rise, the value of the current stock of $\mathrm{C}$ was compared to the value of the projected stock of C in the year 2100 under Scenarios I, II and III. The C stored per hectare in the ENP mangrove forest area will change with the migration of mangroves upland. The price of carbon is also expected to change by 2100 . It was assumed that a strong, international carbon market will develop in the next few decades with active participation by most countries which will be representative of the true price of carbon.

As this study is relevant to the U.S., I used the conservative C price of the U.S. based market RGGI to estimate the market price in the year 2100. To enable the projection of carbon market prices in 2100, I used estimation of carbon market prices by Nordhaus (2010). Nordhaus (2010) used the RICE (regional integrated model of climate and the economy) model to project carbon market prices under different policy scenarios under 
the Copenhagen Accord ${ }^{6}$ for the next century (Table 3.10). I selected the $\mathrm{C}$ price trend of the scenario wherein the Copenhagen Accord is adopted by rich countries only, keeping the current political and policy situation in mind. The $\mathrm{C}$ prices used in the RICE model (Nordhaus, 2010) were in 2005 dollars and the discount rate used was 3 per cent.

Therefore, I first converted the 2010 RGGI C price of $\$ 7 / \mathrm{tC}$ to 2005 dollars ( 7 divided by $\left.(1+0.03)^{5}\right)$, which resulted in a price of $\$ 6.038 / \mathrm{tC}$. Using the $\mathrm{C}$ price trend for 'Copenhagen-rich countries only' scenario estimated by Nordhaus (2010), I estimated the following price trend equation with the intercept forced at the 2010 RGGI market price of $\$ 6.038$. The resultant price trend is given by the equation:

$$
Y_{m}=6.038+0.3946 * t
$$

where,

$Y_{m}$ is the projected C market price for a given future year $t$.

The above equation was used to predict the $\mathrm{C}$ market price for the years 2050 and 2100 (Table 3.10).

\footnotetext{
${ }^{6}$ The 2009 Copenhagen meeting led to the Copenhagen Accord which was adopted by the Conference of Parties (COP 15) to the United Nations Framework Convention on Climate Change (UNFCCC). The COP 15 agreed to a target of limiting the increase in global mean temperatures to below 2 degrees Celsius in concurrence with the majority of scientific view. The Accord is not a legally binding document.
} 
Table 3.10: Carbon Price in Different Runs

\begin{tabular}{lccccccc}
\hline $\mathrm{C}$ price & 2005 & 2010 & 2015 & 2020 & 2025 & 2050 & 2100 \\
\hline $\begin{array}{l}\text { Copenhagen: } \\
\text { rich only }\end{array}$ & 0.00 & 0.07 & 0.39 & 2.21 & 12.40 & 64.11 & 41.55 \\
$\begin{array}{l}\text { Copenhagen: } \\
\text { rich only, with } \\
\mathrm{RGGI}^{\mathrm{b}}\end{array}$ & $7.00^{\mathrm{c}}$ & & & & $25.29^{\mathrm{d}}$ & $48.17^{e}$ \\
$\mathrm{SCC}^{\mathrm{f}}(3 \%)$ & & & & & & \\
$(\$ / \mathrm{tCO}$ & & & & & & \\
$\mathrm{SCC}^{\mathrm{g}}$ estimate & 21.4 & 23.8 & 26.3 & 29.6 & & \\
\hline
\end{tabular}

Note: The data for this table is sourced from Nordhaus, 2010;

a: all prices sourced from Nordhaus, 2010;

b: RGGI 2010 price is used as baseline for this run which follows the same price trend as in a;

$c, d$ and e are prices used to value C storage in ENP mangroves for 2010,2050 and 2100 respectively using equation 3.5;

f: all prices sourced from U.S. Interagency Report on SCC estimates, 2010;

g: SCC estimates used for this study to value C storage in mangrove.

In addition, I used the $\mathrm{C}$ price trend for SCC estimates given by the U.S. Interagency

Report for regulatory impact analysis (2010), to predict the SCC for the years 2050 and

2100. In this case the price trend is given by the equation:

$$
Y_{s c c}=20.827+0.6037 * t
$$

where, $Y_{S C C}$ is the projected $\mathrm{C}$ price for the given year and $\mathrm{t}$ is the time period.

Therefore, the projected carbon market and social cost for 2050 and 2100 were used to compute the change in economic value of the total C stored in ENP mangroves in 2100 for Scenarios I, II and III (Table 3.10). 


\section{Chapter 4}

\section{Results and Discussion}

In this chapter I will present the results of the study in five sections. The first section presents the results for the estimation of $\mathrm{C}$ storage in the mangroves of Everglades National Park, Florida. The results include estimations of the total C present in the (a) aboveground biomass, (b) belowground biomass (roots), (c) sediments, (d) belowground (roots and soil), and (e) entire ecosystem (total carbon) of the mangrove forest of the Everglades National Park. In the second section, a comparative analysis of $\mathrm{C}$ prices across different valuation methodologies discussed in Chapter 3 will be performed. In the third section a range of economic values will be assigned to the $\mathrm{C}$ stored within the mangrove forests of ENP. In the fourth section, I will estimate the carbon sequestered as a result of ENP mangrove transgression in response to sea level rise. In the fifth section, an estimation of change in economic value of carbon stored in ENP mangroves in response to sea level rise is performed

\subsection{Carbon Storage in the Mangrove Forests of Everglades National Park, Florida}

The following sub-sections present the results for estimations of the different components of C storage in the mangrove forests of Everglades National Park, Florida.

\subsubsection{Carbon Storage in the FCE LTER Sites}

Based on the data and calculations in sections 3.5.1, 3.5.1 and 3.5.3 the $\mathrm{C}$ storage in the six FCE LTER sites is presented in Table 4.1 and graphically represented in Figure 4.1. 
Table 4.1: Carbon Storage in the Six FCE LTER Sites in ENP Mangrove Forests

\begin{tabular}{ccccc}
\hline FCE LTER Study Site & $\begin{array}{l}\text { Aboveground } \\
\text { Carbon (Mg/ha) }\end{array}$ & $\begin{array}{l}\text { Belowground } \\
\text { (Roots) Carbon } \\
(\mathrm{Mg} / \mathrm{ha})\end{array}$ & $\begin{array}{l}\text { Soil Carbon } \\
(\mathrm{Mg} / \mathrm{ha})\end{array}$ & Total Carbon (Mg/ha) \\
\hline SRS-4 & $43.00^{\mathrm{a}}$ & $14.1^{\mathrm{b}}$ & $623^{\mathrm{c}}$ & 680 \\
SRS-5 & $47.87^{\mathrm{a}}$ & $19.3^{\mathrm{b}}$ & $794^{\mathrm{c}}$ & 861 \\
SRS-6 & $66.91^{\mathrm{a}}$ & $11.1^{\mathrm{b}}$ & $609^{\mathrm{c}}$ & 687 \\
TS/Ph-6 & $5.50^{\mathrm{a}}$ & $10.6^{\mathrm{b}}$ & $607^{\mathrm{d}}$ & 623 \\
TS/Ph-7 & $5.50^{\mathrm{a}}$ & $20.6^{\mathrm{b}}$ & $500^{\mathrm{d}}$ & 526 \\
TS/Ph-8 & $1.97^{\mathrm{a}}$ & $19.2^{\mathrm{b}}$ & $516^{\mathrm{d}}$ & 537 \\
\hline
\end{tabular}

Notes: a: Chen \& Twilley (1999b); Coronado-Molina et al. (2004); b: Castañeda-Moya et al. (2011) $c=a t$ $1.5 \mathrm{~m}$ depth; $d=$ at $1 \mathrm{~m}$ depth; SRS: Shark River Slough; TS/Ph: Taylor Slough/Panhandle

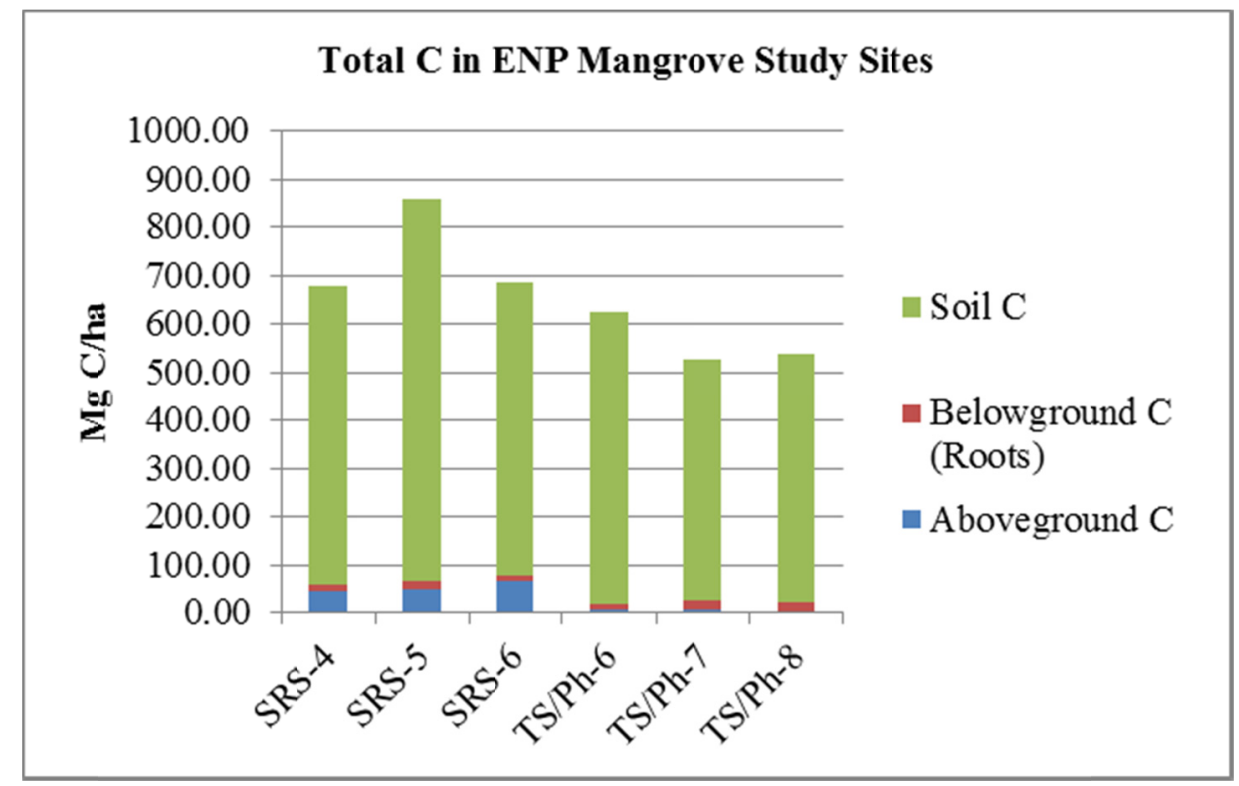

Figure 4.1: Total Carbon Storage in the Six FCE LTER Study Sites in ENP Mangrove Forests

The total carbon storage in the six FCE-LTER study sites was obtained upon addition of soil carbon values extrapolated to represent the variable depths of soil in Shark River Slough and Taylor Slough sites to aboveground and belowground carbon values as explained in section 3.5.4. High carbon values reflect higher biomass in the aboveground 
or belowground portions of the mangrove trees. As discussed in Chapter 2, the biomass allocation in ENP mangroves is dependent on the availability of the nutrient $\mathrm{P}$ (Phosphorus). Because of the upside down nature of the estuary, P is supplied by the tidal waters of the Gulf of Mexico. High tidal frequency at the mouth of the Shark River estuary supplies more P to SRS-6, which results in greater tree heights (Rivera-Monroy et al., 2011) and thus the highest values for aboveground carbon. As P availability decreases at upstream sites of the Shark River, SRS-5 and 4, the tree height, biomass and carbons storage correspondingly decrease. Carbon storage in roots depends on several factors that guide root productivity and biomass. Taylor Slough sites allocate more biomass to roots because of acute $\mathrm{P}$ limitation resulting from the lower tidal frequency and permanence of flooding in these regions (Castañeda-Moya et al., 2011).

Among all FCE-LTER sites, the total carbon storage per hectare is highest for SRS-5 followed by SRS- 6 and SRS-4 among the SRS sites, and TS/Ph-6, 8 and 7 among the $\mathrm{TS} / \mathrm{Ph}$ sites. The high C storage in SRS-5 (861 Mg C/ha) is explained by the combination of high carbon storage in aboveground and belowground biomass, and the soil. SRS-6 has the highest aboveground carbon storage $(66.91 \mathrm{Mg} \mathrm{C} / \mathrm{ha})$ but the $\mathrm{C}$ storage in roots and soil are lowest among the SRS study sites. Therefore, SRS-6 is ranked second in total carbon storage (687 Mg C/ha) among all FCE-LTER study sites. SRS-4 has the least amount of total carbon storage among the SRS study sites as a result of medium tree heights (lower aboveground C) in that region, and lower values for carbon in the roots. Among the TS/Ph study sites, TS/Ph-6 has the highest total carbon (623 Mg C/ha) which is mainly the result of high soil carbon values at this site. $\mathrm{TS} / \mathrm{Ph}-8$ has the second highest 
total carbon storage among TS/Ph sites. TS/Ph- 8 has the lowest aboveground $\mathrm{C}$ storage (because of low tree height and biomass) among all sites but the value for belowground carbon in roots is as high $(19.2 \mathrm{Mg} \mathrm{C} / \mathrm{ha})$ as SRS-5. TS/Ph-7 has the least amount of soil carbon (500 Mg C/ha) among all sites which explains the least amount of total carbon storage in this study site (526 Mg C/ha).

4.1.2 Carbon Storage in the Aboveground Biomass $\left(C_{A G}\right)$ of Mangrove Forests of Everglades National Park

Following the methodology explained in section in 3.5.1, a map of aboveground $\mathrm{C}$ distribution in the mangrove forests in Everglades National Park, Florida was produced (Figure 4.2). The amount of carbon in the aboveground portions $\left(C_{A G}\right)$ of the mangrove forest was calculated as 44 per cent of biomass (Ewe et al., 2006), a conversion factor specific to the Everglades' mangroves. 
$81^{\circ} 0^{\prime} \mathrm{O}^{\prime \prime} \mathrm{W}$

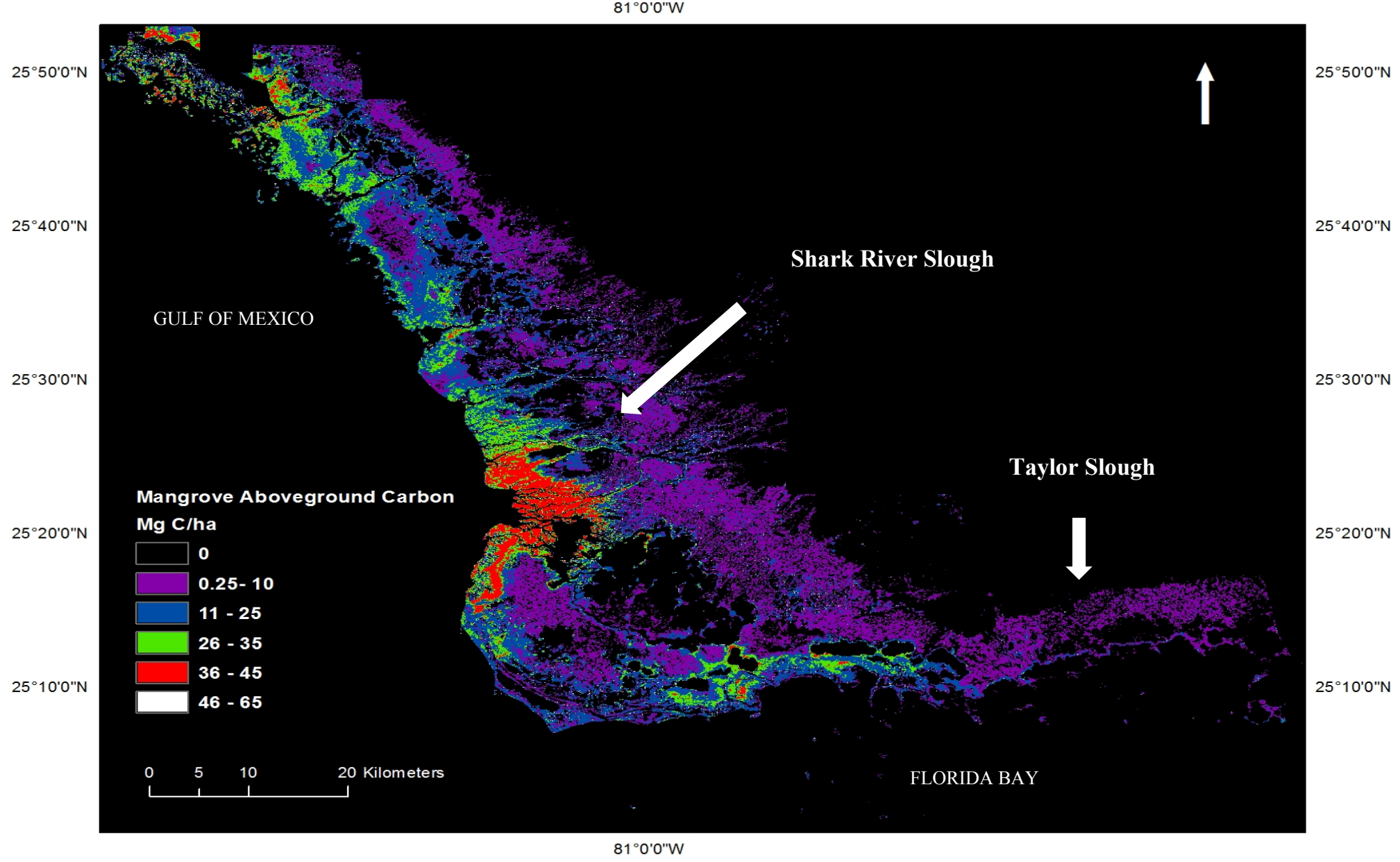

Figure 4.2: Aboveground Carbon Distribution in the Mangrove Forests in Everglades National Park, Florida 
The aboveground storage of carbon follows the same pattern as the standing biomass of mangrove forest of ENP. The total quantity of carbon present in the standing biomass of the ENP mangroves is approximately 21,707 million Mg C (Table 4.2). The aboveground carbon content in the mangroves of ENP ranges from $0.25-64.06 \mathrm{Mg} \mathrm{C} / \mathrm{ha}$ (Mean: 14.24 $\pm 11.2 \mathrm{Mg} \mathrm{C} / \mathrm{ha}$ ). The majority of the mangroves along the landward regions of the forest contain up to $10 \mathrm{Mg} \mathrm{C} / \mathrm{ha}$. These include the scrub dominated mangroves in the eastern regions and the mangroves along the length of the landward boundary of the ENP forest. The lower $\mathrm{C}$ content in the scrub dominated mangroves is a result of poor $\mathrm{P}$ availability along with the low tidal signature and permanent flooding in the eastern regions of the ENP forest (Castañeda-Moya, 2011). In contrast, the riverine and fringe mangroves located in the western coastal regions of the ENP mangroves, contain carbon values ranging from $26-64.1 \mathrm{Mg} \mathrm{C} / \mathrm{ha}$. The highest values for carbon are located at the mouth of the Shark River, Harney Creek and Broad Creek estuaries (Figure 4.2) and can be attributed to the dominant tidal hydrology and higher P availability in the soil.

4.1.3 Carbon Storage in the Belowground Biomass (fine roots) $\left(C_{B G R}\right)$ of Mangrove Forests of Everglades National Park

Following the methodology explained in section in 3.5.2, a map of belowground distribution of carbon in the fine roots of the mangrove forests in Everglades National Park, South Florida was produced (Figure 4.3). The total quantity of carbon present in roots $\left(C_{B G R}\right)$ less than $20 \mathrm{~mm}(0-90 \mathrm{~cm})$ in diameter of the ENP mangroves is approximately 16,917 million Mg C (Table 4.2). 


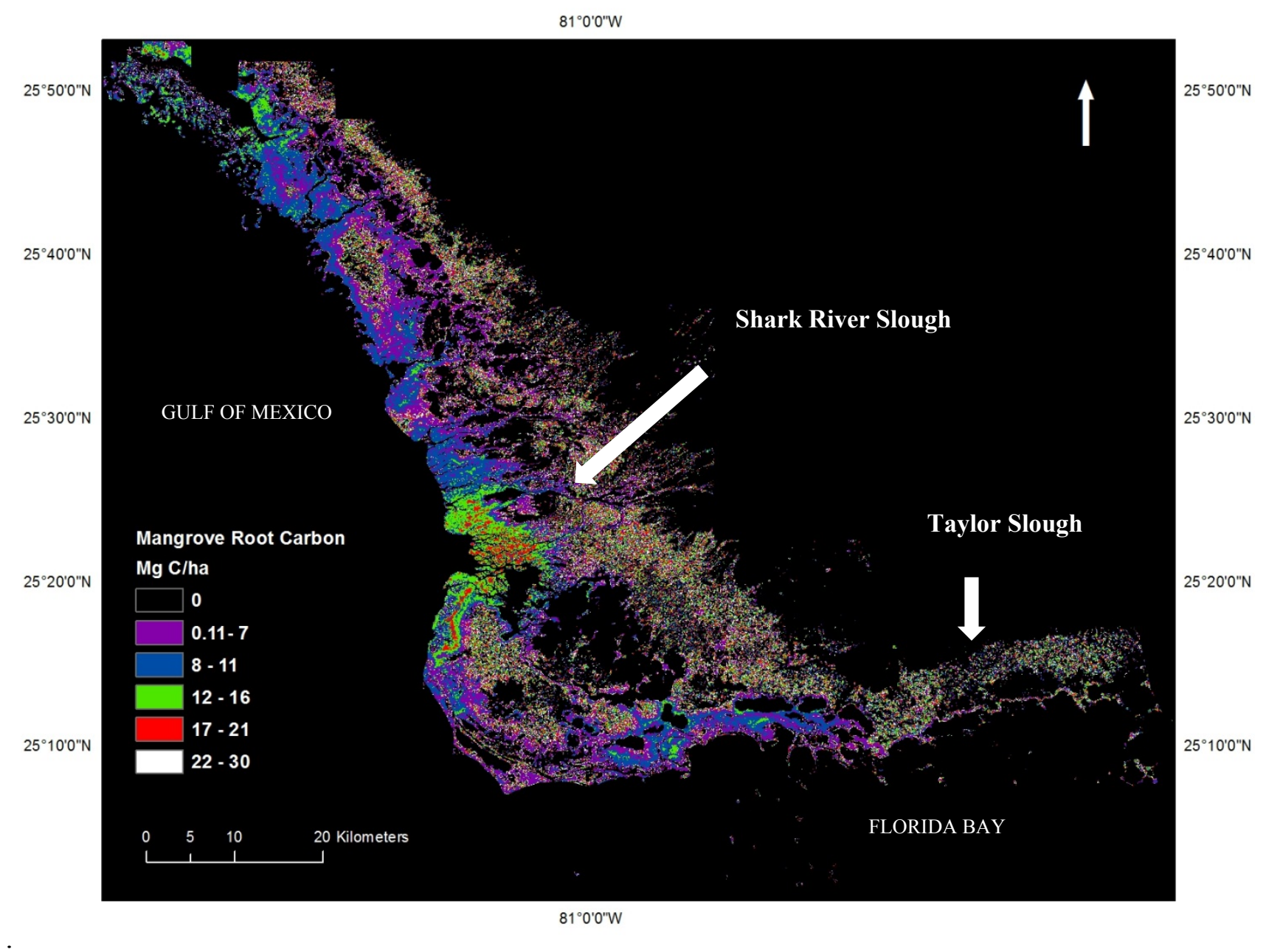

Figure 4.3: Belowground Carbon Distribution in Fine Roots of Mangrove Forests in the Everglades National Park, Florida 
The belowground carbon content in the roots of the mangrove forests of ENP ranges from $0.11-30 \mathrm{Mg} \mathrm{C} / \mathrm{ha}$ (Mean: $10.98 \pm 6.3 \mathrm{Mg} \mathrm{C} / \mathrm{ha}$ ). The high carbon content in the roots is observed throughout the forest (Figure 4.3). The majority of the forest contains $8-11$ $\mathrm{Mg} \mathrm{C} /$ ha. In particular, it is observed that the carbon content in the roots of the scrub mangroves of the southeastern regions of the Taylor Slough is higher. The high carbon content can be correlated to the high root productivity as result of increase in P limitation and permanence of flooding in the southeastern Everglades. The forest area with high values for aboveground $\mathrm{C}$ as observed in the map for aboveground carbon (Figure 4.2) have roots with medium values for $\mathrm{C}$ content ranging from $12-16 \mathrm{Mg} \mathrm{C} / \mathrm{ha}$.

4.1.4 Carbon Storage in the Sediments $\left(C_{B G S}\right)$ of Mangrove Forests of Everglades National Park

Following the methodology explained in section in 3.5.3, a map of belowground carbon distribution in the soil of the mangrove forests in Everglades National Park, South Florida was produced (Figure 4.4). The total quantity of carbon present in the soil $\left(C_{B G S}\right)$ of the ENP mangroves is approximately 952 million Mg C (Table 4.2). 


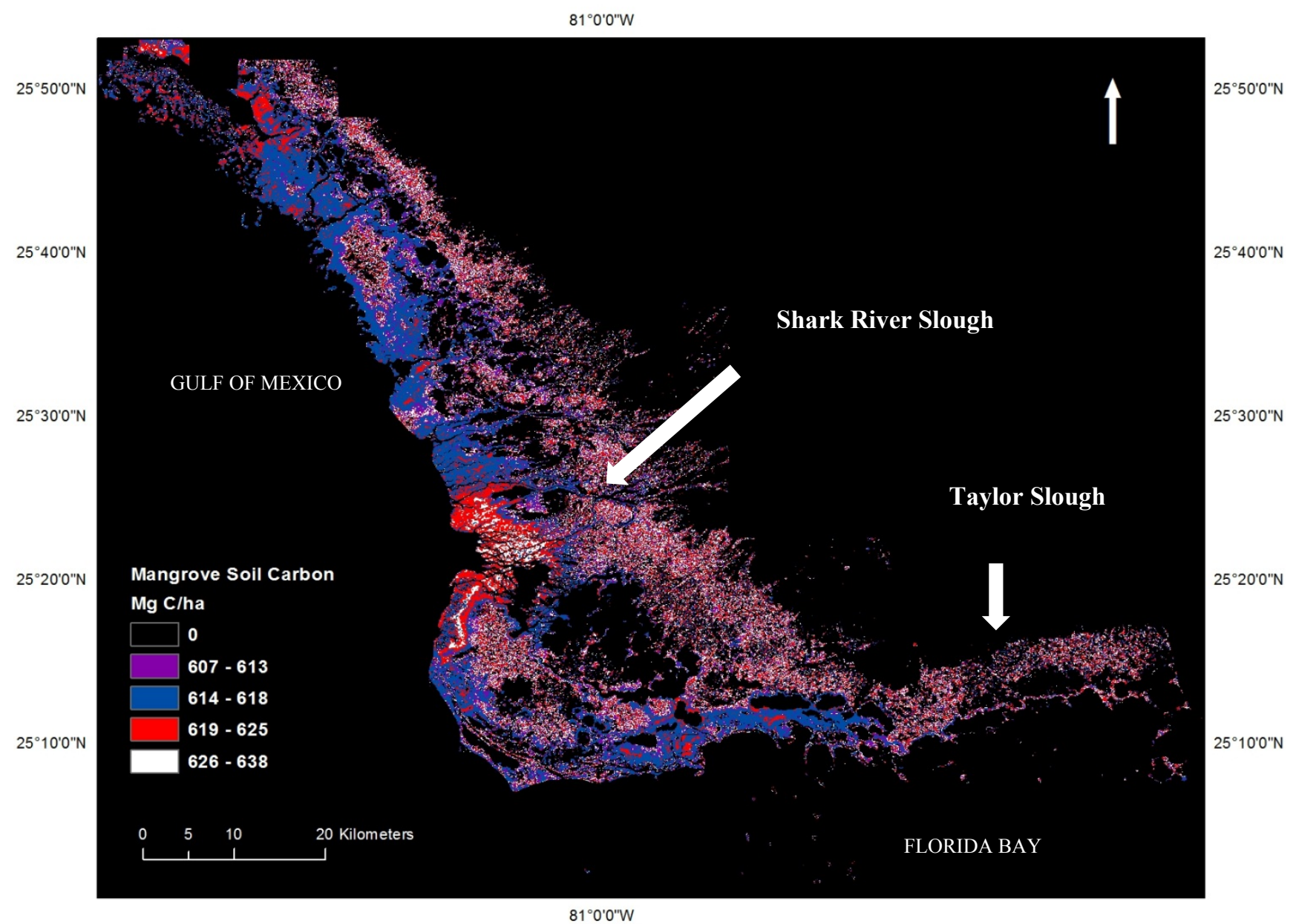

Figure 4.4: Carbon Distribution in the Soil of Mangrove Forests in Everglades National Park, Florida 
Unlike the distribution of the carbon stored in the living biomass, the spatial distribution of soil carbon in the mangrove forest of ENP follows an even pattern (Mean $617.8 \pm 6.3$ $\mathrm{Mg} \mathrm{C} / \mathrm{ha}$ ). The carbon values are spread across a narrow range. The coastal regions of the forest has soil carbon values in the medium range of $614-618 \mathrm{Mg} \mathrm{C} / \mathrm{ha}$, while the highest values are spread across the landward regions of the mangrove forest. The higher values for soil carbon in the western regions of ENP can be correlated to the presence of the deeper layers of peat soil present in the forest.

4.1.5 Belowground Carbon Storage (soil and fine roots) $\left(C_{B G R-S}\right)$ in the Mangrove Forests of Everglades National Park

The belowground $\mathrm{C}$ pool was expressed as a sum of the $\mathrm{C}$ present in the soil and roots of the mangrove forest. A map of the distribution of the total belowground $\mathrm{C}$ storage of the mangrove forest was produced (Figure 4.5). The total quantity of the carbon present in the belowground pool of roots and soil $\left(C_{B G R-S}\right)$ in the ENP mangroves is 968,910 million $\operatorname{Mg}$ C.

The total belowground pool of carbon $(968,910$ million $\mathrm{Mg} \mathrm{C}$ ) is significantly higher than the aboveground $\mathrm{C}$ pools (21,707 million $\mathrm{Mg} \mathrm{C}$, approximately 44 times more) in the mangrove forests of ENP. The total belowground carbon is distributed unlike the aboveground carbon, but exhibits a similar patchiness across the landscape. The conspicuous gradient of total belowground carbon distribution can be correlated to the presence of strong environmental gradients like hydroperiod, nutrients and regulators like salinity. 


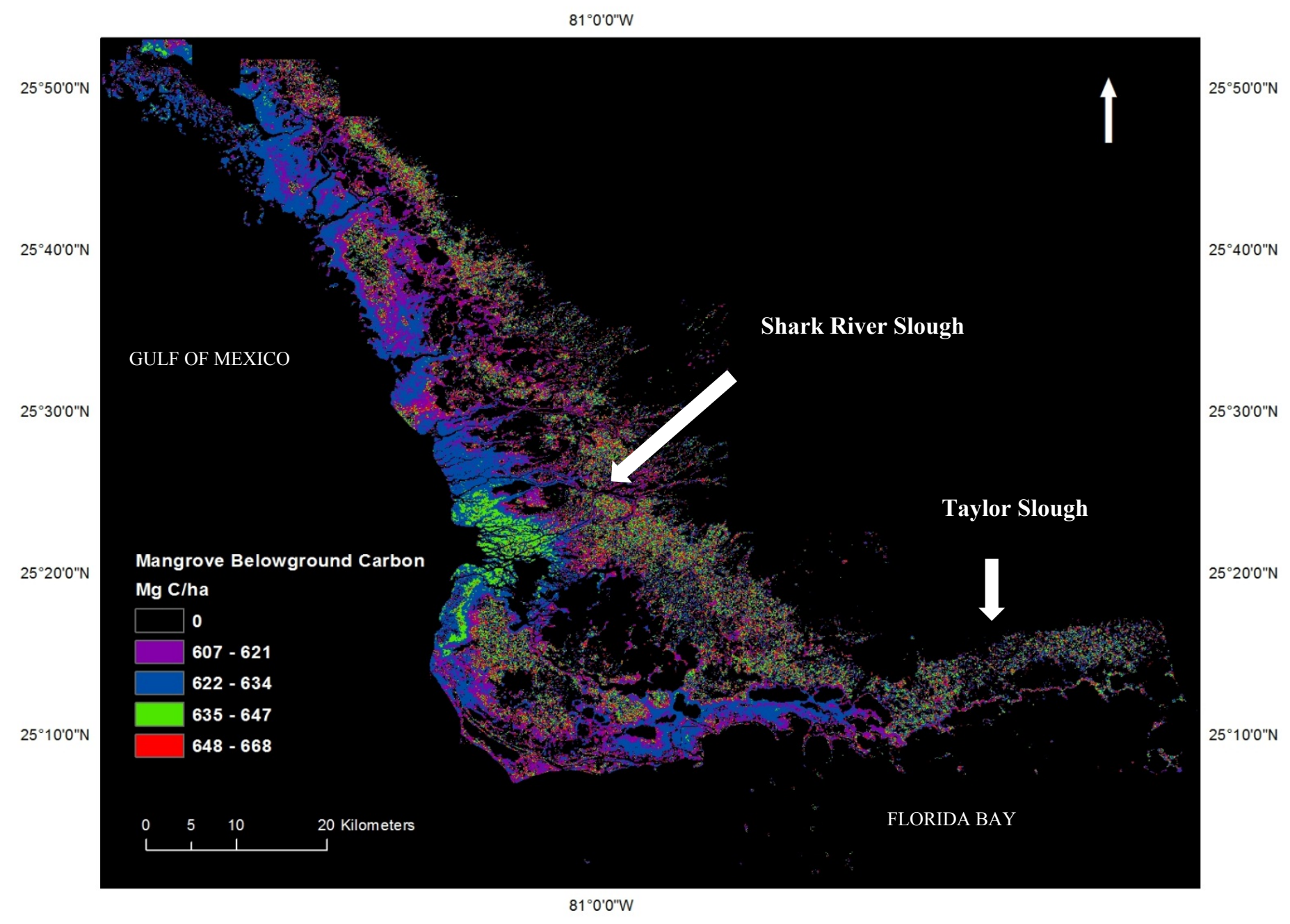

Figure 4.5: Total Belowground Carbon Distribution in the Mangrove Forests in Everglades National Park, Florida 
The highest values for belowground carbon $(635-668 \mathrm{Mg} \mathrm{C} / \mathrm{ha})$ are distributed throughout the forest. In addition to the highest aboveground C pools (Figure 4.2), the SRS estuary exhibits significant values for belowground carbon (635 - 647 Mg C/ha).

\subsubsection{Total Carbon Storage (TC) in the Mangrove Forest Ecosystem in Everglades} National Park

As described in the methodology in section 3.5.5, a map of the total C storage in the mangrove forests of ENP was generated (Figure 4.6). The total carbon present in the entire ecosystem was expressed as a sum of the aboveground and total belowground $\mathrm{C}$ storage. The total C storage in the mangrove forests of the Everglades National Park is approximately 990,724 million Mg C (Table 4.2).

The spatial distribution of the total carbon exhibits a conspicuous gradient across the Everglades' mangrove landscape. The highest values are located at close to the mouth of the Shark River estuary, followed by the Harney and Broad Creek estuaries. The dominance of tidal hydrology, availability of the nutrient $\mathrm{P}$ and deep layers of the peat soil are factors that can be correlated with the high carbon content in these regions. The lower values for carbon content in the ecosystem are located in the south eastern Everglades and towards the landward boundary of the ENP mangrove forest landscape. The shallow layers of soil, absence of tidal signature and $\mathrm{P}$ availability are contributing factors to the low $\mathrm{C}$ content in the interior forest regions and the south eastern Everglades. 


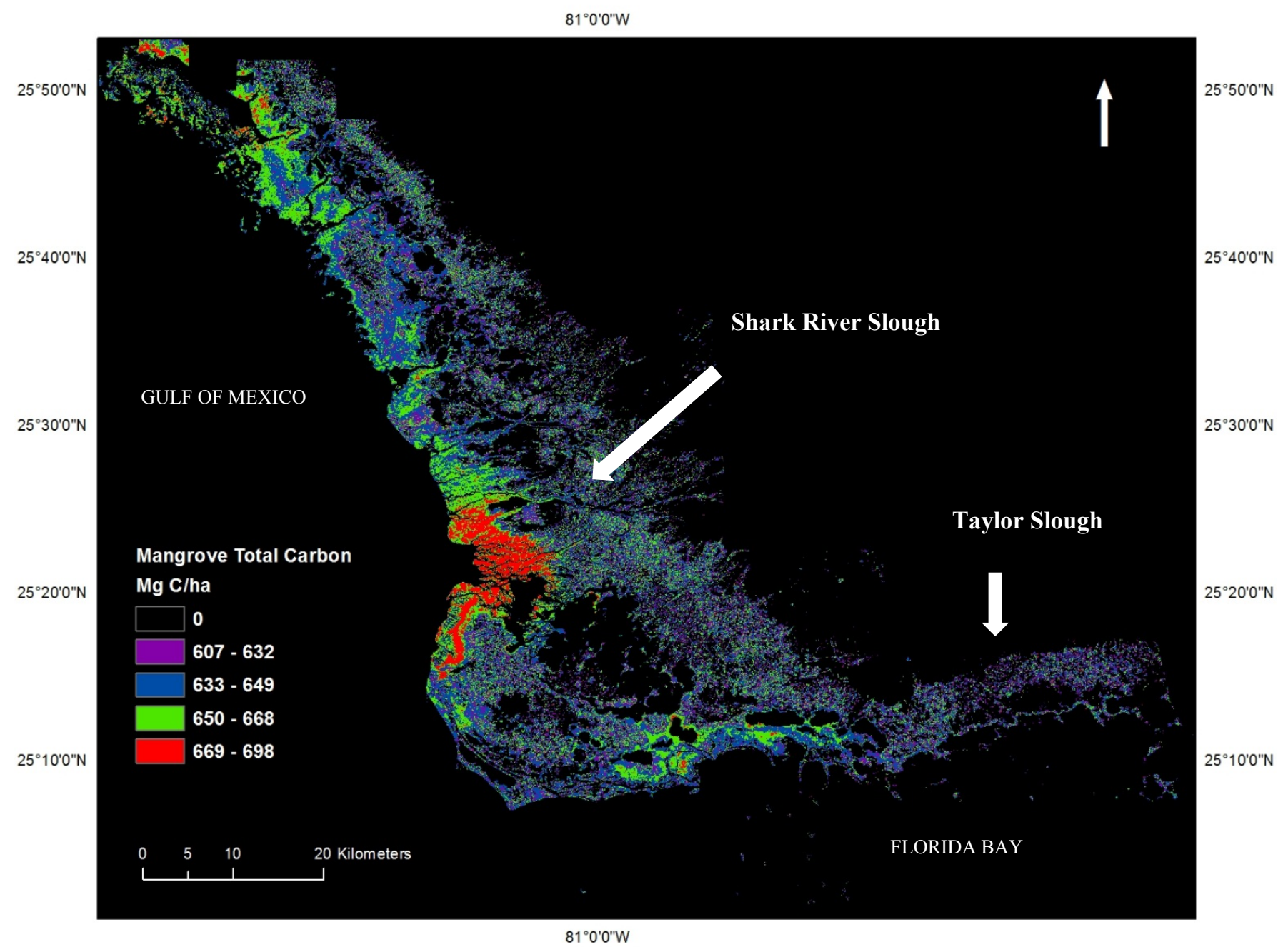

Figure 4.6: Total Carbon Distribution in the Mangrove Forests in Everglades National Park, Florida 
Table 4.2: Carbon Storage in the Mangrove Forests of the Everglades National Park, Florida

\begin{tabular}{|c|c|c|c|c|c|c|c|}
\hline & Mangrove Forest Component & $\begin{array}{l}\text { Minimum } \\
\text { (Mg C/ha) }\end{array}$ & $\begin{array}{l}\text { Maximum } \\
\text { (Mg C/ha) }\end{array}$ & $\begin{array}{c}\text { Mean estimate } \\
(\mathrm{Mg} \mathrm{C} / \mathrm{ha})\end{array}$ & $\begin{array}{l}\text { Standard } \\
\text { Deviation }\end{array}$ & $\begin{array}{c}\text { Amount of } \\
\text { Carbon }^{\mathrm{a}} \\
\text { (million } \mathrm{Mg} \mathrm{C} \text { ) }\end{array}$ & $\%$ \\
\hline$\left(C_{A G}\right)$ & Aboveground Carbon Storage & 3 & 712 & 158 & 124 & 21,707 & 2.2 \\
\hline$\left(C_{B G R}\right)$ & Belowground Carbon (Roots) & 1 & 333 & 122 & 70 & 16,917 & 1.71 \\
\hline$\left(C_{B G S}\right)$ & Belowground Carbon (Soil) & 6,755 & 7,089 & 6,864 & 70 & 952 & 96.09 \\
\hline$\left(C_{B G R-S}\right)$ & $\begin{array}{l}\text { Belowground Carbon Storage } \\
\text { (Roots and Soil) }\left(C_{B G R}+C_{B G S}\right)\end{array}$ & 6,753 & 7,422 & 6,989 & 144 & 968,910 & 97.80 \\
\hline$(T C)$ & Total Carbon $\left(C_{A G}+C_{B G R}+C_{B G S}\right)$ & 6,753 & 7,756 & 7,144 & 167 & 990,724 & 100 \\
\hline
\end{tabular}

Note: a: The values will not add up because of rounding up of components in ArcMap. 


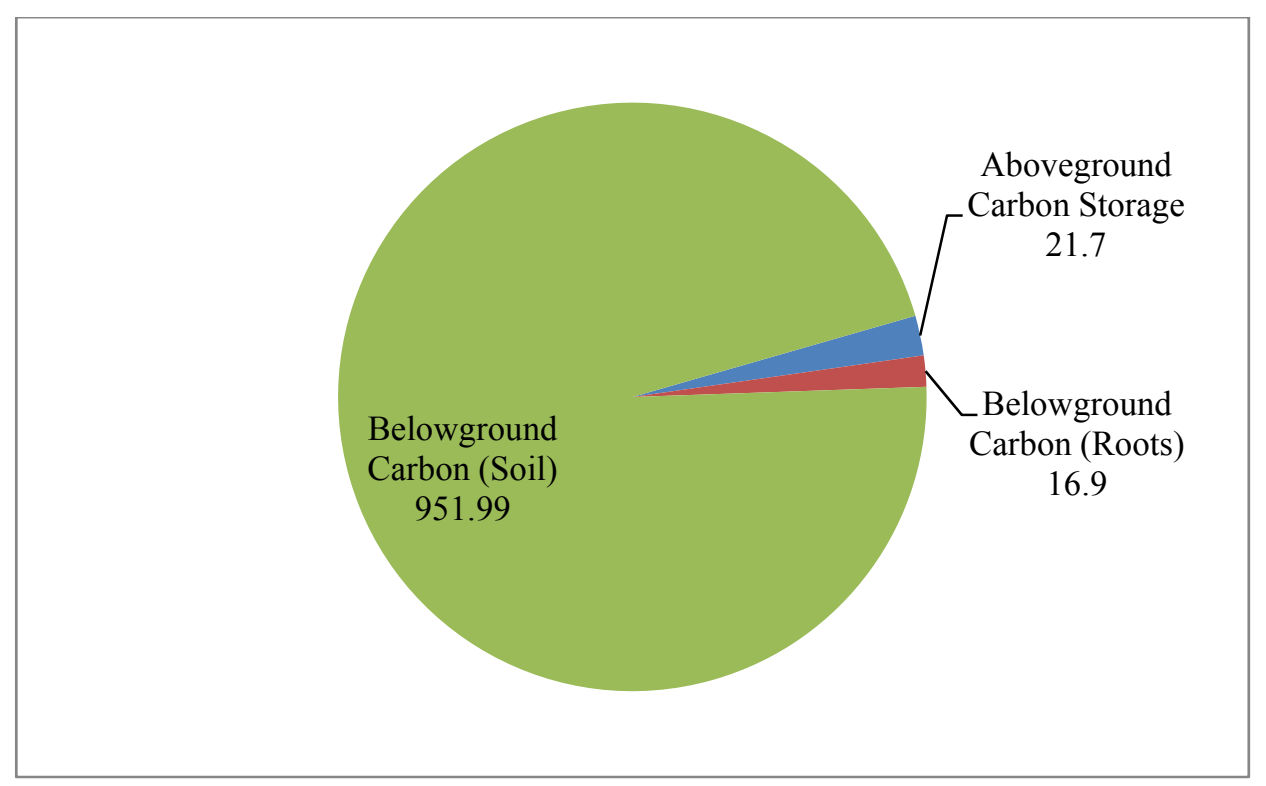

Figure 4.7: Carbon Storage (million $\mathrm{Mg} \mathrm{C}$ ) in the Different Forest Components of ENP Mangroves

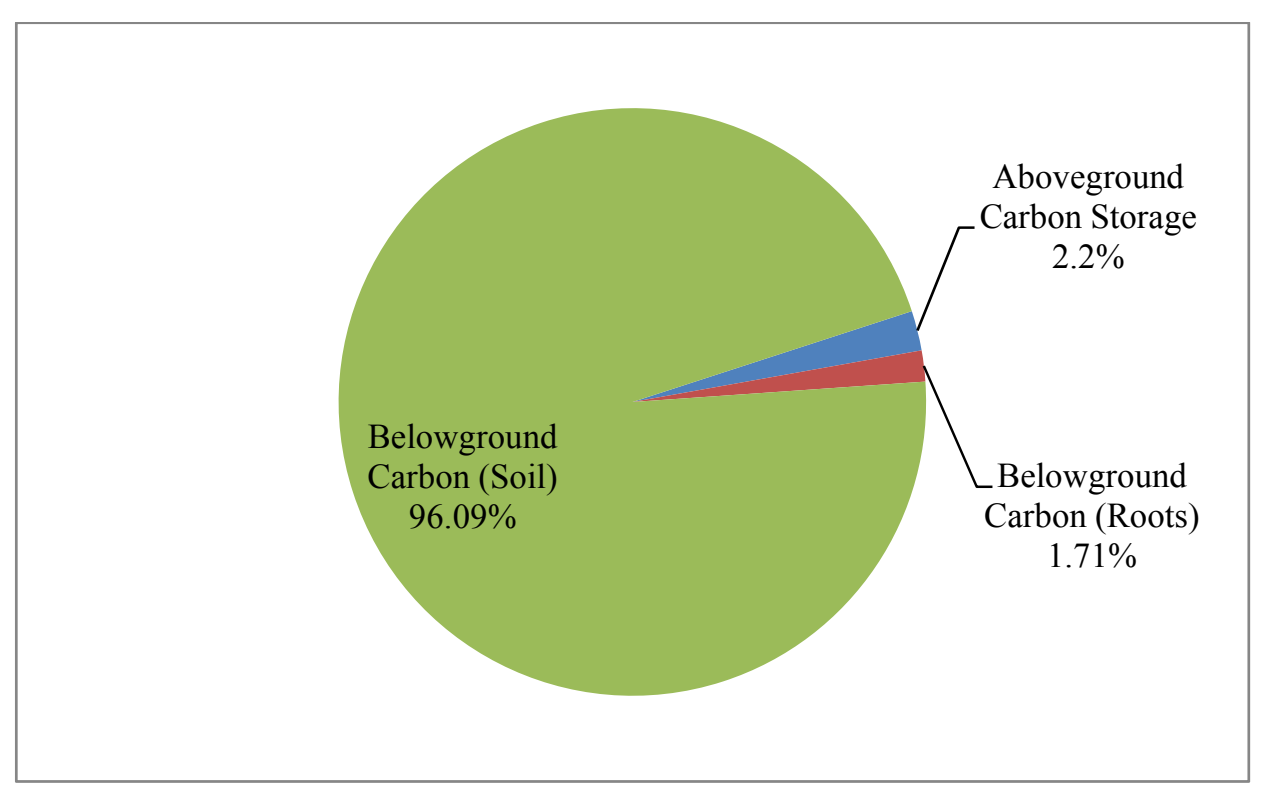

Figure 4.8: Quantity of Carbon Storage in Different Forest Components as a Percentage of Total Carbon Storage (990,724 million $\mathrm{Mg} \mathrm{C}$ ) in ENP mangroves 
4.1.7 Comparison of Carbon Stock in ENP Mangroves with Terrestrial Ecosystems and Mangroves in the Indo-Pacific

The carbon stock density in tropical, boreal and temperate forests is reported as $242 \mathrm{Mg}$ $\mathrm{C} / \mathrm{ha}, 239 \mathrm{Mg} \mathrm{C} / \mathrm{ha}$ and $155 \mathrm{Mg} \mathrm{C} /$ ha respectively (Pan et al., 2011). Donato et al. (2011) estimated that the carbon storage in the mangrove forests of the Indo-Pacific region contain on average $1023 \mathrm{Mg} \mathrm{C} / \mathrm{ha}$. This study estimated the total carbon storage by measuring the aboveground biomass, the biomass of fine roots, and soil carbon content in the ENP mangroves. The data indicate that the ENP mangroves contain an average of 7,144 Mg C/ha. Thus, the ENP mangroves contain significantly higher carbon stock than terrestrial ecosystems. The carbon stock in ENP mangroves is 7 times higher than the carbon storage estimated for the Indo-Pacific mangroves (Table 4.3).

The ENP mangroves store approximately $4 \%$ of the total carbon in the biomass and $96 \%$ of the total carbon in soil. The carbon in the soil of the Indo-Pacific mangroves was recorded at $71-98 \%$ and $49-90 \%$ of the total storage for estuarine and oceanic sites, respectively (Donato et al., 2011) Tropical forests store $56 \% \mathrm{C}$ in biomass and $32 \%$ in soil, and boreal forests store $20 \%$ in biomass and 60\% in soil (Pan et al., 2011). 
Table 4.3 Comparison of Carbon Storage across Different Ecosystems

\begin{tabular}{|c|c|c|c|c|}
\hline Ecosystem & $\begin{array}{l}\text { Mean Estimate of } \\
\mathrm{C} \text { per hectare (Mg } \\
\mathrm{C} / \mathrm{ha})\end{array}$ & Source & $\begin{array}{l}\% \text { of total } \mathrm{C} \text { present } \\
\text { in Biomass }\end{array}$ & $\begin{array}{l}\% \text { of total C } \\
\text { present in Soil }\end{array}$ \\
\hline Tropical & 242 & Pan et al., 2011 & 56 & 32 \\
\hline Temperate & 155 & Pan et al., 2011 & \multicolumn{2}{|c|}{ Data not available } \\
\hline Boreal & 239 & Pan et al., 2011 & 20 & 60 \\
\hline \multirow[t]{2}{*}{$\begin{array}{l}\text { Indo-Pacific } \\
\text { Mangroves }\end{array}$} & 1023 & Donato et al., & $\begin{array}{l}71-98 \% \text { in } \\
\text { estuarine }\end{array}$ & \\
\hline & & 2011 & $\begin{array}{l}\text { mangroves; } 49- \\
90 \% \text { in oceanic } \\
\text { mangroves }^{\mathrm{a}}\end{array}$ & \\
\hline ENP Mangroves & 7144 & This study & 96 & 4 \\
\hline
\end{tabular}

Note: a: the percentage of total C storage in the Indo-Pacific mangroves represents the C in soil as well as roots

\subsection{Comparative Analysis of Carbon Prices across Valuation Methodologies}

The purpose of the comparative analysis of carbon prices across and within valuation methodologies was done to depict the variation in price estimates and understand how different factors affect the final estimates for social and marginal costs, and market price of carbon. 


\subsubsection{Social Costs of Carbon}

The vast numbers of social costs of carbon (SCC) estimates seen in the literature, as analyzed by Tol (2011), are based on the few studies done on total damage cost studies of climate change. The variation is derived from the assumptions made in different SCC studies about the discount rate used to estimate future costs and benefits. A higher discount rate implies that the cost of climate change incurred in the future has a lower present value. For example, the sample mean estimate for SCC in the meta-analysis by Tol (2011) for 3\% rate of time preference was $\$ 19 / \mathrm{tC}$ and $\$ 276 / \mathrm{tC}$ for studies which used a $0 \%$ rate of time preference. The discount rate depends on the pure rate of time preference, the growth rate of per capita consumption, and the elasticity of marginal utility of consumption (Tol, 2009). Calculations of SCC also differ on the basis of projected estimates of $\mathrm{CO}_{2}$ emissions, rate of global warming, population and economic scenarios assumed for the future.

The mean of all estimates of SCC from Tol's (2011) meta-analysis includes the estimates in the gray literature, making it much higher than the mean of SCC for peer reviewed literature. The gray literature tends to support extreme scenarios for climate change in their SCC estimates. Two estimates by the Integrated Assessment Model (IAM), CASES, are chosen. The SCC estimate used by Ding et al. (2010) (\$133/tC), has a lower discount rate than the one used by Chiabai et al. (2007) $(\$ 10 / \mathrm{tC})$. The average of SCC estimates published by Nordhaus is lower than most other authors, including Tol's, indicating that the costs of climate change may not be as high as estimated by others (Figure 4.9). 
As can be seen in Figure 4.9, the estimates for social costs of carbon range from $\$ 10 / \mathrm{tC}$ to $\$ 177 / \mathrm{tC}$. For the final valuation of carbon storage in ENP mangroves, four of these SCC estimates were selected. The mean estimate for SCC, $\$ 177 / \mathrm{tC}$, from all peer reviewed literature analyzed by Tol (2011) is considered appropriate for the valuation of C storage in ENP mangroves as it represents the credible and qualified estimates among the scientific community. In addition, two mean estimates, $\$ 35 / \mathrm{tC}$ and $\$ 59 / \mathrm{tC}$, from the work of two different scientists Nordhaus and Tol, respectively, both of whom represent two different streams of thought in the scientific community are included. For the valuation of carbon stored in a forest in the United States, as in the present study, it was considered appropriate to use the SCC estimate of the United States Government's Interagency Report of $\$ 86 / \mathrm{tC}$ as the fourth estimate. In particular, the absence of longterm and stable carbon markets in the country makes it fitting to use the SCC estimate that the U.S. Government recommends for regulatory impact analysis. 


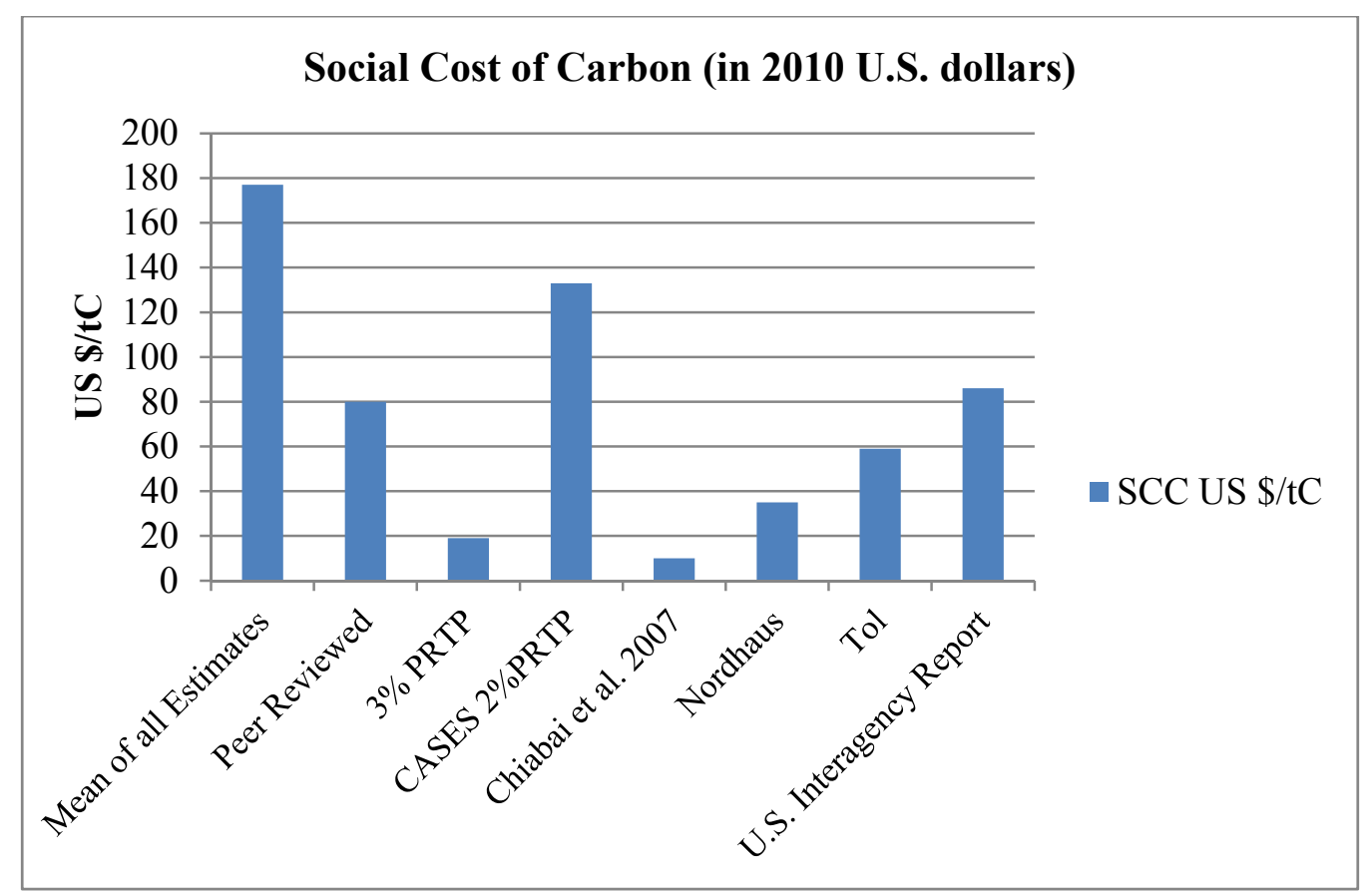

Figure 4.9: Comparison of Social Costs of Carbon

\subsubsection{Marginal Abatement Costs}

Variations observed in marginal abatement costs result from the level of stabilization target used, choice of control variable ( $\mathrm{CO}_{2}$ versus multigas) and assumptions based on future technologies employed (Kuik et al., 2008). MACs increase as the level of emission targets decrease. The MACs derived from meta-analytical studies included in the comparison range from $\$ 103$ - $\$ 233 / \mathrm{tC}$ and are based on ambitious abatement goals (Figure 4.10). Estimates for marginal abatement costs are much higher than social costs of carbon and are hence not used for the final estimates to calculate the change in economic value of C storage in ENP mangroves in section 4.5. 


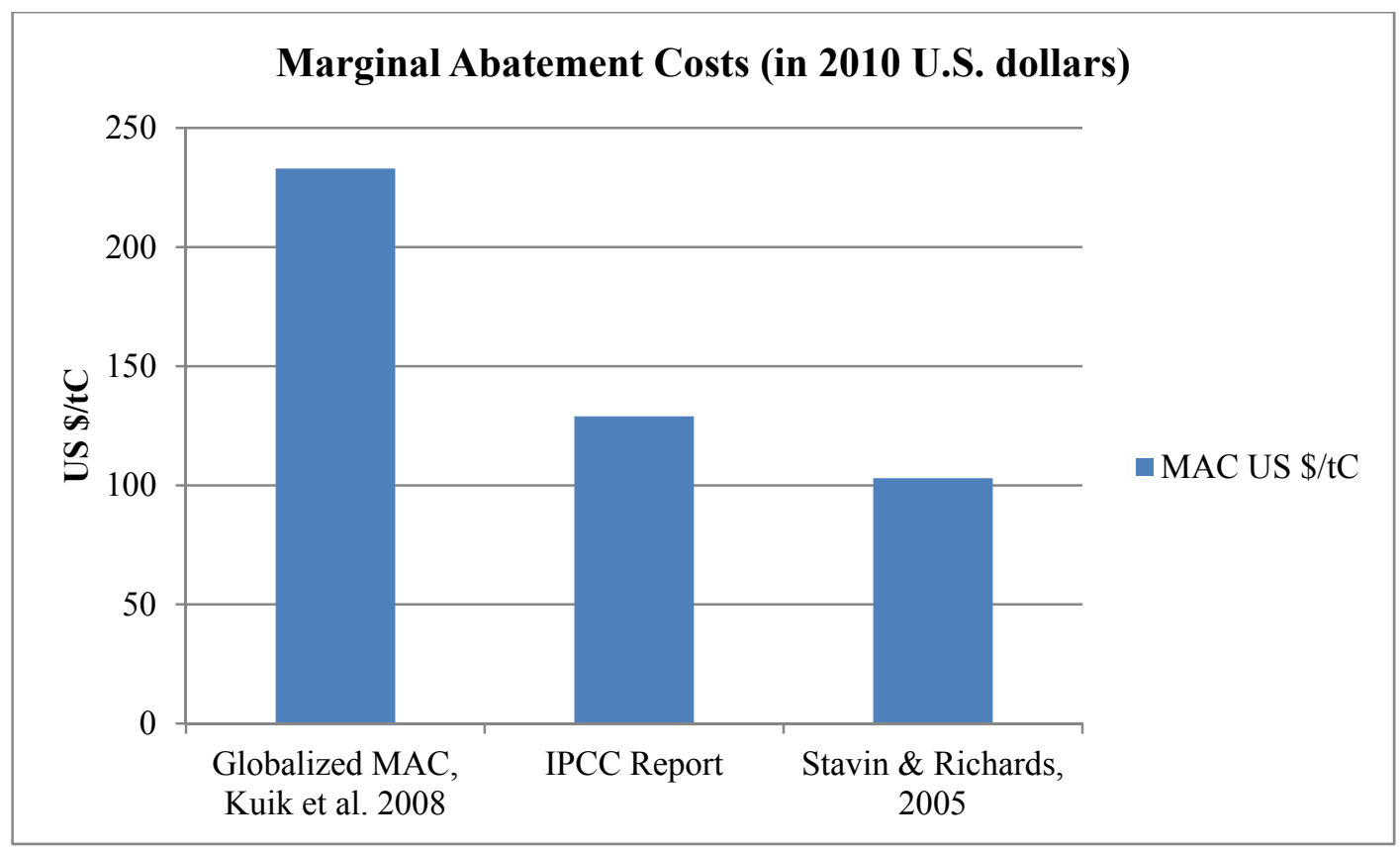

Figure 4.10: Comparison of Marginal Abatement Costs

\subsubsection{Market Prices}

As discussed in Chapter 2, market prices for regulatory markets like the European Union's Emission Trading System are higher than voluntary markets like REDD and voluntary carbon markets as a result of high demand and stricter standards for verification (Figure 4.11). The carbon price from European markets is strong but may not be appropriate to use for valuing the carbon storage of forests in a different region such as the United States. Carbon price from REDD markets are applicable for payment of ecosystem services in developing countries. To estimate the value of $\mathrm{C}$ storage in ENP mangroves, it is considered appropriate to use the market price from RGGI as it is a U.S. based carbon market, relevant to the study area and the most conservative estimate among other markets. 


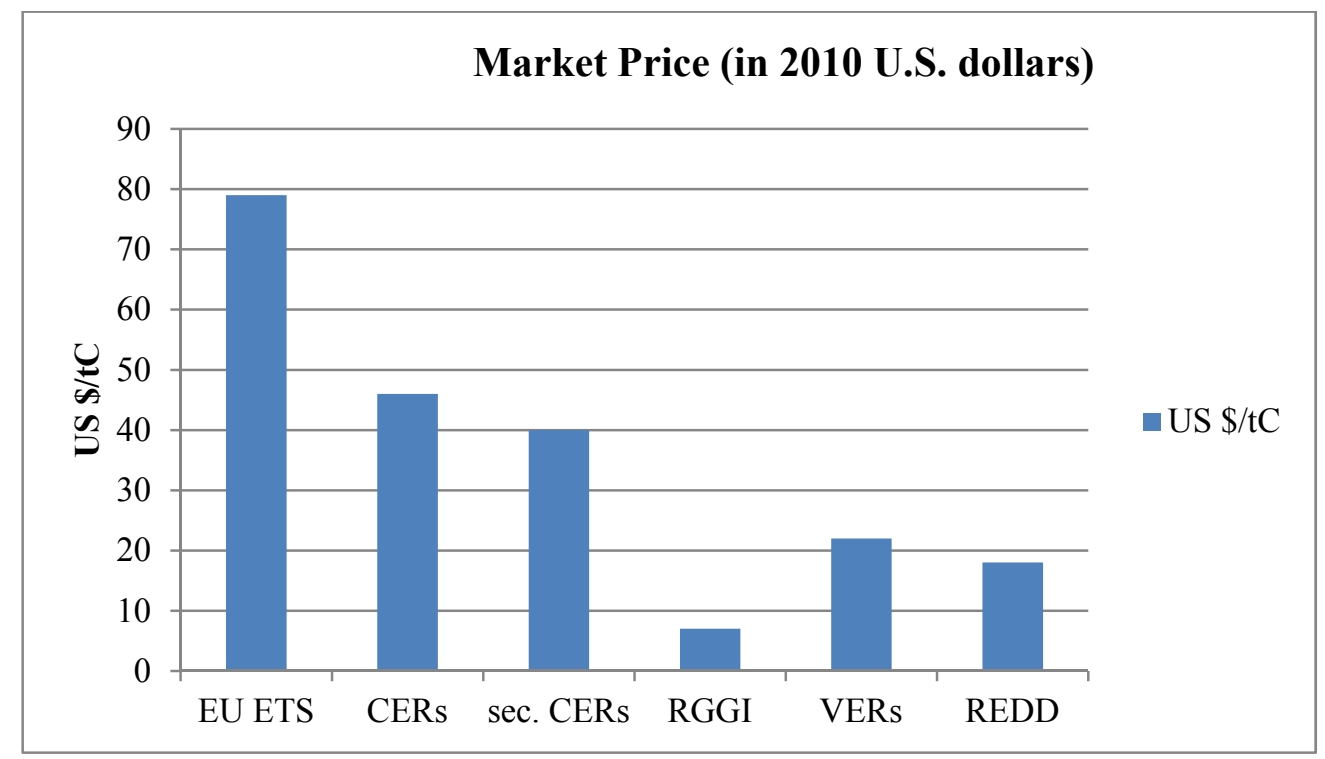

Figure 4.11: Comparison of Market Prices

4.2.4 Discussion on Comparative Analysis of Carbon Prices based on different Valuation Methodologies

The comparative analysis of carbon prices based on the three different valuation methodologies discussed indicates that there is no single carbon price (Figures 4.9, 4.10 and 4.11). Carbon prices also vary across countries and markets with several technological, regulatory, economic, and social factors influencing them.

As discussed in Chapter 2, the market price is the value of traded carbon emission rights, the SCC is the cost of the damage imposed by the incremental increase in carbon emissions, and MACs represent the costs of reducing emissions. In an ideal world, SCC and MACs should be the same at the margin but are not so in real world conditions. 
There are several reasons for the differences in carbon prices across and within valuation methodologies.

(1) Market prices and SCCs are generated by valuation methodologies like the market price method and damage cost methods which along with the stated valuation approach reflect the demand or maximum WTP of consumers for carbon sequestration service. The market price of carbon and SCC represent the marginal benefits or the consumer price (WTP) for carbon. The market prices for carbon range from $\$ 7 / \mathrm{tC}$ (RGGI) to $\$ 79 / \mathrm{tC}$ (EU ETS). The social costs of carbon range from $\$$ $10 / \mathrm{tC}$ to $\$ 177 / \mathrm{tC}$ (Figure 4.9). On the supply side, the producers' cost for carbon sequestration is estimated by the damage avoidance approach which generates marginal abatement costs (MACs). Marginal abatement costs vary from $\$ 103 / \mathrm{tC}$ to $\$ 233 / \mathrm{tC}$ (Figure 4.10).

The demand-side methodologies reflect different values for $\mathrm{C}$ prices than the supplyside methodologies. Given the elasticities of supply and demand, the calculations of benefits and costs are replete with uncertainties (Dietz \& Fankhauser, 2009) resulting in different prices for carbon. The market price of the long-term regulatory market as the EU ETS $(\$ 79 / \mathrm{tC})$, the marginal benefits from the peer reviewed SCC estimates $(\$ 80 / \mathrm{tC})$ and the U.S. Interagency Report $(\$ 86 / \mathrm{tC})$, all demand-side carbon prices, lie in the same ballpark. The prices based on the supply-side of the market or MACs (meta-analytical estimates: $\$ 129 / \mathrm{tC}$ and $\$ 233 / \mathrm{tC}$, Figure 4.10) are higher than the demand-side carbon prices. This indicates that the consumers participating in the 
carbon market are currently not in the position or are not willing to pay a full price for carbon required to supply the benefits of carbon sequestration.

(2) Social costs of carbon $(\$ 10 / \mathrm{tC}-\$ 177 / \mathrm{tC}$, Fig. 4.9) and marginal abatement costs ( $\$ 103 / \mathrm{tC}-\$ 233 / \mathrm{tC}$, Fig. 4.10) estimate carbon prices in the context of climate change effects on ecosystems, which are often derived by using Integrated Assessment Models (IAMs). These models use economic tools and mathematical modeling to combine scientific knowledge on climate change with socio-economic aspects of economic growth under possible climate change scenarios. The presence of uncertainties regarding key parameters of climate change models and the kind of model used to estimate carbon prices contribute vastly to the conundrum. The complexity and non-linearity of ecosystem services and functions complicate the process of modeling. Ecosystems are open systems even as their functions are constrained by the laws of thermodynamics. Several assumptions have to be made during the modeling for analytical purposes making it difficult for the models to arrive at stable estimates for carbon price. However, IAMs provide valuable insights into the uncertainties related to benefits and costs and therefore assist in giving direction to areas where further research is needed.

(3) Calculations of SCC are based on what kind of environmental damages will occur in the future and on the nature of climate change. As the evidence base for both climate change and related environmental damages is meager, the range of estimates of SCC in published literature $\left[\$ 35 / \mathrm{tC}\right.$ at the $33^{\text {rd }}$ percentile and $\$ 669 / \mathrm{tC}$ at the $95^{\text {th }}$ percentile, in Tol's (2011) meta-analysis] is very broad and it consequently weakens estimates of SCC. The broad range represents the costs of risk bearing (with respect to the 
economy and human well-being) and is largely influenced by the value judgments on risk aversion (Dietz \& Fankhauser, 2009). The non-linearity and complexity of climate science, how it is affected by greenhouse gas emission and to what extent and how the environment will be consequently affected by global climate change makes the SCC estimates tentative at best. The difficulty in interpretation of environmental damages in economic terms adds to the conundrum. However, marginal benefits gained by reducing emissions by one ton reflected in the form of social costs are extremely useful as they guide incremental contributions that countries can make to address the problem of climate change (Tol, 2011).

There is a certain amount of uncertainty, albeit lower than SCC, associated with MACs wherein assumptions are made regarding the technological changes for abatement in the future.

(4) The logical question that arises is why prices for carbon are relatively low in the current fledgling carbon markets. Voluntary markets command the lowest range of carbon prices $(\$ 7-22 / \mathrm{tC})$ and regulatory markets price are priced slightly higher $(\$ 40-79 / \mathrm{tC})$. The market price for carbon varies substantially between markets, especially between European markets, US markets and voluntary markets such as REDD. The European market prices $(\$ 79 / \mathrm{tC})$ are higher due to the mandatory nature of the market. The carbon emission reductions or carbon sequestration projects that qualify for acceptance in the EU ETS are highly regulated and subject to stringent verification requirements. However, the carbon credits generated out of the voluntary market may not have similar verification requirements. In the case of United States carbon markets are mostly voluntary in nature and confined to certain regions. They 
lack the regulatory structure and magnitude of the European carbon markets. As a result the price for carbon generated in US carbon markets (e.g., RGGI) is much lower and may not adequately reflect the true price of carbon.

\subsubsection{Economic, Political and Social Criteria for Valuation of Mangroves}

Based on the discussion above, it is useful to develop a simple set of economic, political and social criteria based on the stage of policy cycle a country is currently in. The criteria can act as a guide to setting the appropriate $\mathrm{C}$ price to value mangrove forests in general and the mangrove forest ecosystem in south Florida in particular.

In the absence of a strong network of carbon markets in a country such as the United States, the price of carbon for ENP mangroves can be determined by estimating the costs or impacts of mangrove degradation to the region as well as the country. In this context, damage costs that calculate total effects of climate change can be used to derive social costs of carbon based on the discount rate appropriate to policy requirements. The SCC calculated by the United States Government represents the WTP of the society to avoid future damage to the ENP mangrove forest by alterations in water inflow from upstream sources and sea level rise caused by global warming. It is therefore useful to use the SCC estimated by the U.S. Government to value the carbon stored within the ENP mangroves.

Alternatively, the cost of restoring ENP mangroves can be calculated so as to maintain their resilience towards the impacts of press and pulse events that they are subjected to. Marginal abatement costs are opportunity costs that may be incurred in the future upon the loss of mangrove forest area in the Florida Coastal Everglades. Estimated costs could 
involve replacing the sequestration service provided by this natural $\mathrm{C}$ sink with forestbased sequestration at large scale level throughout the country (as seen in the Stavins \& Richards, 2005 report), and/or use of less carbon intensive technology by the society. When a regulatory carbon market is first established in a country, MACs are used to derive the preliminary carbon abatement price or carbon permit price. The carbon permit price represents the price of eliminating each ton of carbon emission from the atmosphere.

The low market prices for carbon in current U.S. markets reflect the disparity between targets to conserve natural $\mathrm{C}$ sinks such as the ENP mangroves and the individual WTP. Currently, the RGGI is the only functional market at present in the U.S. and has a relatively low price of $\$ 7 / \mathrm{tC}$. The $\mathrm{C}$ price in markets outside the country ranges from $\$ 18 / \mathrm{tC}-\$ 79 / \mathrm{tC}$. For the purpose of a conservative estimate for valuing the carbon storage in ENP mangroves, the final estimates for this study used the RGGI pricing for carbon. Carbon markets are likely to grow nationally and internationally in the next few decades leading to strong and stable prices. Until then, the carbon price observed in countries which presently lack well-established carbon markets such as the United States may be unsuitable for policy purpose. Such carbon prices may, however, provide a benchmark for the possible price of carbon.

Finally, stated valuation methodologies can assist in the valuation of a public good such as carbon sequestration by ENP mangroves. Currently this study found no public surveys based on stated valuation methodology in south Florida (or in the country) that can measure the public's awareness about the importance of C storage by the ENP mangrove 
forests and willingness to pay for such a service. The WTP of individuals in this region can be evaluated by multiple surveys to measure people's WTP for the sequestration service provided by the ENP mangroves in the absence of carbon markets. Such WTP can be useful information for policy development, appraisal or if required, the establishment of carbon tax.

The political scenario in the United States and in Florida has not allowed for the setting of a single price for carbon in the country or state. This is a result of lack of public will to account for carbon in the national accounting system. There is indeed a certain lack of awareness and recognition of the importance of $\mathrm{C}$ storage in natural sinks in the society. A synergistic play of society's recognition for the need to mitigate harmful effects of climate change along with technological changes and a tangible change in behavioral patterns are required to advance the policy cycle in this region. The politics of climate change has played an important role in slowing down the process. Because of the absence of a strong public and political will to set the price for carbon in the region, this study uses the conservative price reflected in RGGI to value the $\mathrm{C}$ storage in ENP mangroves. 
Table 4.4: Criteria for Valuation of ENP Mangroves

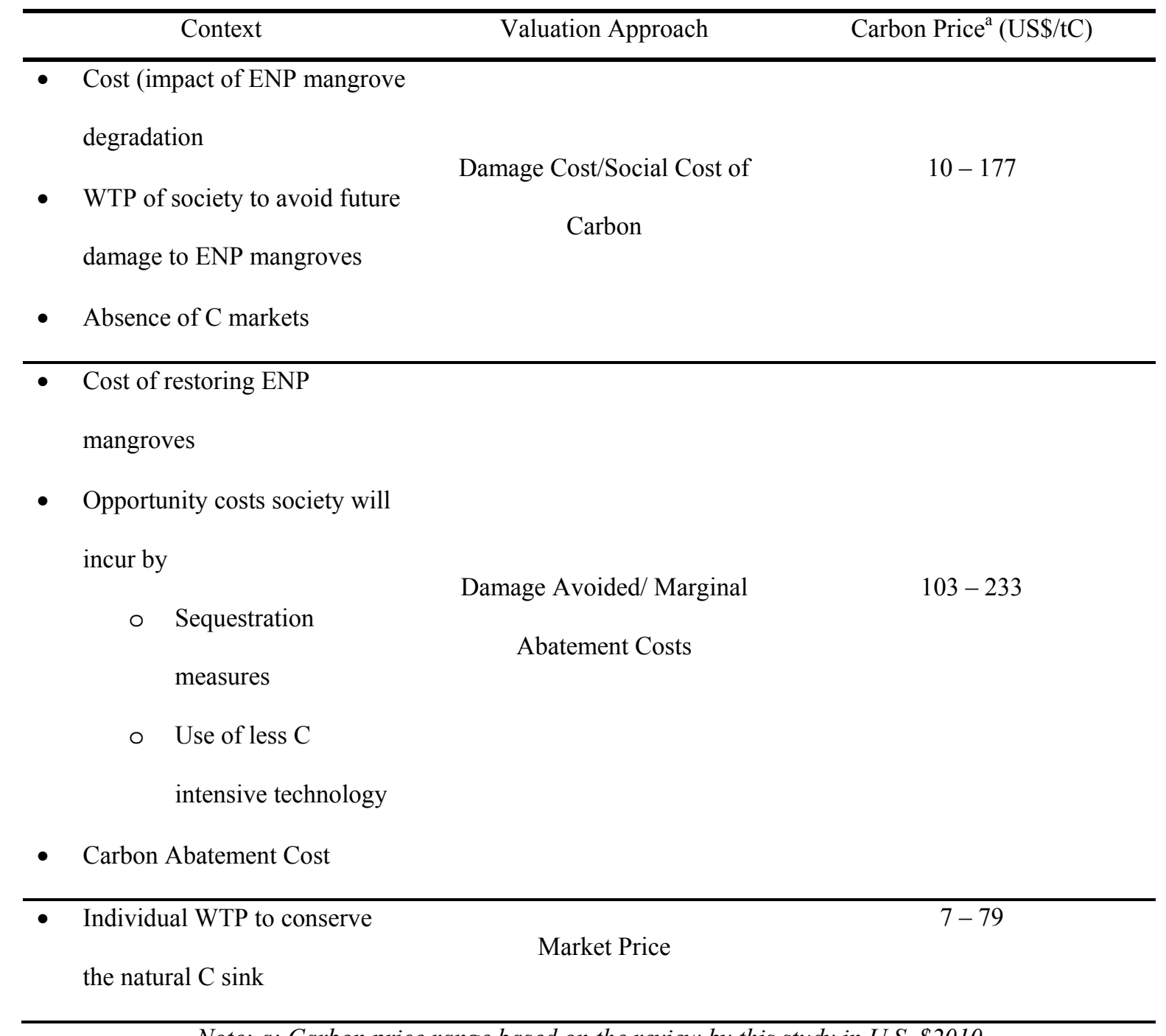

Note: a: Carbon price range based on the review by this study in U.S. \$2010

\subsubsection{Biological Criteria for Valuation of Mangroves}

In addition to the political, social and economic reasons for carbon price variance discussed above, there are several biological reasons that might influence the carbon price. When setting the price for carbon sequestered and stored in mangroves, it will also be appropriate to pay attention to the following factors: 
(1) The geological age of the forest: A mature and intact mangrove forest has more interconnectivity, functional redundancy and offers a variety of ecosystem services in comparison to younger, single species plantations. An older forest has a higher monetary value (Nickelson, 1999 as cited in Alongi, 2011) and hence should be valued using relevant methodology. In the case of mangrove plantations, carbon payments are made using net sequestration rates within the framework for REDD+ or payments for ecosystem services (PES). In the case of mature, older forests like the mangroves of ENP, payments made for sequestration rates as well as the geological carbon stored may be appropriate. Therefore, market prices alone may be insufficient to value the significant $\mathrm{C}$ storage of forests such as the ENP mangroves.

(2) Variability in ecosystem functions and services: The sequestration abilities of mangroves are non-linear and vary with time and space as discussed in chapter 2. Carbon payments have to take into account the variable nature of this dynamic ecosystem. This indicates that regular documentation of $\mathrm{C}$ storage in mangroves is essential to monitor the changes in the $\mathrm{C}$ pool in light of the several pulse and press events that affect them.

(3) Status of the forest as a protected area: Protected areas are designated for the main purpose of conservation of biodiversity but they also regulate climate through carbon storage (Campbell et al., 2008). As a result of limited or no extractive uses, forests in protected areas become significant sinks of carbon. Accounting for carbon stocks in a nation's protected areas is recommended for payment for these existing sinks of carbon based on opportunity costs. The valuation of carbon sequestration and storage services in protected areas depends on the magnitude of carbon stored, the level of management and 
enforcement of a protected mangrove forest, amount of resource use permitted, the governance and land use change pressures determine the capability of the system to store carbon (Campbell et al., 2008). The mangrove forests in Everglades National Park, Florida have not been subjected to extractive uses for several decades in the recent past.

The magnitude of carbon stored in forests such as the ENP mangroves is significant as proved by the findings of this study (section 4.1). The $\mathrm{C}$ storage in ENP mangroves is highly significant in comparison to the neotropical mangrove forests in developing countries in the Americas that face constant pressures of human activities despite being designated as protected. Protected areas that lie in more restrictive IUCN management category (e.g. categories I-II) are more effective in reducing deforestation (Clarke et al. 2008). However, protected areas too face the problem of leakage wherein deforestation within their boundaries is avoided but pressures of deforestation are displaced elsewhere.

Keeping all these factors in mind, the study first provided a range of economic values to the ENP mangroves using all the valuation methodologies discussed (Figures 4.9, 4.10 and 4.11). The range of values can be useful in decision making and for consideration in different policy scenarios.

For the final valuation, two carbon prices are chosen to value the C storage in ENP mangroves. Based on the social, economic and political situation in the United States, this study considered it appropriate to use the most conservative market price in the country, the RGGI market price, to value the C storage in ENP mangroves. However, because of the biological nature of the forest and the level of conservation and protection accorded to these mangrove forests as part of the Everglades National Park, it is considered 
appropriate to use the SCC derived from the U.S. Interagency Report (2010) to value the C storage. Thus, the carbon price based on the market price (RGGI) provided the lowerbound price for carbon and the C price based on U.S. Government's SCC provided the upper-bound price for carbon to value C storage of ENP mangroves (Table 4.5).

Table 4.5: Monetary Valuation for Carbon Storage in ENP Mangroves

\begin{tabular}{lcl}
\hline & Carbon Price $(\$ / \mathrm{tC})$ & Source \\
\hline $\begin{array}{l}\text { Market Price (lower- } \\
\text { bound) }\end{array}$ & 7 & RGGI \\
$\begin{array}{l}\text { SCC } \\
\text { (upper-bound) }\end{array}$ & 86 & U.S. Interagency Report \\
& & \\
\hline
\end{tabular}

In section 4.6, the estimation of the marginal value of carbon sequestration in the ENP mangroves in response to the significant hydrological disturbance in the form of sea level rise, was performed using the current and projected RGGI market price and SCC relevant to the study area (Table 3.10).

\subsection{Economic Valuation of the Carbon Stored in the Mangrove Forests of Everglades National Park, Florida}

Following the method explained in section 3.7, the total value of carbon stored in ENP mangroves and the value of carbon per hectare in the ENP mangroves was calculated for each valuation methodology. Estimates of social costs of carbon, marginal abatement costs and the different market prices were used to calculate the value of the carbon stored in ENP mangroves (Table 4.6). Marginal abatement costs yield the highest estimates for 
economic value of carbon stored in ENP mangroves ranging from US $\$ 69,351$ to \$202,108 million (mean value: \$131,767 million). Using the social cost of carbon estimates, the economic value of carbon stored within the mangrove forest ecosystem in Everglades National Park ranges from US $\$ 34,675$ to $\$ 85,202$ million (mean value: $\$ 64,397$ million). According to the market prices (regulatory and voluntary markets) the economic value of the total carbon in mangrove ecosystem of ENP ranges from $\$ 6,935$ to $\$ 78,267$ million (mean value: $\$ 35,006$ million). The average value of carbon per area hectare of ENP mangroves is $\$ 950,152$ for marginal abatements costs, $\$ 464,360$ for social cost of carbon and $\$ 252,421$ according to market prices. A comparison of the total economic value of carbon storage in the ENP mangroves across valuation methodologies is depicted in Figure 4.12. 
Table 4.6: Economic Valuation of Total Carbon (TC) Storage in the Mangrove Forests of the Everglades National Park, Florida

\begin{tabular}{|c|c|c|c|c|c|c|}
\hline $\begin{array}{l}\text { Valuation } \\
\text { Methodology }\end{array}$ & Examples & $\begin{array}{l}\text { Cost of } \\
\text { Carbon } \\
(\$ / \mathrm{tC})\end{array}$ & $\begin{array}{l}\text { Total Value of C } \\
\text { in ENP mangrove } \\
\text { forests (million } \$ \text { ) }\end{array}$ & $\begin{array}{l}\text { Mean } \\
\text { estimate } \\
(\text { million } \$)\end{array}$ & $\begin{array}{l}\text { Value of ENP mangroves per ha } \\
\text { (thousand } \$ / \text { ha) }\end{array}$ & $\begin{array}{l}\text { Mean estimate } \\
\text { (thousand } \$ / \mathrm{ha} \text { ) }\end{array}$ \\
\hline \multirow{4}{*}{$\begin{array}{l}\text { Social Cost of } \\
\text { Carbon }\end{array}$} & Peer Reviewed & 80 & 79,258 & 64,397 & 572 & 464 \\
\hline & US Interagency Report & 86 & 85,202 & & 614 & \\
\hline & Tol & 59 & 58,453 & & 421 & \\
\hline & Nordhaus & 35 & 34,675 & & 250 & \\
\hline \multirow{5}{*}{$\begin{array}{l}\text { Marginal } \\
\text { Abatement } \\
\text { Cost }\end{array}$} & Globalized MAC & 204 & 202,108 & 131,767 & 1,457 & 950 \\
\hline & Fisher \& Nakicenovic & 125 & 123,841 & & 893 & \\
\hline & et al. 2007 & & & & & \\
\hline & Stavins \& Richards, & 70 & 69,351 & & 500 & \\
\hline & 2005 & & & & & \\
\hline \multirow[t]{5}{*}{ Market Prices } & EU ETS & 79 & 78,267 & 35,006 & 564 & 252 \\
\hline & CERs & 46 & 45,573 & & 329 & \\
\hline & sec CERs & 40 & 39,629 & & 286 & \\
\hline & RGGI & 7 & 6,935 & & 50 & \\
\hline & VERs & 22 & 21,796 & & 157 & \\
\hline
\end{tabular}


Notes: (i) Total Carbon in ENP mangroves (TC): 990,724,732 Mg C (Mg C=tC); (ii) Amount of carbon per hectare in ENP mangroves: 7144 Mg C/ha; (iii) ENP mangrove forest area: 144,447 ha; a: Mean estimate of 311 peer reviewed publications(Tol, 2011); $b$ : SCC for Regulatory Impact Analysis, US

Government; c: Tol, 2011; d: (Kuik et al. 2008); e: Fisher \& Nakicenovic et al. 2007; f: Stavins \& Richards, 2005; g: All market prices are average prices for 2010; $h$ : European Union's Emission Trading System; i: Certified Emission Reductions of the Clean Development Mechanism; $j$ : C prices from Regional Greenhouse Gas Initiative; $k$ : Voluntary Emission Reduction units; l: Reducing Emissions for Deforestation and Degradation 


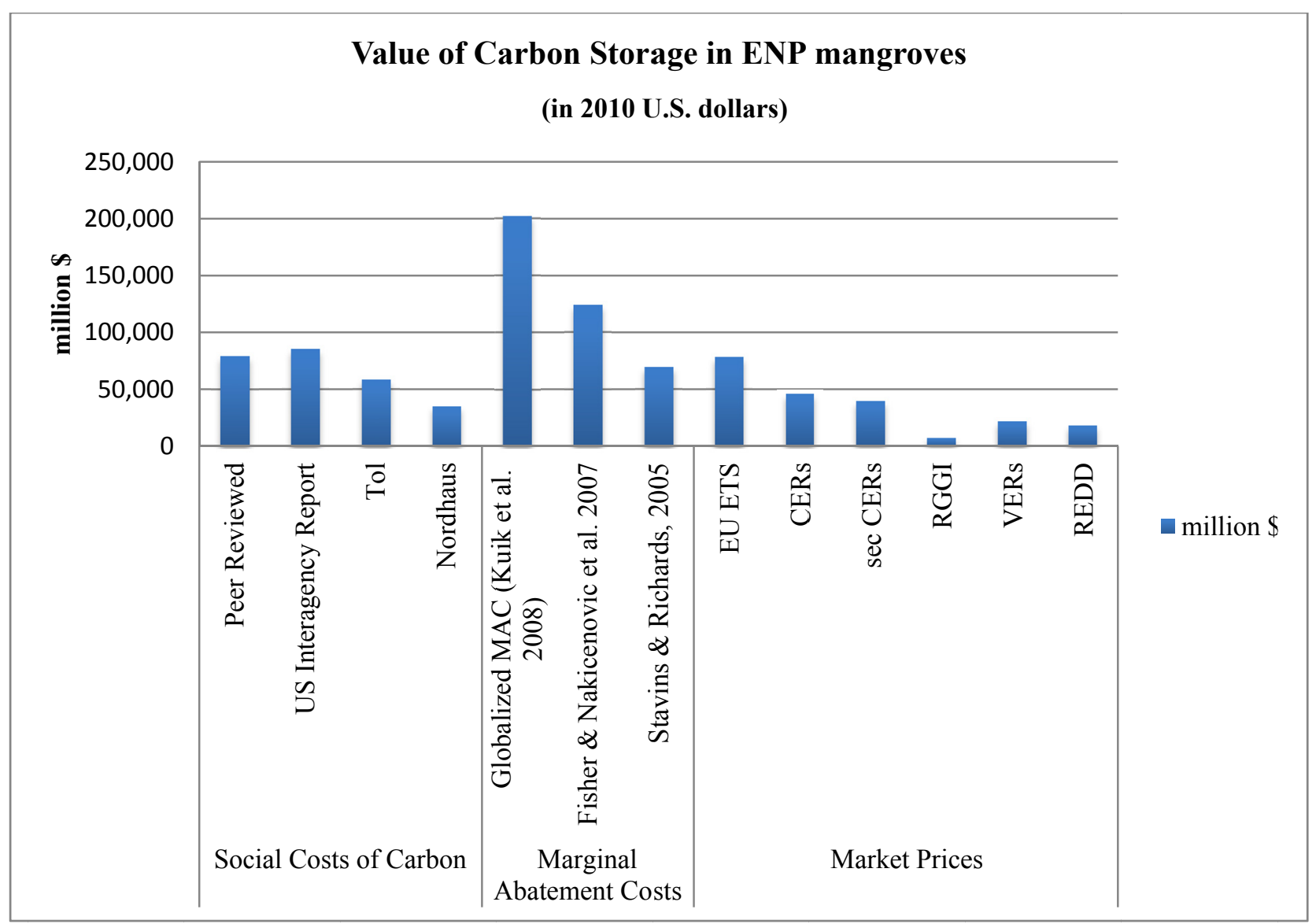

Figure 4.12: Comparison of the Total Economic Value of Carbon Storage across Valuation Methodologies in the Mangrove Forests of the Everglades Nation Park, Florida

\subsection{Estimation of Total Carbon Sequestered in the Zone of Mangrove Transgression as a result of Sea Level Rise by the year 2100}

As discussed in Chapter 3, section 3.8, it was assumed that sea level rise by the year 2100 , can lead to mangrove transgression into fresh water ecosystems upland, resulting in change in the carbon stock of ENP mangroves. The baseline year was assumed as the year 2010. Three scenarios of sea level rise based on IPCC projections were assumed. In Scenario I, it was assumed that sea level will rise up to $0.2 \mathrm{~m}$ by 2100 , and the carbon 
sequestered in the zone of mangrove transgression is calculated using equation (3.4). The assumption of landward transgression of ENP mangroves was based on the projection of the integrated landscape ecosystem model SELA-MANGRO (Doyle, 2003, USGS Fact Sheet FS-030-03).

According to the methodology described in section 3.8.1, the carbon stock in the zone of mangrove transgression in Scenario I increased by $9,567 \mathrm{Mg} \mathrm{C}$ in 2050 and by 47,775 $\mathrm{Mg} \mathrm{C}$ in 2100 (baseline year is 2010). The total carbon stock in ENP mangroves in 2050 and 2100 was calculated as a sum of total C (TC) currently present in the forest (Table 4.2) and the $\mathrm{C}$ sequestered by mangrove migration in scenario I (Equation 3.4). Therefore under Scenario I, the total carbon stock in the entire mangrove forest of ENP including the zone of transgression was estimated to be $990,734,299 \mathrm{Mg} \mathrm{C}$ in 2050 and $990,772,507 \mathrm{Mg} \mathrm{C}$ in 2100.

In Scenario II, sea level rise of $0.38 \mathrm{~m}$ was assumed for the year 2100 , and the carbon sequestered in the zone of mangrove transgression was estimated in a method similar to Scenario I. The carbon stock in the zone of mangrove transgression in Scenario II in the next 90 years was estimated using Equation 3.4 and was calculated to be $17,220 \mathrm{Mg} \mathrm{C}$ for 2050 and 85,995 Mg C for 2100. Consequently, the total carbon stock in ENP mangroves in 2050 and 2100 was calculated as a sum of total C currently present in the forest (Table 4.2) and the C sequestered by mangrove migration in Scenario II (Equation 3.4).

Therefore under Scenario II, the total carbon stock in the entire mangrove forest of ENP including the zone of transgression was estimated as $990,741,952 \mathrm{Mg} \mathrm{C}$ for 2050 and $990,810,727 \mathrm{Mg} \mathrm{C}$ for 2100. 
In Scenario III, sea level rise of $0.56 \mathrm{~m}$ was assumed for the year 2100 , and the carbon sequestered in the zone of mangrove transgression was calculated in a method similar to Scenario I and II. The carbon stock in the zone of mangrove transgression in Scenario III in the next 100 years was calculated as $28,700 \mathrm{Mg} \mathrm{C}$ for 2050 and $143,325 \mathrm{Mg} \mathrm{C}$ for 2100. Consequently the total carbon stock in ENP mangroves in 2050 and 2100 was calculated as a sum of total $\mathrm{C}$ currently present in the forest (Table 4.2) and the $\mathrm{C}$ sequestered by mangrove migration in Scenario III (Equation 3.4). Therefore under Scenario III, the total carbon stock in the entire mangrove forest of ENP including the zone of transgression was estimated at $990,753,432 \mathrm{Mg} \mathrm{C}$ for 2050 and $990,868,057 \mathrm{Mg}$ C for 2100 .

The increase in the carbon stock in the three different scenarios, compared to the baseline year, was not found to be significant. The small increase in the carbon stock in the three different scenarios compared to the baseline year could be explained by the value of the carbon sequestration rate [2.1 $\mathrm{Mg} \mathrm{C}^{-1} \mathrm{year}^{-1}$ (Chmura et al., 2003)] used by this study. This value represents the global value of carbon sequestration by mangroves and was used as no specific value for the annual rate of carbon sequestration by ENP mangroves was available. It is also possible that the IPCC estimates for sea level rise used by this study are very conservative. Sea level rise could be much higher within the next century, given the larger uncertainties regarding ice sheet dynamics (Engel, 2010).

This study assumes that rise in sea level will lead to landward transgression of ENP mangroves based on projected rise in sea levels (IPCC) and areal transgression of mangroves (Doyle, 2003). However, the study acknowledges that the assumptions of 
areal transgression may be complicated by several factors such as the rate of sea level rise which could be much higher than the predictions used. Changes in the amount of fresh water inflow from the upper Everglades as a result of change in water management decisions and change in the frequency and magnitude of tropical storms and hurricanes can also influence how the ENP mangroves respond to sea level rise. Local factors like nearby coastal development, land surface slope and soil substrates with their ability to withstand changes in water levels and the quality of habitat across the expected path of transgression will influence the landward migration of the Everglades' mangroves (Engel, 2010).

In the event that sea-level rise is much higher than the conservative IPCC estimates used in this study, several possibilities could arise. The rise in sea level could lead to coastal mangrove communities being eroded and dissected as a result of saline water intrusion. In such a case, the increase in the total carbon stock in ENP mangroves could decrease considerably. On the other hand, if the sea level rise is abrupt and substantial, the mangrove communities along the coastline could get buried, storing the carbon reserves in the undisturbed ocean reservoir for thousands of years. However, this study did not find any published quantitative estimates for the change in carbon stock of ENP mangroves in response to sea level rise. Therefore, the estimates in this study for change in carbon stock in ENP mangroves are based on the estimates for landward transgression of mangroves provided by Doyle (2003, USGS Factsheet). 


\subsection{Estimation of Economic Value Changes in the Carbon Stock of ENP Mangroves in Response to Sea Level Rise}

Following the methodology explained in 3.8.2, two carbon prices per ton of carbon sequestered were selected to determine the marginal value of the $\mathrm{C}$ stored in ENP mangroves for the years 2010, 2050 and 2100. The first, lower-bound $\mathrm{C}$ price is the market price based on RGGI (2010). To determine the value of C stored in ENP mangroves in 2010 , the baseline year for this study, the RGGI 2010 carbon price $(\$ 7 / \mathrm{tC})$ is used. To project the 2010 RGGI price for 2050 and 2100, the price trend ( $\mathrm{Y}=6.038+$ $0.3946 *$ t) for the 'Copenhagen-rich countries only' scenario estimated by Nordhaus (2010) using the RICE model was employed. Thus the projected RGGI price for the years 2050 and 2100 were $\$ 25.29 / \mathrm{tC}$ and $\$ 48.17 / \mathrm{tC}$, respectively (Table 3.10). These correspond to the lower-bound values for the carbon price used in this study.

To provide a wider perspective based on different valuation methodologies, the SCC estimate for Regulatory Impact Analysis published by the United States Interagency Working Group (2010) was used. The SCC estimate for the baseline year 2010 is $\$ 86 / \mathrm{tC}$ (in 2010 U.S. dollars, using a discount rate of 3\%). The SCC for 2050 and 2100 were calculated using the price trend $(\mathrm{Y}=20.827+0.6037 * \mathrm{t})$ and are projected at $\$ 180.06 / \mathrm{tC}$ and $\$ 301.41 / \mathrm{tC}$, respectively. These correspond to the upper-bound values for carbon price used in this study.

The baseline and projected carbon prices from RGGI market and the SCC estimate of the U.S. Interagency Report are used to determine the change in economic value of carbon storage in ENP mangrove forests as a result of sea level rise in the next 90 years. The 
change in economic value of the carbon stored within the ENP mangrove ecosystem represents the cost or benefit associated with sea level rise in the year 2100 . The mangrove forest size in the baseline year 2010 is 144,447 ha. The forest area was assumed to increase to 164,447 ha by 2050 and 194,447 ha by 2100 in Scenario I, 230,447 ha by 2050 and 234,447 ha by 2100 in Scenario II, and 270,447 ha by 2050 and 294,447 ha by 2100 in Scenario III because of mangrove transgression to upland ecosystems in response to sea level rise of $0.2,0.38$ and $0.56 \mathrm{~m}$ respectively (assumptions based on Doyle, 2003). According to the estimates of this study, the carbon stored within the ENP forests did not increase significantly in Scenarios I, II and III in comparison to the baseline value in 2010. However, the carbon stored in the mangrove ecosystem per hectare (year 2100) decreased by 1.4 times in Scenario I with respect to the baseline year. The C storage (for the year 2100) decreased by 1.7 times and 2.1 times in Scenarios II and III, respectively, in comparison to the baseline year (Table 4.7). 
Table 4.7: Change in the Carbon Stock in the ENP Mangroves and its Economic Value under Different Scenarios

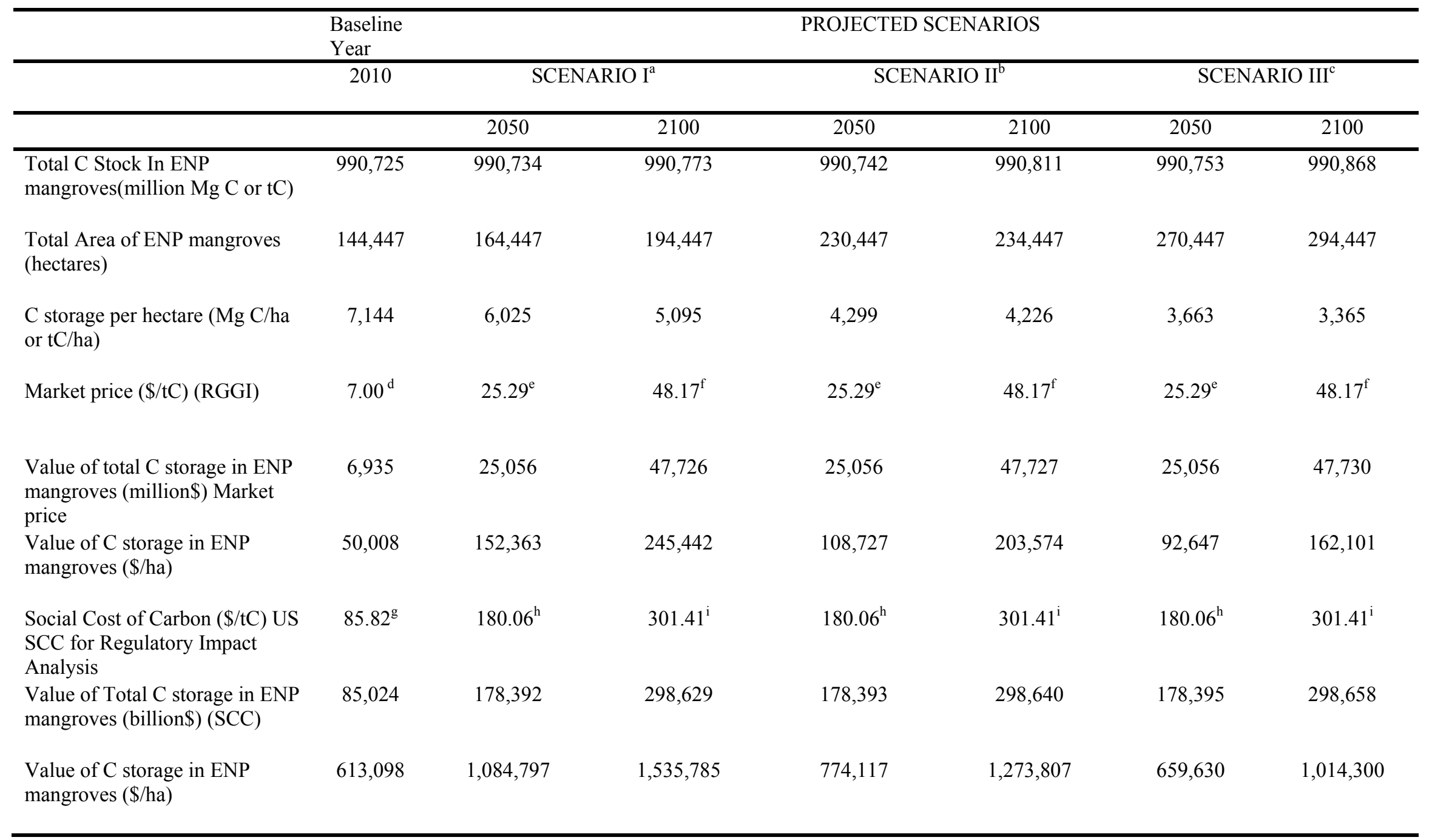

Notes: All prices are in 2010 U.S. dollars. 
a: SI, 2100: Scenario for sea level rise 0.2m in the year 2100 with mangrove transgression of 50,000ha;

b: SII, 2100: Scenario for sea level rise 0.38m in the year 2100 with mangrove transgression of 90,000ha;

c: SIII, 2100: Scenario for sea level rise 0.56m in the year 2100 with mangrove transgression of 150,000ha;

d: RGGI 2010 market price; e and f: RGGI market price predicted for 2050 and 2100, respectively, using RICE model C market trend (Nordhaus, 2010);

g: U.S. SCC estimate for Regulatory Impact Analysis (2010);

$h$ and $i$ : U.S. SCC estimate for Regulatory Impact Analysis, projected for 2050 and 2100, respectively, with discount rate 3\% 
To economically value the carbon stored per hectare in ENP mangroves for the baseline year, 2010, the carbon market price $(\$ 7 / \mathrm{tC})$ of the U.S. based RGGI was used (Tables 3.10 and 4.5). According to the RGGI carbon market price, the present value of $\mathrm{C}$ storage in ENP mangroves is $\$ 50,008 / \mathrm{ha}$. The RGGI market price is projected at $\$ 25.29 / \mathrm{tC}$ for 2050 and $\$ 48.17 / \mathrm{tC}$ for 2100 (using the price trend for Copenhagen-rich countries only' scenario estimated by Nordhaus (2010) using the RICE model) (Section 3.8.2). Accordingly, the value of total carbon in ENP mangroves increased from $\$ 6,935$ million in 2010 (baseline) to $\$ 25,056$ million in 2050 and $\$ 47,726$ million in 2100 for Scenario I. The value of the total carbon stock increases to $\$ 25,056$ million in 2050 and $\$ 47,477$ million in Scenario II. In Scenario III, the value of the total carbon stock increases to $\$ 25,056$ million in 2050 and $\$ 47,730$ million in 2100 .

Thus, the total economic value of the carbon storage in ENP mangroves, using RGGI prices, increased by approximately 3.6 times in 2050 for all three Scenarios considered, and increased by approximately 6.5 times for all three scenarios in 2100 , compared to the baseline year, 2010. However, not unlike the values observed for total carbon storage, the economic value of the total carbon stock in ENP mangroves, based on RGGI prices, did not differ significantly across the three scenarios considered in this study.

A observed by the above estimations, the value of carbon storage in ENP mangroves increased as a result of sea level rise but the carbon stored per unit area in the ENP mangrove forest decreases. The value of carbon storage per hectare for the baseline year (2010) is $\$ 50,008 /$ ha with respect to RGGI market price. The value of carbon storage per hectare in ENP mangroves increased to $\$ 152,363 /$ ha in 2050 and $\$ 245,442 /$ ha for 
Scenario I in 2100. Thus even though the carbon stored per hectare decreased, the economic value of carbon stored per hectare in the mangrove forest increased by 3 times in 2050, and by approximately 5 times in 2100 in Scenario I compared to the baseline year. The increase in the value of carbon stored per hectare in ENP mangroves can be attributed to the increase in the dollar value of carbon in future carbon markets such as the RGGI. However, in Scenarios II and III where sea level rises further, the economic value of carbon storage per hectare decreased $(\$ 108,727 /$ ha in 2050 and $\$ 203,574 /$ ha in Scenario II, and \$92,647/ha in 2050 and $\$ 162,101 /$ ha in 2100 in Scenario III) in comparison to Scenario I as the quantity of carbon stored per unit area decreased. Thus, the marginal economic value of carbon stored per unit hectare in ENP mangroves increased in Scenario I compared to the baseline year, but decreased with higher sea level rise in Scenarios II and III when compared to Scenario I.

Alternatively, the application of the U.S. government's social cost of carbon for regulatory impact analysis to determine the value of carbon storage in ENP mangroves yielded a higher value. Using the U.S. Government's SCC, the current economic value of the total carbon stored in ENP mangroves is $\$ 85,024$ billion. The SCC is estimated to increase to $\$ 180.06 / \mathrm{tC}$ and $\$ 301.41 / \mathrm{tC}$ in 2050 and 2100 , respectively. Accordingly, the value of the carbon stock increased to $\$ 178,392$ billion in 2050 and to $\$ 298,629$ billion in 2100 for Scenario I. The value of the carbon stock increased to $\$ 178,393$ billion in 2050 and to $\$ 289,640$ billion in 2100 for Scenario II. In Scenario III, the value of the total carbon stock increases to $\$ 178,395$ billion in 2050 and to $\$ 298,657$ billion in 2100 . 
The total economic value of the carbon storage in ENP mangroves, using SCC values, increased by approximately 2 times in 2050 for all three Scenarios considered, and increases by approximately 3.5 times for all three scenarios in 2100 , compared to the baseline year, 2010. However, similar to the values estimated for the RGGI price and not unlike the values observed for carbon storage, the economic value of the total carbon stock in ENP mangroves, using SCC values, did not differ significantly across the three scenarios considered in this study.

The marginal economic value of carbon stored in ENP mangroves for the baseline year using the U.S. government's SCC is $\$ 613,098 /$ ha. The marginal value of the carbon stored within ENP mangroves increased to $\$ 1,084,797$ in 2050 and to $\$ 1,543,785 /$ ha in 2100 in Scenario I with the increase in the projected values of SCC. In Scenario II, the value of carbon stored per hectare increased to $\$ 774,117 /$ ha in 2050 and to $\$ 1,273,807$ in 2100. In Scenario III, the value of carbon stored per hectare increased to $\$ 659,630 /$ ha in 2050 and to $\$ 1,014,300$ in 2100 . The decrease in carbon stored per hectare is reflected in the marginal economic values of carbon storage per hectare in ENP mangroves for Scenarios II and III respectively.

The change in the economic value of the total carbon stock in ENP mangroves in the years 2050 and 2100 under Scenarios I, II and III are summarized in Table 4.8. 
Table 4.8: Change in Economic Value of the Total Carbon Stock in ENP Mangroves under Different Scenarios

\begin{tabular}{|c|c|c|c|c|c|c|c|}
\hline & \multirow{3}{*}{$\begin{array}{c}\text { Baseline } \\
\text { Year } \\
\mathbf{2 0 1 0}\end{array}$} & \multicolumn{6}{|c|}{ PROJECTED SCENARIOS } \\
\hline & & \multicolumn{2}{|c|}{ SCENARIO I ${ }^{\mathrm{a}}$} & \multicolumn{2}{|c|}{ 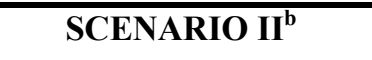 } & \multicolumn{2}{|c|}{ 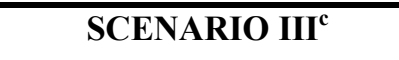 } \\
\hline & & 2050 & 2100 & 2050 & 2100 & 2050 & 2100 \\
\hline $\begin{array}{l}\text { Value of total C storage in ENP } \\
\text { mangroves (million \$) Market } \\
\text { price }^{\mathrm{d}}\end{array}$ & 6,935 & 25,056 & 47,726 & 25,056 & 47,727 & 25,056 & 47,730 \\
\hline $\begin{array}{l}\text { Value of total C storage in ENP } \\
\text { mangroves (billion } \$ \text { ) (SCC) }\end{array}$ & 85,024 & 178,392 & 298,629 & 178,393 & 298,640 & 178,395 & 298,658 \\
\hline
\end{tabular}

Note: All prices are in 2010 U.S. dollars.

a: Scenario I: Scenario for sea level rise $0.2 \mathrm{~m}$ in the year 2100 with mangrove transgression of 50,000ha;

b: Scenario II: Scenario for sea level rise $0.38 \mathrm{~m}$ in the year 2100 with mangrove transgression of 90,000ha;

c: Scenario III: Scenario for sea level rise $0.56 \mathrm{~m}$ in the year 2100 with mangrove transgression of 150,000ha;

d: Market price based on RGGI 2010; RGGI market price is $\$ 7 / t C$ for 2010, market price is predicted as $\$ 25.29 / t C$ for 2050 and $\$ 48.17 / t C$ for 2100 using RICE model C market trend (Nordhaus, 2010);

e: SCC based on for U.S. SCC estimate for Regulatory Impact Analysis (2010). The SCC is \$85.82/tC for 2010. The SCC estimate for Regulatory Impact Analysis projected as $\$ / t C$ for 2050 and $\$ / t C$ for 2100 with discount rate $3 \%$. 


\section{Chapter 5}

\section{Summary of Results and Conclusions}

The main purpose of this research was to provide the methodology for estimation of the total carbon storage in the mangrove forests in south Florida, based on reliable and scientific data. The total carbon storage in the mangrove forests of Everglades National Park in south Florida was calculated for the first time, based on the available data on the aboveground and belowground (fine roots and soil) carbon pools of the forest. Secondly, this study provided a methodological framework for the economic valuation of carbon storage in the mangrove forests of south Florida. The economic valuation was based on a comprehensive review of valuation methodologies and the selection of appropriate carbon prices for the study area. This study produced the first estimates for the economic valuation of the carbon stock in ENP mangroves. Lastly, this study estimated the change in economic value of the carbon storage in the ENP mangroves in response to the significant hydrological disturbance in the form of sea level rise.

The high spatial resolution of the aboveground biomass data accompanied by field data

for belowground $\mathrm{C}$ storage (soil and fine roots) allowed for the first reliable estimates of whole ecosystem carbon storage in the mangrove forests of Everglades National Park in south Florida. The total C storage in the mangrove forests was estimated at 990,724

million $\mathrm{Mg} \mathrm{C}$. The aboveground $\mathrm{C}$ pool in the ENP mangroves was 21,707 million $\mathrm{Mg} \mathrm{C}$ and the belowground $\mathrm{C}$ pool (fine roots and soil) was 968,910 million $\mathrm{Mg} \mathrm{C}$. In terms of per hectare values, the mean estimate of aboveground $\mathrm{C}$ in the ENP mangroves was 158 $\mathrm{Mg} \mathrm{C} / \mathrm{ha}$ ( \pm 124 std. deviation), and the mean estimate for the belowground $\mathrm{C}$ (fine roots 
and soil) in the ENP mangroves was $6,989 \mathrm{Mg} \mathrm{C} / \mathrm{ha}$ ( \pm 144 std. deviation). The aboveground $\mathrm{C}$ pool is large and comparable to the aboveground carbon pool of $159 \mathrm{Mg}$ $\mathrm{C} /$ ha in the Indo-Pacific mangroves estimated by Donato et al., 2011. But the belowground $\mathrm{C}$ pool dominates the storage, accounting for $97.8 \%$ of the total $\mathrm{C}$ pool in ENP mangroves. The ENP mangrove soils alone contribute the majority of the belowground $\mathrm{C}$ storage with $6,864 \mathrm{Mg} \mathrm{C} /$ ha which can be correlated to the soil bulk density and the depth of the peat soils in the forest. The mangrove forests of the ENP store approximately $4 \%$ of carbon in their biomass and $96 \%$ in the soil. The estimation of soil carbon is restricted to a maximum of $1.5 \mathrm{~m}$ depth of soil while the peat soils in the western Everglades is up to $4-5 \mathrm{~m}$ deep, making the estimates for soil $\mathrm{C}$ storage in this study fairly conservative. These data strongly indicate that the high productivity observed in the ENP mangroves is supported by significant $\mathrm{C}$ storage.

The total C storage per hectare in the mangrove forests in Everglades National Park is 7,144 Mg C/ha, much higher than the major global forest domains. The carbon storage in tropical forests is $242 \mathrm{Mg} \mathrm{C} / \mathrm{ha}$, boreal forests store $239 \mathrm{Mg} \mathrm{C} /$ ha and temperate forests store $150 \mathrm{Mg} \mathrm{C} / \mathrm{ha}$ (Pan et al., 2011). The C storage estimated in this study far exceeds the storage of $1023 \mathrm{Mg} \mathrm{C} /$ ha estimated for tropical mangrove forests in the Indo-Pacific region by Donato et al. (2011), underscoring the unique characteristics of ENP mangroves. The high $\mathrm{C}$ storage per hectare in the mangrove wetland forests of ENP indicates that they are a significant global natural $\mathrm{C}$ sink. The significant $\mathrm{C}$ storage in ENP mangroves can be correlated to the geological age and maturity of the forest that offer a complexity of structure, function and ecosystem services that cannot be found in 
immature, replanted forests (Alongi, 2011). Because the Everglades' mangroves lie in strictly protected areas (IUCN Category II) of the Everglades National Park, their relatively undisturbed nature adds to the quality and value of $\mathrm{C}$ storage.

This study produced GIS maps, presented in section 4.1, for aboveground and belowground carbon, and the total $\mathrm{C}$ storage in the mangrove forests of Everglades National Park, Florida. These are the first maps produced documenting the quantity and distribution of $\mathrm{C}$ storage in the mangrove ecotone regions of the Everglades National Park. The carbon storage exhibits spatial variability and a distinct gradient across the Everglades landscape. The spatial variability in C storage observed in the maps correlates with the conspicuous gradient of biomass across the Everglades mangrove ecotone, with higher values in the western regions of the ENP as a result of higher nutrient $(\mathrm{P})$ availability.

To provide an economic valuation, a comprehensive review of appropriate valuation methodologies was performed. Carbon prices from social costs of carbon, marginal abatement costs and market prices were identified and narrowed down to suitable estimates in terms of their applicability to this study. The wide range of economic values provide a valuation framework for mangrove forests world-wide to cover the variability of mangroves in terms of geographic regions, and their biological nature such as geological age and variability in ecosystem services. The estimates for economic valuation for C storage in ENP mangroves ranged from $\$ 500,000 / \mathrm{ha}$ - $\$ 1,457,000 / \mathrm{ha}$ using marginal abatement costs which yielded the highest estimates, $\$ 250,000 /$ ha - 
$\$ 614,000 /$ ha using social costs of carbon, and $\$ 50,000 /$ ha $-\$ 564,000 /$ ha using market prices.

The wide range of economic values helped to determine the value of $\mathrm{C}$ storage in ENP mangroves for different policy scenarios. While performing economic valuation, it is considered prudent to value carbon sequestration at the conservative market prices available. In the case of ENP mangroves, it was considered appropriate to use the market price from RGGI $(\$ 7 / \mathrm{tC})$ as it is the only currently active market operational in the United States. The RGGI carbon price provided a lower-bound value for carbon price for this study. However, taking into account the geological age of the mature forests of ENP and the strict nature of conservation status in the protected areas of ENP, it behooved this study to provide an upper-bound economic value based on the quality of carbon storage in ENP mangroves. In this regard, the SCC from the U.S. Interagency Report $(\$ 86 / \mathrm{tC})$ was selected to convey the appropriate value for C storage in ENP mangroves. Thus, the economic value of the $\mathrm{C}$ storage in ENP mangroves is approximately $\$ 50,000 /$ ha (lowerbound estimate) based on U.S based market price, and $\$ 614,000 /$ ha (upper-bound estimate) based on the U.S. based SCC values.

Finally, the change in the total carbon stock in ENP mangroves in response to three scenarios of sea level rise (projected sea level rise in 2100: $0.2 \mathrm{~m}$ in Scenario I, $0.38 \mathrm{~m}$ in Scenario II and $0.56 \mathrm{~m}$ in Scenario III) was estimated. The estimations for the total carbon stock in ENP mangroves for the years 2050 and 2100 across all three Scenarios did not differ significantly from the baseline value of 990,724 million $\mathrm{Mg} \mathrm{C}$ in 2010. In Scenario I, the total carbon stock in the mangrove forest of ENP was estimated to be 
$990,734,299 \mathrm{Mg} \mathrm{C}$ in 2050 and $990,772,507 \mathrm{Mg} \mathrm{C}$ in 2100. In Scenario II, the total carbon stock in the entire mangrove forest of ENP was estimated as 990,741,952 Mg C for 2050 and $990,810,727 \mathrm{Mg} \mathrm{C}$ for 2100 . In Scenario III, the total carbon stock in the entire mangrove forest of ENP was estimated at 990,753,432 Mg C for 2050 and 990,868,057 Mg C for 2100.

The increase in the carbon stock in the three different scenarios, compared to the baseline year, was not found to be significant. The small increase in the carbon stock in the three different scenarios compared to the baseline year could be explained by the value of the carbon sequestration rate [2.1 Mg C ha ${ }^{-1}$ year $^{-1}$ (Chmura et al., 2003)] used by this study. This value represents the global value of carbon sequestration by mangroves and was used as no specific value for the annual rate of carbon sequestration by ENP mangroves was available. It is also possible that the IPCC estimates for sea level rise used by this study are very conservative. Sea level rise could be much higher within the next century, given the larger uncertainties regarding ice sheet dynamics (Engel, 2010).

This study assumed that rise in sea level will lead to landward transgression of ENP mangroves based on projected rise in sea levels. Sea level rise scenarios were based on IPCC projections and the values for areal transgression of mangroves were based on the integrated landscape vegetation model used by Doyle (2003). However, the study acknowledges that the assumptions of areal transgression may be complicated by several factors such as the rate of sea level rise which could be much higher than the predictions used. Changes in the amount of fresh water inflow from the upper Everglades as a result of change in water management decisions and change in the frequency and magnitude of 
tropical storms and hurricanes can also influence how the ENP mangroves respond to sea level rise. Local factors like nearby coastal development, land surface slope and soil substrates with their ability to withstand changes in water levels and the quality of habitat across the expected path of transgression will influence the landward migration of the Everglades' mangroves (Engel, 2010). A combination of all these factors may lead to loss of mangrove communities. However, this study did not find any published quantitative estimates for the change in carbon stock of ENP mangroves in response to sea level rise. Therefore, the estimates in this study for change in carbon stock in ENP mangroves were based on the estimates for landward transgression of mangroves provided by Doyle (2003, USGS Factsheet FS-030-03).

The carbon storage per hectare for the baseline year (2010) was estimated as 7,144 Mg $\mathrm{C} /$ ha. The carbon storage per hectare in ENP mangroves, however, decreased by 1.4 times in Scenario I (5,095 $\mathrm{Mg} \mathrm{C} / \mathrm{ha})$ in the year 2100, with respect to the baseline year. The C storage (for the year 2100) decreased by 1.7 times and 2.1 times in Scenarios II (4,226 Mg C/ha) and III (3,365 Mg C/ha), respectively, in comparison to the baseline year. For the year 2050, the carbon stored per hectare decreased by 1.2, 1.6 and 1.9 times, respectively, for Scenarios I, II and III. The small increase in total C storage is attributed to the areal increase of mangrove forests in the Everglades landscape. However, the decrease in $\mathrm{C}$ storage per unit area can be explained by the reasoning that the newer mangroves in the zone of transgression will be between one to ninety years old by 2100 and will not have sequestered the same amount carbon as the older mangroves in the present areal extent of the forest. 
The economic value of the total carbon stock in ENP mangroves in the year 2010 is $\$ 6,935$ million according to the lower-bound estimates for this study (RGGI). The economic value of C stock in ENP mangroves increased to $\$ 25,056$ million in 2050 for Scenarios I, and was the same for Scenarios II and III. The estimation for the total carbon stock in ENP mangroves in 2100 was similar for all three Scenarios. The carbon stock increased to $\$ 47,276$ million in 2100 for Scenario I, $\$ 47,727$ million in 2100 for Scenario II, and increased to $\$ 47,730$ million in 2100 for Scenario III.

The economic value of the total carbon stock in ENP mangroves in the year 2010 was $\$ 85,024$ billion according to the upper-bound estimates for this study (SCC value from U.S. Interagency Report, 2010). In this case, the economic value of C stock in ENP mangroves increased to $\$ 1758,392$ billion in 2050 and $\$ 298,629$ billion in 2100 for Scenario I (projected sea level rise: $0.2 \mathrm{~m}$ in 2100). The economic value of $\mathrm{C}$ stock in ENP mangroves increased to $\$ 178,393$ billion in 2050 and $\$ 298,640$ billion in 2100 for Scenario II (projected sea level rise: $0.38 \mathrm{~m}$ in 2100). The economic value of C stock in ENP mangroves increased to $\$ 178,395$ billion in 2050 and $\$ 298,658$ million in 2100 for Scenario III (projected sea level rise: $0.56 \mathrm{~m}$ in 2100).

The total economic value of the carbon storage in ENP mangroves increased by approximately 3.6 times in 2050 for all three Scenarios considered, and increased by approximately 6.8 times for all three scenarios in 2100 , compared to the baseline year, using the lower-bound estimates for carbon prices. The total economic value of the carbon stock increases by approximately 2 times in 2050 for all scenarios, and by 3.5 times 2100 for all scenarios, using the upper-bound SCC values for carbon price. Not 
unlike the values observed for carbon storage, the economic value of the total carbon stock in ENP mangroves, based on market prices and SCC, does not differ significantly across the three scenarios considered in this study. The gain in total economic value is attributed to the projection of $\mathrm{C}$ prices in the future. It is assumed that carbon prices are likely to increase in the future as a result of growth of carbon markets, accompanied by strong and stable carbon prices.

The economic value of the carbon stored per hectare, increased by approximately 3 times in Scenario I, but by only 2 times in Scenario II and increased by 1.8 times in Scenario III, using the lower-bound carbon price (RGGI). For 2100, the value of carbon stored per hectare increased by approximately 5, 4 and 3 times in Scenarios I, II and III, respectively, using RGGI prices. The value for carbon stored per hectare decreases with time as market prices for carbon are projected to increase in the next few decades and level off later. The value of the carbon stored per hectare increased by $1.8,1.3$ and 1.1 times in Scenarios I, II and III, in 2050, using the upper bound values for carbon price. Similarly, the value of carbon stored per hectare increased by 2.5 times in Scenario I, but the increased by 2 and 1.6 times in Scenarios II and III. The change in economic value per hectare is explained by the decrease in carbon stored per hectare and the changes in the projected price of carbon. The increase in the value of $\mathrm{C}$ storage per hectare is attributed to the increase in $\mathrm{C}$ prices in future carbon markets even as the $\mathrm{C}$ storage per hectare decreases in all scenarios. In case of higher sea level rise the $\mathrm{C}$ storage per hectare decreases further $(5,095,4,226$ and 3,365 Mg C/ha for $2.0 \mathrm{~mm} /$ year, 3.8mm/year and $5.6 \mathrm{~mm} /$ year sea level rise, respectively, in 2100), although the marginal values for C 
sequestration are higher than current values $(\$ 245,442 / \mathrm{ha}, \$ 203,574 / \mathrm{ha}$ and $\$ 162,101 / \mathrm{ha}$ for Scenarios I, II and III, respectively).

The aim of this study was to collate reliable, scientific data available for aboveground and belowground $\mathrm{C}$ pools in the mangrove ecosystem of Everglades National Park and account for a robust and conservative estimate for total $\mathrm{C}$ storage in this natural carbon sink. A pertinent range of economic values for the $\mathrm{C}$ storage in ENP mangroves based on an exhaustive review of valuation methodologies was estimated. The final estimates for valuation of $\mathrm{C}$ storage in ENP mangroves were based on the biological attributes of the forest, its status as protected area and the social, economic and political milieu of the study site. As a result, the economic valuation of C storage in ENP mangroves by this study can be considered scientifically justified and socially acceptable.

\section{Policy Implications}

The estimation of clear, quantifiable GHG benefits from the ENP mangroves can have several implications. Firstly, the knowledge about the quantity of $\mathrm{C}$ storage has the ability to change public perception in Florida about how the carbon sequestration service by ENP mangroves supports their well-being and the associated global benefits. Secondly, the economic valuation can help to engage and foster the growth of carbon markets in the region and country. Thirdly, effective management strategies can be developed by recognizing the economic effects of presses and pulses on the $\mathrm{C}$ storage in ENP mangroves. Finally, this study has not only important scientific but political ramifications as well. The knowledge of the economic value of the carbon stored in ENP 
mangroves can assist in policy changes in the future so that the ENP mangroves can be included in climate change mitigation strategies.

The increase in carbon stock in ENP mangroves in response to sea level rise as estimated by this study is accompanied by a significant increase in the economic value of the carbon storage. This study assumed that rise in sea level will lead to landward transgression of ENP mangroves based on projected rise in sea levels (IPCC) and areal transgression of mangroves (Doyle, 2003). However, it is acknowledged that the increase in areal transgression assumed will be complicated by several factors such as the rate of sea level rise which could be much higher than the predictions used, changes in the amount of fresh water inflow from the upper Everglades as a result of change in water management decisions, and change in the frequency and magnitude of tropical storms and hurricanes. Local factors like nearby coastal development, land surface slope and soil substrates with their ability to withstand changes in water levels and the quality of habitat across the expected path of transgression will influence the landward migration of the Everglades' mangroves.

The ENP mangroves are subject to multiple presses and pulses, like changes in quantity and quality of fresh water inflow as a result of water management decisions, pressures of urban development and the magnitude and frequency of tropical storms and hurricanes. The collective effect of all presses and pulses on carbon storage in ENP mangroves is uncertain and may result in the loss of carbon stock in ENP mangroves in the future. The estimates of the value of carbon storage established by this study can be useful in establishing the costs of inaction associated with the failure to prevent such losses in 
carbon stock. For instance, the cost of avoiding the future loss of ENP mangroves could be estimated by using the social costs of carbon. The cost of no action or the failure to prevent ENP mangrove degradation could range from \$178,408 million in 2050 (Scenario I) to $\$ 303,409$ million (Scenario III) in 2100 (Table 4.8).

The restoration of ENP mangroves is imperative in the light of several presses and pulses that operate on the Everglades' mangroves. The costs of restoring mangroves in Miami, Florida range from $\$ 5,300$ to $\$ 200,000 /$ ha, with a mean cost of $\$ 99,000 /$ ha (Milano, 1999 as cited in Yee, 2010). The estimates for the value of C storage in ENP mangroves based on marginal abatement costs can be used to perform the cost-benefit analysis of mangrove restoration in the Everglades.

Carbon sequestration and storage is one of the many ecosystem services that the ENP mangroves provide. It must be emphasized that the economic value of carbon sequestration and storage as estimated by this study is just one part of the total economic value of all ecosystem services provided by the ENP mangrove forests. Future studies on the valuation of other ecosystem services by ENP mangroves can help in determining the total value of this ecosystem.

\section{Future Directions}

In the face of major hydrological disturbances in the form of sea level rise and humanengineered alterations in water inflow accompanied by the frequent occurrence of hurricanes, it is imperative that the scientific community embarks on a full-fledged social-ecological integrated approach to the study of C storage and sequestration by ENP 
mangroves. The role of human decisions in shaping future decisions and policy that will eventually influence the C storage capacity of the ENP mangroves cannot be underestimated. The integration of the ecological domain of study with the social domain can help improve the understanding of $\mathrm{C}$ sequestration and storage by ENP mangroves by leaps and bounds. A consistent monitoring of $\mathrm{C}$ storage to record the changes in sequestration services by ENP mangroves will help understand the effect of presses and pulses on this region. The establishment of the baseline values for C storage by ENP mangroves in this study is the first step in this direction. 


\section{References}

A. Myrick Freeman III. (2003). The measurement of environmental and resource values: Theory and methods (Second ed.). Washington D.C.: Resources for the Future.

Aburto-Oropeza, O., Ezcurra, E., Danemann, G., Valdez, V., Murray, J., \& Sala, E. (2008). Mangroves in the Gulf of California increase fishery yields. Proceedings of the National Academy of Sciences, USA, 105(30), 10456-10459.

Alongi, D. (2002). Present state and future of the world's mangrove forests Cambridge University Press, Edinburgh Bldg, Shaftesbury Rd, Cambridge, CB2 2RU, UK, [mailto:journals_subscriptions@cup.org], [URL:http://www.uk.cambridge.org/journals/pmu]. doi:10.1017/S0376892902000231

Alongi, D. (2008). Mangrove forests: Resilience, protection from tsunamis, and responses to global climate change. Estuarine Coastal and Shelf Science, 76, 1-13.

Alongi, D. (2011). Carbon payments for mangrove conservation: Ecosystem constraints and uncertainties of sequestration potential. Environmental Science \& Policy, 14(4), 462-462-470. doi:10.1016/j.envsci.2011.02.004

Barbier, E. B., Hacker, S. D., Kennedy, C., Koch, E. W., Stier, A. C., \& Silliman, B. R. (2011). The value of estuarine and coastal ecosystem services. Ecological Monographs, 81(2), 169-193.

Bouillon, S., Borges, A., Castaneda-Moya, E., Diele, K., Dittmar, T., Duke, N., Kristensen, E., Lee, Shing Y., Marchand, C., Middelburg, J.K., Rivera-Monroy, V.H., Smith III, T.S., Twilley, R. (2008). Mangrove production and carbon sinks: A revision of global budget estimates. American Geophysical Union, 2000 Florida Ave., N.W. Washington DC 20009 USA, [mailto:service@agu.org], [URL:http://www.agu.org]. doi:10.1029/2007GB003052

Bouillon, S., Rivera-Monroy, V., Twilley, R. R., \& Kairo, J. J. (2009). The management of natural coastal carbon sinks. (No. 53pp). Gland, Switzerland: IUCN.

Campbell, A., Miles, L., Lysenko, I., Gibbs, H., \& Hughes, A. (2008). Carbon storage in protected areas. Technical report. UNEP World Conservation Monitoring Centre.

Canadell, J. G., \& Raupach, M. R. (2008). Managing forests for climate change mitigation. Science (Washington), 320, 1456-57.

Castaneda, E. (2010). Landscape patterns of community structure, biomass and net primary productivity of mangrove forests in the Florida coastal everglades as a function of resources, regulators, hydroperiod, and hurricane disturbance. (Doctor 
of Philosophy). Louisiana State University and Agricultural and Mechanical College, Lafayette, LA.

Castaneda-Moya, E., Twilley, R., Rivera-Monroy, V. H., Marx, B. D., Coronado-Molina, C., \& Ewe, S. M. L. (2011). Patterns of root dynamics in mangrove forests along environmental gradients in the Florida Coastal Everglades, USA. Ecosystems, doi:10.1007/s10021-011-9473-3

Castaneda-Moya, E., Twilley, R., Rivera-Monroy, V., Zhang, K., Davis, S., \& Ross, M. (2010). Sediment and nutrient deposition associated with hurricane Wilma in mangroves of the Florida Coastal Everglades. Estuaries and Coasts, 33(1), 45-58. doi:10.1007/s12237-009-9242-0

CERP, (2000). Comprehensive everglades restoration plan, U.S. army corps of Engineer and South Florida Water Management District, Florida. Retrieved 6/5, 2011, from http://www.evergladesplan.org/

Chen, R., \& Twilley, R. R. (1999). Patterns of mangrove forest structure and soil nutrient dynamics along the Shark River Estuary, Florida. Estuaries, 22, 955-70.

Chen, R., \& Twilley, R. R. (1999). A simulation model of organic matter and nutrient accumulation in mangrove wetlands soils. Biogeochemistry, 44, 93-118.

Chiabai, A., Travisi, C., Ding, H., Markandya, A., \& Nunes, P. A. (2009). Economic valuation of forest ecosystem services: Methodology and monetary estimates. 11th Annual BIOECON Conference on Economic Instruments to Enhance the Conservation and Sustainable use of Biodiversity,

Childers, D. L. (2006). A synthesis of long-term research by the Florida Coastal Everglades LTER program. Hydrobiologia, 569(1)

Chmura, G. L., Anisfeld, S. C., Cahoon, \& Lynch, J. C. (2003). Global carbon sequestration in tidal, saline wetland soils. Global Biogeochemical Cycles, 17(4) doi:10.1029/2002GB001917

Cintron, G., \& Schaeffer-Novelli, Y. (1984). Methods for studying mangrove structure. In S. C. Sneadaker, \& J. G. Sneadaker (Eds.), The mangrove ecosystems: Research methods (pp. 3-17). Paris: UNESCO.

Collins, Scott L., Carpenter, S. R., Swinton, Scott M., Orenstein, Daniel, E., Childers, Daniel, L., Gragson, Ted L., Grimm, Nancy M., Grove, J Morgan, Harlan, Sharon L., Kaye, Jason P., Knapp, Alan K., Kofinas, Gary P., Magnuson, John J., McDowell, William H., Melack, John M., Ogden, Laura a., Robertson, G Philip, Smith, Meliinda D., Whitmer, Ali C.(2010). An Integrated Conceptual framework for long-term social-ecological research. Frontiers in Ecology and the Environment, doi: $10.1890 / 100068$ 
Coronado-Molina, C., Day Jr., J. W., Reyes, E., \& Perez, B. C. (2004). Standing crop and aboveground biomass partitioning of a dwarf mangrove forest in Taylor River slough, Florida. Wetlands Ecology and Management, 12, 157-164.

Davis, S. M., Childers, D. L., Lorenz, J. J., Wanless, H. R., \& Hopkins, T. E. (2005). A conceptual model of ecological interactions in the mangrove estuaries of the Florida Everglades. Wetlands, 25(4), 832-832-842. doi:10.1043/02775212(2005)025[0832:ACMOEI]2.0.CO;2

Dieter, M., \& Elsasser, P. (2002). Quantification and monetary valuation of carbon storage in the forests of Germany in the framework of national accounting. (Institute for Economics Working Paper 2002 / 8). Hamburg, Germany: Federal Research Centre for Forestry and Forest Products; University of Hamburg.

Dietz, S., \& Fankhauser, S. (2009). Environmental prices, uncertainty and learning. (Working Paper No. 12).Centre for Climate Change Economics and Policy.

Ding, H., Dias Nunes, P. A., \& Teelucksingh, S. S. (2010). European forests and carbon sequestration services: An economic assessment of climate change impacts. Rochester.

Donato, D. C., Kauffman, J. B., Murdiyarso, D., Kurnianto, S., Stidham, M., \& Kanninen, M. (2011). Mangroves among the most carbon-rich forests in the tropics. Nature Geoscience, doi:10.1038/NGE01123

Doren, R. F., Rutchey, K., \& Welch, R. (1999). The Everglades: A perspective on the requirements and applications for vegetation map and database products. Photogrammetric Engineering and Remote Sensing, 65(2), 155-161.

Doyle, T. W. (2003). Predicting Future Mangrove Forest Migration in the Everglades Under Rising Sea Level. U.S. Geological Survey Fact Sheet FS-030-03, U.S. Geological Survey.

Ellerman, A. D., \& Decaux, A. (1998). Analysis of post-Kyoto $\mathrm{CO}_{2}$ emissions trading using marginal abatement curves. (No. 40).MIT Joint Program on the Science and Policy of Global Change. Retrieved from (http://web.mit.edu/globalchange/www/MITJPSPGC Rpt40.pdf).

Engel, V. (2010). Sea level rise and altered hydrology impact mangrove communities. In W. L. Kruczynski, \& P. Fletcher (Eds.), South Florida marine environments: An ecological synthesis. Cambridge, MD: University of Maryland, IAN Press.

Ewe, S. M. L., Gaiser, E. E., Childers, D. L., Iwaniec, D., River-Monroy, V. H., \& Twilley, R. R. (2006). Spatial and temporal patterns of aboveground net primary productivity (ANPP) along two fresh-water estuarine transects in the Florida Coastal Everglades. Hydrobiologia, 569, 459-474. 
Fankhauser, S. (1994). Valuing climate change-the economics of the greenhouse. London: EarthScan.

Fromard, F., Puig, H., Mougin, E., Marty, G., Betoulle, J., \& Cadamuro, L. (1998). Structure, above-ground biomass and dynamics of mangrove ecosystems: New data from French Guiana

Hope, C. W. (2006). The marginal impact of $\mathrm{CO}_{2}$ from PAGE2002: An integrated assessment model incorporating the IPCC's five reasons for concern. Integrated Assessment Journal, 6(1), 19-56.

Hussain, S. A., \& Badola, R. (2008). Valuing mangrove ecosystem services: Linking nutrient retention function of mangrove forests to enhanced agroecosystem production. Wetlands Ecology and Management, 16(6), 441-450.

doi:10.1007/s11273-008-9080-z

Interagency Working Group on Social Cost of Carbon, United States Government. (2010). Social cost of carbon for regulatory impact analysis. (No. Executive Order 12866). United States Government.

Koch, E. W., Barbier, E. B., Silliman, B. R., Reed, D. J., Perillo, G., Hacker, S. D., Granek, E.F., Primavera, J. H., Muthiga, N., Polasky, S., Halpern, B. B., Kennedy, C. J., Kappel, C. V., Wolasnki, E. (2009). Non-linearity in ecosystem services: Temporal and spatial variability in coastal protection. Frontiers in Ecology and the Environment, 7(1), 29-37. doi:10.1890/080126

Komiyama, A., Ong, J. E., \& Poungparn, S. (2008). Allometry, biomass, and productivity of mangrove forests: A review. Aquatic Botany, 89(2), 128-137.

doi:10.1016/j.aquabot.2007012.006

Krauss, K. W., Doyle, T. W., Twilley, R. R., Rivera-Monroy, V., \& Sullivan, J. K. (2006). Evaluating the relative contributions of hydroperiod and soil fertility on growth of south Florida mangroves. Hydrobiologia, 569(1), 311-311-324. doi:10.1007/s10750-006-0139-7

Kuik, O., Brander, L., \& Tol, R. S. J. (2008). Marginal abatement costs of carbon-dioxide emissions: A meta-analysis. Economic and Social Research Institute,

Kulshreshtha, S. N., Lac, S., Johnston, S., \& Kinar, C. (2000). Carbon sequestration in protected areas of Canada: An economic valuation. (No. 549).Canada Parks Council; Economics Framework Project.

Laffoley, D., \& Grimsditch, G. (2009). The management of natural coastal carbon sinks. Gland: IUCN. 
Light, S. S., \& Dineen, J. W. (1994). Water control in the Everglades: A historical perspective. In S. Davis, \& J. C. Ogden (Eds.), Everglades: The ecosystem and its restoration (pp. 47-84). Delray Beach, FL: St. Lucie Press.

Linacre, N., Kossoy, A., \& Ambrosi, P. (2011). State and trends of the carbon market 2011. (). Washington D. C.: Carbon Finance at the World Bank.

Lodge, T. E. (2005). The Everglades handbook: Understanding the ecosystem. Boca Raton (FL): CRC Press.

Lugo, A. E., \& Snedaker, S. C. (1974). The ecology of mangroves. Annual Review of Ecological Systems, 5, 39-64.

Maddison, D. J. (2003). The amenity value of the climate: The household production function approach. Resource and Energy Economics, 25(2), 155.

McCormick, B., Clement, R., Fischer, D., Lindsay, M., \& Watson, R. (2010). Measuring the economic benefits of America's Everglades restoration. (No. Mather Economics). Palmetto Bay, Florida: Everglades Foundation.

Millenium Ecosystem Assessment. (2005). Ecosystems and human wellbeing: Synthesis. Washington, DC: Island Press.

Nickelson, D. J. (1999). Trade-offs of mangrove area development in the Philippines. Ecological Economics, 28, 279-298.

Noe, G., Childers, D. L., \& Jones, R. D. (2001). Phosphorus biogeochemistry and the impacts of phosphorus enrichment: Why are the everglades so unique? Ecosystems, 4, 603-624.

Nordhaus, W. (2007). The challenge of global warming: Economic models and environmental policy.

Nordhaus, W. D. (1994). Expert opinion on climate change. American Scientist, 82(1), 45-51.

Nordhaus, W. D. (1994). Managing the global commons: The economics of climate change. Cambridge, MA: MIT Press.

Nordhaus, W. D. (2006). Geography and macroeconomic: New data and new findings. Proceedings of the National Academy of Sciences, USA, 103(10), 3510-3517. doi:10.1073/pnas.0509842103.

Nordhaus, W. D. (2010). Economic aspects of global warming in a pots-copenhagen environment. Proceedings of the National Academy of Sciences, USA, 107(26), 11721-11726. doi:10.1073/pnas.1005985107 
Nordhaus, W. D., \& Yang, Z. (1996). RICE: A regional dynamic general equilibrium model of optimal climate-change policy. American Economic Review, 64(1-2), 195225.

Pachauri, R. K., \& Resinger, A. (2007). The Fourth Assessment Report Climate Change. IPCC.

Pan, Y., Birdsey, R. A., Fang, J., Houghton, R., Kauppi, P. E., Kurz, W. A., Phillips, O. L., Shvidenko, A., Lewis, S. L., Canadell, J. G., Ciais, P., Jackson, R. B., Pacala, S. W., McGuireA. D., Piao, S., Rautiainen, A., Sitch, S., Hayes, D. (2011). A large and persistent carbon sink in the world's forests. Science (Washington), 333(6045), 988993.

Pearce David W., Cline, W. R., Achanta, A. N., Fankhauser, S., Pachauri, R. K., Tol, R. S. J., \& Vellinga, P. (1996). The social costs of climate change: Greenhouse damage and the benefits of control. In J. P. Bruce, H. Lee \& E. F. Haites (Eds.), Climate change 1995: Economic and social dimensions- contribution of working group III to the second assessment report of the intergovernmental panel on climate change (pp. 179-224). Cambridge, MA: Cambridge University Press.

Peters-Stanley, M., Hamilton, K., Marcello, T., \& Sjardin, M. (2011). Back to the future: State of the voluntary carbon markets 2011. Ecosystem Marketplace; Bloomberg New Energy Finance.

Potomac Economics. (2011). Annual report on the market for $\mathrm{RGGI} \mathrm{CO}_{2}$ allowances: 2010. RGGI, Inc.

Price, R., Thornton, S., \& Nelson, S. (2007). The social cost of carbon and the shadow price of carbon: What they are, and how to use them in economic appraisal in the UK. London, U.K.: Economics Group, Department for Environment, Food and Rural Affairs.

Redondo-Brenes, A., \& Montagnini, F. (2006). Growth, productivity, aboveground biomass, and carbon sequestration of pure and mixed native tree plantations in the Caribbean lowlands of Costa Rica Elsevier B.V. doi:10.1016/j.foreco.2006.05.067

Reid, W. V. (2006). Nature: The many benefits of ecosystem services. Nature, 443(749).

Rivera-Monroy, Victor H. , Twilley, Robert R. , Davis III, Stephen E. , Childers, Daniel L. , Simard, Marc , Chambers, Randolph , Jaffe, Rudolf, Boyer, Joseph N. , Rudnick, David T. , Zhang, Keqi , Castañeda-Moya, Edward, Ewe, Sharon M. L. , Price, René M. , Coronado-Molina, Carlos , Ross, Michael , Smith III, Thomas J. , Michot, Beatrice, Meselhe, Ehab, Nuttle, William, Troxler, Tiffany G. and Noe, Gregory B. (2011). The role of Everglades Mangrove Ecotone Region (EMER) in regulating nutrient cycling and wetland productivity in south Florida. Critical 
Reviews in Environmental Science and Technology, 41(6), 633-669. Retrieved from http://dx.doi.org/10.1080/10643389.2010.530907

Ross, M. S., Ruiz, P. L., Telesnicki, G. J., \& Meeder, J. F. (2001). Estimating aboveground biomass and production in mangrove communities of Biscayne National Park, Florida. Wetlands Ecology and Management, 9, 27-37.

Ross, M. S., Meeder, J. F., Sah, J. P., Ruiz, P. L., \& Telesnicki, G. J. (2000). The southeast saline everglades revisited: A half century of coastal vegetation change. Journal of Vegetation Science (MS \# 1949), 11, 101-12.

Saenger, P., \& Snedaker, S. (1993). Pantropical trends in mangrove above-ground biomass and annual litter fall.

Sathirathai, S. (1997). Economic Valuation of Mangroves and the Roles of Local Communities in the Conservation of Natural Resources: Case Study of Surat Thani, South of Thailand, Ottawa: International Development Research Center. http://www.idrc.ca/uploads/user-S/10536137110ACF9E.pdf

Simard, M., Zhang, K., Rivera-Monroy, V., Ross, M. S., Ruiz, P. L., Castaneda-Moya, E., Twilley, R. R., Rodriguez, E. (2006). Mapping height and biomass of mangrove forests in the Everglades National Park with SRTM elevation data. Photogrammetric Engineering and Remote Sensing, 72(3)

Sklar, F., McVoy, C., Van Zee, R., Gawlik, D., Swift, D., Park, W. Fitz, C., Wu, Y., Rudnick, D., Fontaine, T., Miao, S., Ferriter, A., Krupa, S., Armentano, T., Tarboton, K.(2002). In Porter K. (Ed.), The effects of altered hydrology on the ecology of the Everglades; the Everglades, Florida Bay, and coral reefs of the Florida Keys; an ecosystem sourcebook. United States (USA): CRC Press, Boca Raton, FL, United States (USA).

Smith, T., \& Whelan, K. (2006). Development of allometric relations for three mangrove species in south Florida for use in the greater everglades ecosystem restoration Springer-Verlag. doi:10.1007/s11273-005-6243-z

Smoak, J.M., Breithaupt, J., Smith III, T.J. and C.J. Sanders; Sediment accretion and organic carbon burial relative to sea-level rise and storm events in two mangrove forest in Everglades National Park, Catena, revisions submitted.

Stavins, R., \& Richards, K. (2005). The cost of U.S. forest-based carbon sequestration. Pew Center on Global Climate Change.

Tol, R. S. J. (1995). The damage costs of climate change toward more comprehensive calculations. Environmental and Resource Economics, 21(1), 47-73. 
Tol, R. S. J. (2002). Estimates of the damage costs of the climate change-part II: Dynamic estimates. Environmental and Resource Economics, 21(2), 135-60.

Tol, R. S. J. (2005). The marginal damage costs of carbon dioxide emissions: An assessment of the uncertainties. Energy Policy, 33, 2064-2074. doi:10.1016/j.enpol.2004.04.002

Tol, R. S. J. (2011). The social cost of carbon. Annual Review of Resource Economics, 3(1), 419-443.

Tol, R. S. J. (2002). New estimates of the damage costs of climate change: Part II. Dynamic estimates. Environmental and Resource Economics, 21(1)

Tol, R. S. J. (2009). The economic effects of climate change. The Journal of Economic Perspectives, 23(2), 29-29-51. doi:10.1257/jep.23.2.29

Tol, R. S. J. (2009). The economic effects of climate change. The Journal of Economic Perspectives, 23(2), 29-29-51. doi:10.1257/jep.23.2.29

Tsang, F., \& Burge, P. (2011). Paying for carbon emissions reduction. (No. OP12). Santa Monica, CA: RAND Corporation. Retrieved from http://www.rand.org/pubs/occasional papers/OP312.

Twilley, R. R., Chen, R. H., \& Hargis, T. (1992). Carbon sinks in mangroves and their implications to carbon budget of tropical coastal ecosystems. Water, Air, and Soil Pollution, 64, 265-288.

Twilley, R. R., \& Rivera-Monroy, V. H. (2009). Ecogeomorphic models of nutrient biogeochemistry for mangrove wetlands. In G. M. E. Perillo, E. Wolanski, D. R. Cahoon \& M. M. Brinson (Eds.), Coastal wetlands: An integrated ecosystem approach. New York, NY: Elsevier.

Wanless, H. R., Parkinson, R. W., \& Tedesco, L. P. (1994). Sea level control on stability of Everglades wetlands. In S. M. Davis, \& J. C. Ogden (Eds.), Everglades: The ecosystem and its restoration (pp. 199-223). Delray Beach, FL, USA: St. Lucie Press.

Welch, R., Madden, M., \& Doren, R. F. (1999). Mapping the Everglades. Photogrammetric Engineering and Remote Sensing, 65(2), 163-170.

The world's mangroves 1980-2005: A thematic study prepared in the framework of the global forest resources assessment 2005. (2007). (FAO Forestry Paper 153). Rome: Food and Agriculture Organization of the United Nations. 
Yee, S. M. (2010). REDD and BLUE carbon: Carbon payments for mangrove conservation. (MAS Marine Biodiversity and Conservation Capstone Project.). San Diego, CA: University of California, San Diego.

Yohe, G. W et al. (2007). Perspectives on climate change and sustainability. (Climate Change 2007: Impacts, Adaptation and Vulnerability. Contribution of Working Group II to the Fourth Assessment Report of the Intergovernmental Panel on Climate Change. Cambridge, UK: Cambridge.

Zhang, K., Simard, M., Ross, M., Rivera-Monroy, V., Houle, P., Ruiz, P., Twilley, R. R.,Whelan, K. (2008). Airborne laser scanning quantification of disturbances from hurricanes and lightning strikes to mangrove forests in everglades national park, USA. Sensors, (8), 2262-2292. 